\title{
Reducing the Likelihood of Future Human Activities That Could Affect Geologic High-Level Waste Repositories
}

This document is

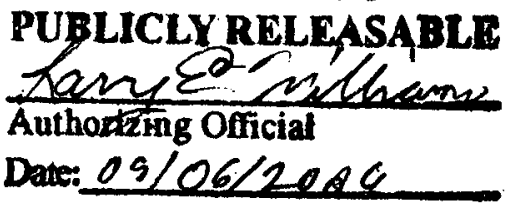

Human Interference Task Force

\author{
Technical Report \\ May 1984
}

prepared for

Office of Nuclear Waste Isolation

Battelle Memorial Institute 505 King Avenue

Columbus, OH 43201-2693

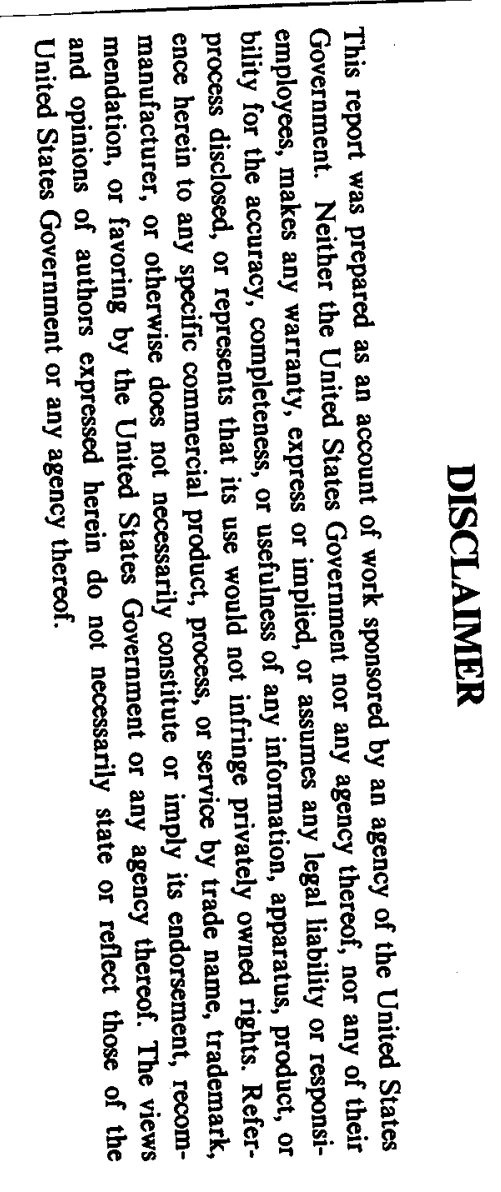

The content of this report was effective as of December 1983. This report was prepared by Office of Nuclear Waste Isolation under Contract No. DE-AC02-83CH10140 with the U.S. Department of Energy. 


\section{DISCLAIMER}

This report was prepared as an account of work sponsored by an agency of the United States Government. Neither the United States Government nor any agency Thereof, nor any of their employees, makes any warranty, express or implied, or assumes any legal liability or responsibility for the accuracy, completeness, or usefulness of any information, apparatus, product, or process disclosed, or represents that its use would not infringe privately owned rights. Reference herein to any specific commercial product, process, or service by trade name, trademark, manufacturer, or otherwise does not necessarily constitute or imply its endorsement, recommendation, or favoring by the United States Government or any agency thereof. The views and opinions of authors expressed herein do not necessarily state or reflect those of the United States Government or any agency thereof. 


\section{DISCLAIMER}

Portions of this document may be illegible in electronic image products. Images are produced from the best available original document. 
$i / i$

\section{ACKNOWLEDGMENTS}

The Human Interference Task Force ${ }^{\star}$ is very grateful for the valuable contributions of the task force consultants:

Dr. Warren Berry, Materials Science

Dr. Paul Ekman, Nonverbal Communication

Dr. David Givens, Anthropology and Nonverbal Communication

Dr. Maureen Kaplan, Archaeology

Dr. George Kukla, Long-Term Climatology

Dr. Thomas Sebeok, Linguistics and Semiotics

Dr. Percy Tannenbaum, Behavioral Psychology and Public Policy

They took the time to comprehend the issues we faced and to apply their expertise toward achieving the objectives we established. They also exhibited the patience necessary to tutor us in the appropriate application of their specialties. We have drawn heavily upon the references and the guidance they provided throughout this document, far more than the citations alone might suggest.

We also express our thanks to Brenda Jerman of Battelle Memorial Institute who provided the technical editing necessary to make the esoteric become comprehensible.

*See Appendix B for the 1ist of members. 


\section{ABSTRACT}

The disposal of radioactive wastes in deep geologic formations provides a means of isolating the waste from people until the radioactivity has decayed to safe levels. However, isolating people from the wastes is a different problem, since we do not know what the future condition of society will be. The Human Interference Task Force was convened by the U.S. Department of Energy to determine whether reasonable means exist (or could be developed) to reduce the likelihood of future humans unintentionally intruding on radioactive waste isolation systems. The task force concluded that significant reductions in the likelihood of human interference could be achieved, for perhaps thousands of years into the future, if appropriate steps are taken to communicate the existence of the repository. Consequently, for two years the task force directed most of its study toward the area of long-term communication. Methods are discussed for achieving long-term communication by using permanent markers and widely disseminated records, with various steps taken to provide multiple levels of protection against loss, destruction, and major language/societal changes. Also developed is the concept of a universal symbol to denote "Caution - Biohazardous Waste Buried Here". If used for the thousands of non-radioactive biohazardous waste sites in this country alone, a symbol could transcend generations and language changes, thereby vastly improving the likelihood of successful isolation of all buried biohazardous wastes. 
Page

1 THE HUMAN INTERFERENCE ISSUE $\ldots \ldots \ldots \ldots \ldots \ldots \ldots \ldots \ldots \ldots \ldots \ldots \ldots \ldots \ldots$

1.1 INTRODUCTION $\ldots \ldots \ldots \ldots \ldots \ldots \ldots \ldots \ldots \ldots \ldots \ldots \ldots \ldots \ldots \ldots \ldots \ldots$

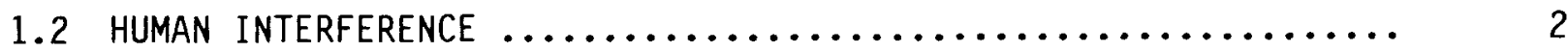

1.3 SIGNIFICANCE OF HUMAN INTERFERENCE ACTIVITIES $\ldots \ldots \ldots \ldots \ldots \ldots \ldots$

1.4 PROTECTING AGAINST HUMAN INTERFERENCE $\ldots \ldots \ldots \ldots \ldots \ldots \ldots \ldots \ldots \ldots .6$

2 HUMAN INTERFERENCE TASK FORCE APPROACH AND FINDINGS $\ldots \ldots \ldots \ldots \ldots \ldots .$.

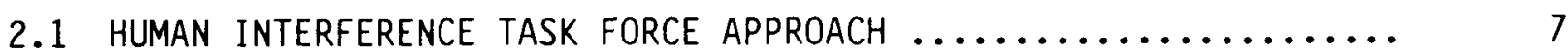

2.2 PREMISES BOUNDING THE STUDY $\ldots \ldots \ldots \ldots \ldots \ldots \ldots \ldots \ldots \ldots \ldots \ldots \ldots \ldots$

2.3 LOGIC FOR ANALYZING HUMAN INTERFERENCE POTENTIAL ........... 12

2.4 HUMAN INTERFERENCE TASK FORCE FINDINGS $\ldots \ldots \ldots \ldots \ldots \ldots \ldots \ldots \ldots \ldots$.

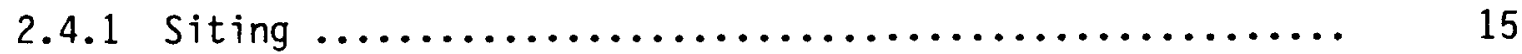

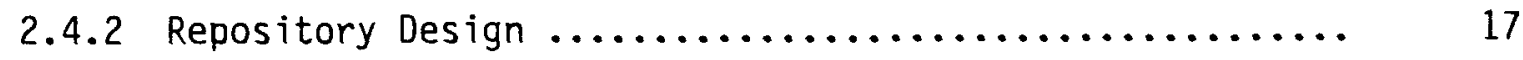

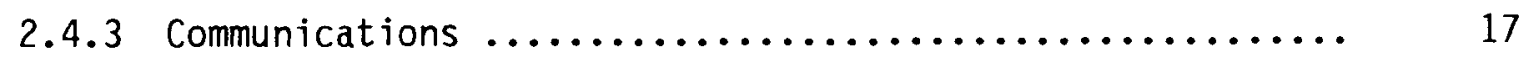

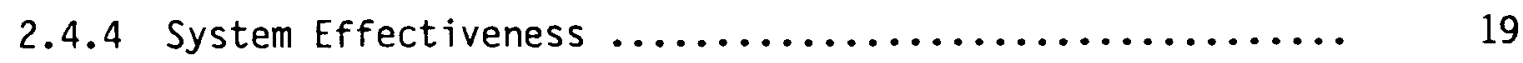

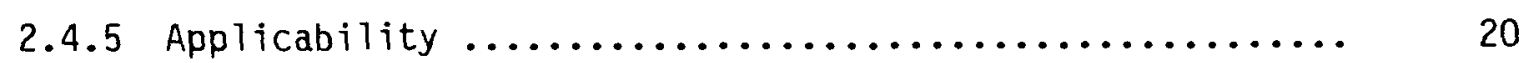

3 SITING, LAND USE, AND INSTITUTIONAL CONTROLS ................ 22

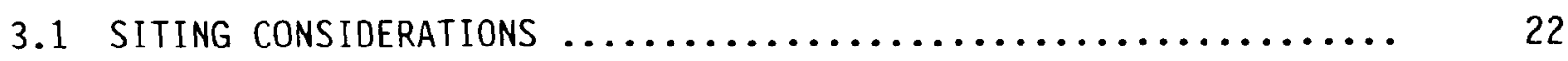

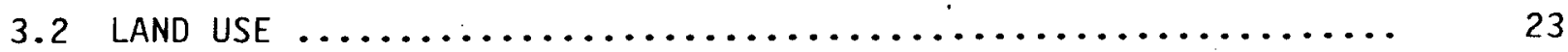

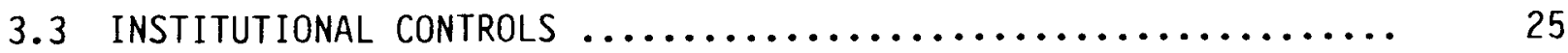

4 COMMUNICATION AS A MEANS OF REDUCING THE LIKELIHOOD

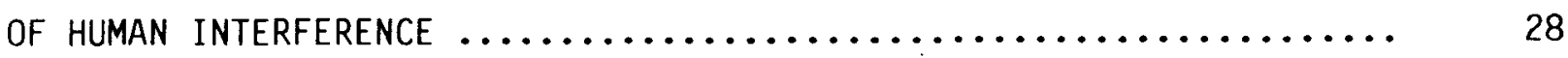

4.1 BASIC ELEMENTS OF MESSAGE COMMUNICATIION $\ldots \ldots \ldots \ldots \ldots \ldots \ldots \ldots \ldots \ldots$

4.2 MESSAGE DURABILITY AND DETECTABILITY $\ldots \ldots \ldots \ldots \ldots \ldots \ldots \ldots \ldots \ldots \ldots$

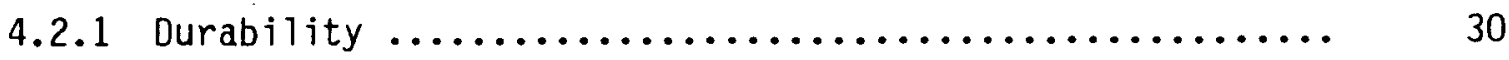

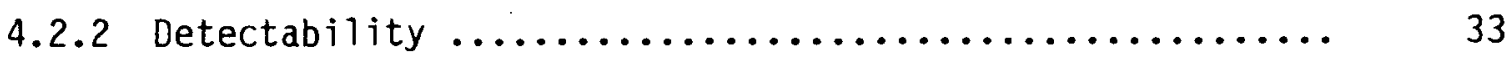

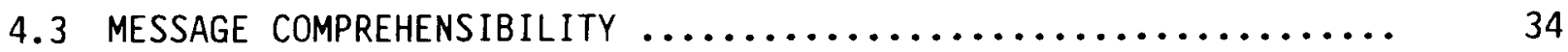

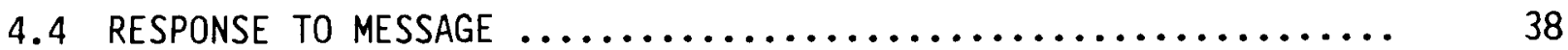


TABLE OF CONTENTS

(Continued)

Page

4.4.1 Message Information $. \ldots \ldots \ldots \ldots \ldots \ldots \ldots \ldots \ldots \ldots \ldots . . \ldots \ldots$

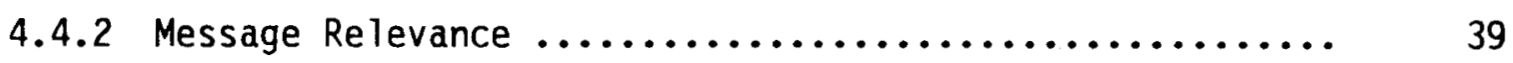

4.4.3 Factual Basis ................................. 41

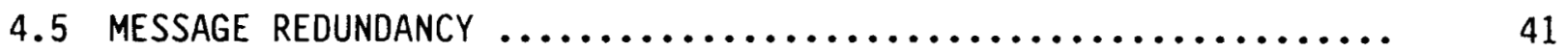

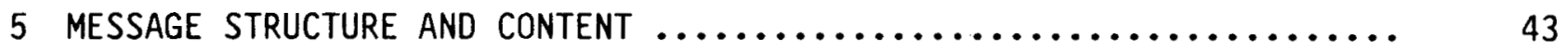

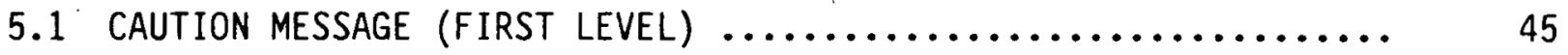

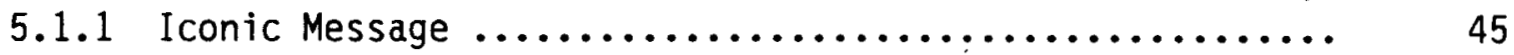

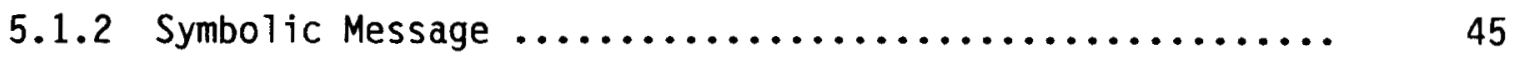

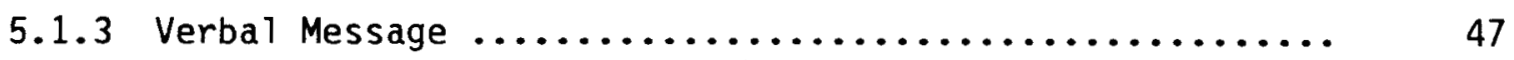

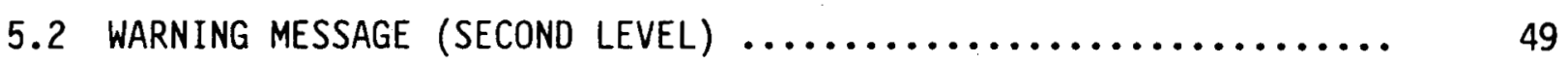

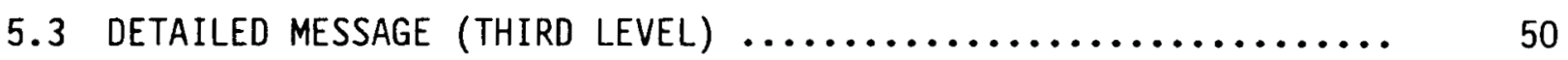

5.4 DETAILED TECHNICAL INFORMATION (FOURTH LEVEL) $\ldots \ldots \ldots \ldots \ldots \ldots$.

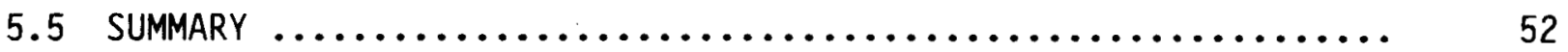

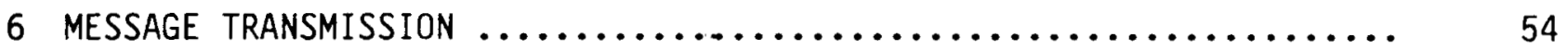

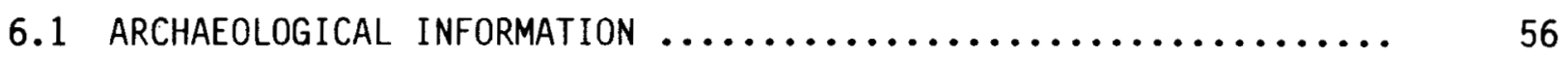

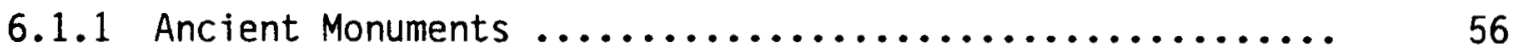

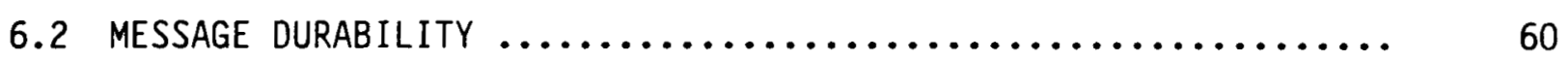

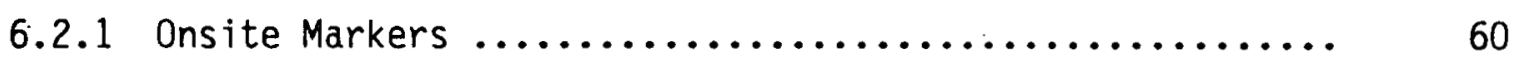

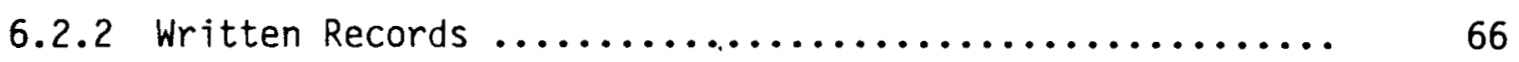

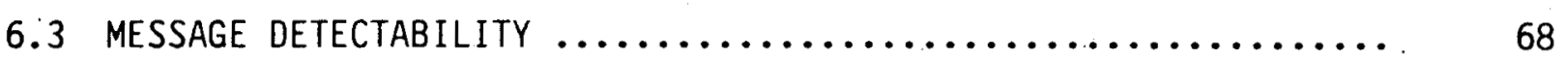

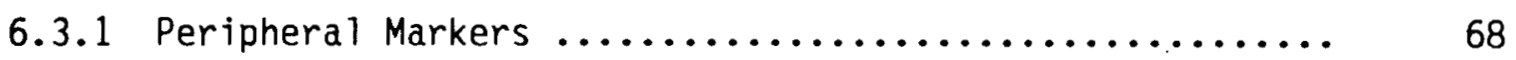

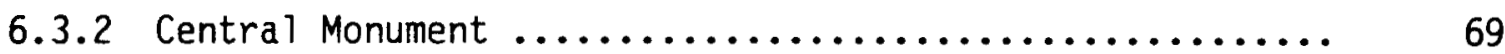

6.3.3 Earthworks and Anomalies .......................... 71

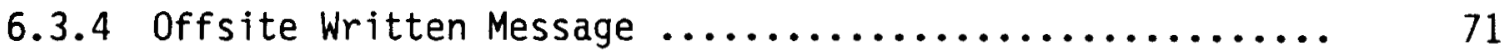

6.3.5 Oral Transmission .............................. 74

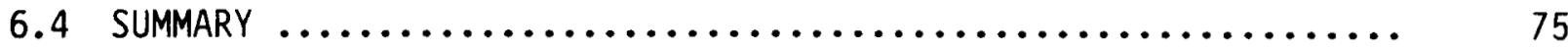

7 COMMUNICATION SYSTEMS COMPONENTS AND THEIR APPLICATIONS $\ldots \ldots \ldots \ldots \ldots$ 
TABLE OF CONTENTS

(Continued)

Page

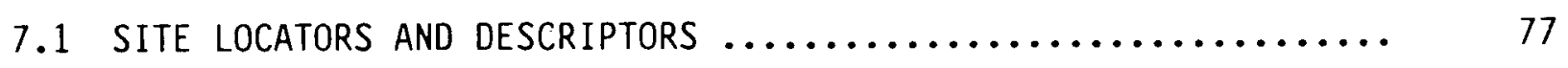

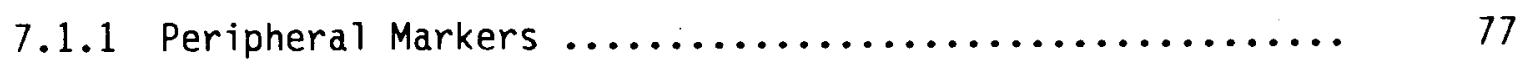

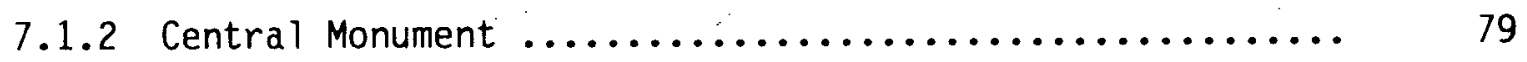

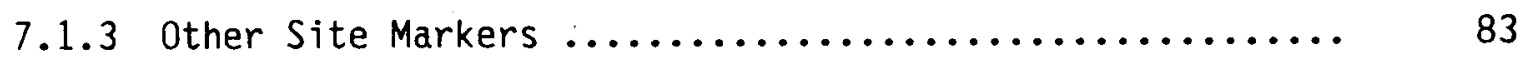

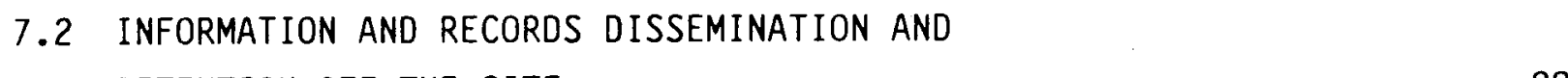

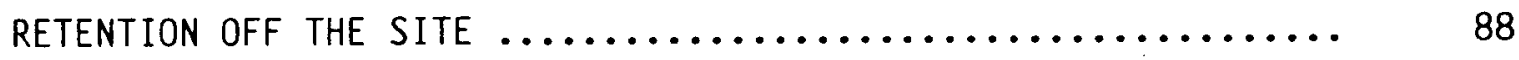

7.2.1 Identification of Repository Locations on Maps and Charts ............................ 89

7.2.2 Distribution and Archiving of Documents and Maps ....... 90

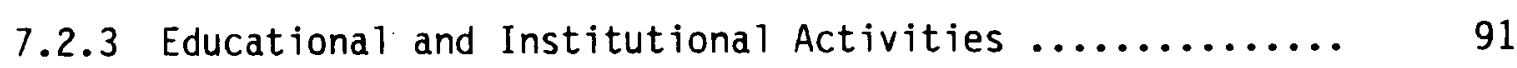

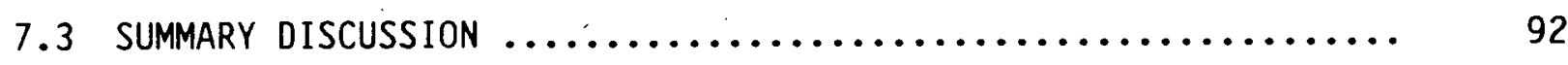

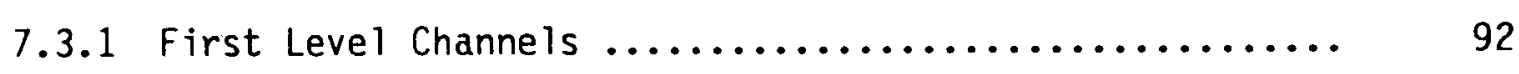

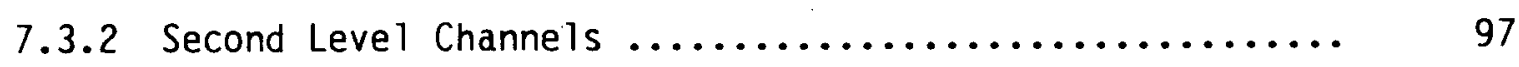

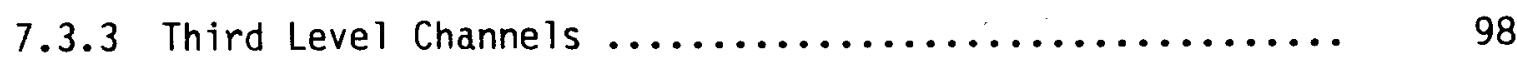

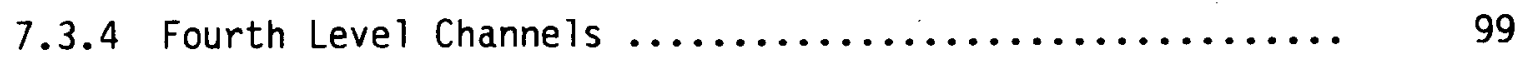

7.4 OVERALL ASSESSMENT OF COMMUNICATION METHODS $\ldots \ldots \ldots \ldots \ldots \ldots \ldots . . . \ldots$

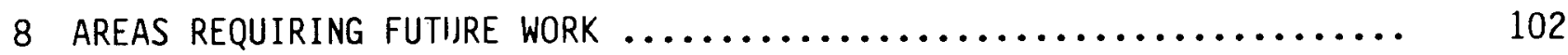

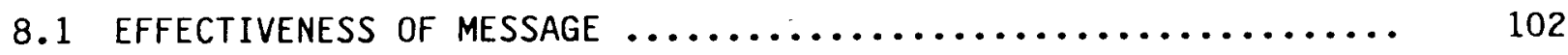

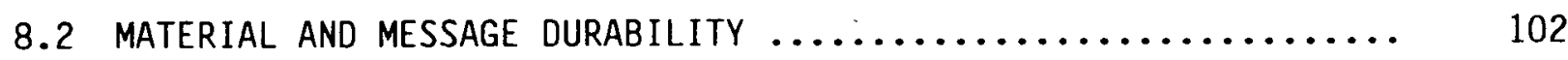

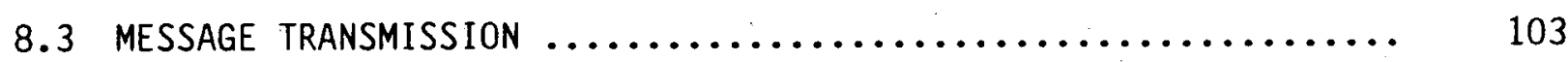

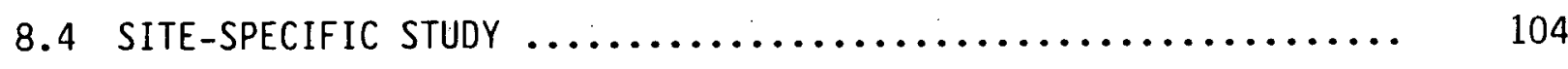

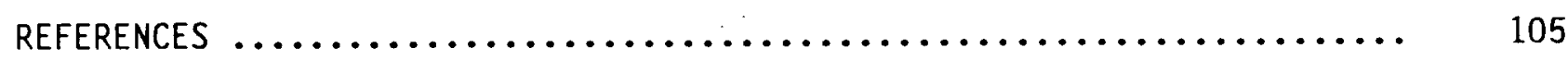

APPENDIX A PICTOGRAPHIC PRESENTATION OF BIOHARZARDOUS

CAUTION MESSAGE................................. 113

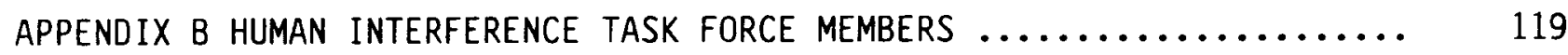




\section{LIST OF FIGURES}

Page

1-1 Direct Intrusion by Exploratory Drilling and Resulting Connection of Aquifers ................... 4

$2-1 \quad$ Human Interference Logic flow ........................ 13

3-1 Reducing the Likelihood of Human Interference ............. 22

4-1 Elements of Effective Long-Term Communications ............. 28

4-2 Basic Elements of Communication ...................... 29

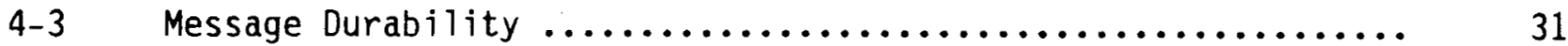

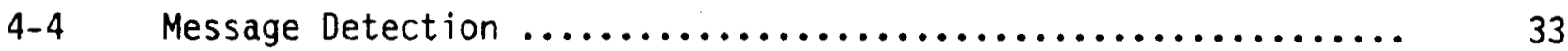

4-5 Effective Message Comprehension ..................... 34

4-6 Response to Messages ............................. 39

5-1 Comprehension and Response ........................ 43

5-2 Symbol, "Caution - Biohazardous Waste Buried Here".......... 48

5-3 Example of Third Level Message ...................... 51

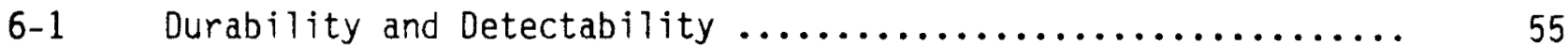

$6-2 \quad$ Stonehenge $\ldots \ldots \ldots \ldots \ldots \ldots \ldots \ldots \ldots \ldots \ldots \ldots \ldots \ldots \ldots \ldots \ldots \ldots$

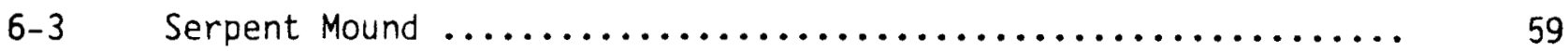

6-4 Two Possible Construction Methods for a Quasi-Monolith ....... 63

7-1 Peripheral Markers .......................... 78

7-2 Peripheral Marker Message ........................ 80

7-3 Central Monument ............................. 81

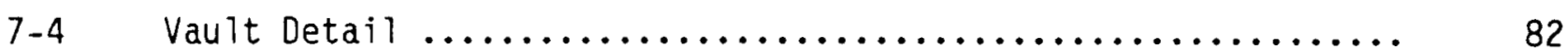

7-5 Alternate Central Monument ........................ 84

7-6 Alternate Central Monument Detail ...................... 85

7-7 Typical Central Monument Plaza ...................... 87

A-1 Pictographic Presentation of Biohazardous

Caution Message .............................. 117

\section{LIST OF TABLES}

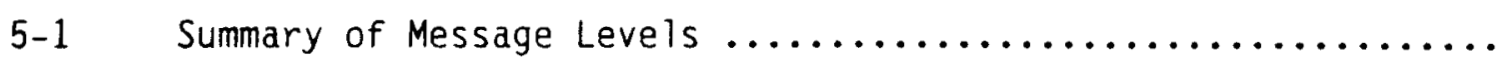




\section{THE HUMAN INTERFERENCE ISSUE}

\subsection{INTRODUCTION}

For nearly two decades the United States government has been evaluating potential concepts for the permanent disposal of high-level radioactive wastes. The leading contender of the options considered by the United States and by foreign governments has been the solidification of wastes into a relatively insoluble form and the interment of those solidified wastes inside large rock formations several hundred meters below the earth's surface (deep geologic disposa1). The rock formation that is chosen for disposal would be at a depth and location relatively free from circulating ground water in order to minimize the likelihood of waste movement from the place of burial.

Considerable efforts have been devoted to locating rock formations with suitable geologic, thermal-mechanical, geochemical, and hydrologic properties so that:

1. Circulating ground water would be unlikely to contact the waste.

2. If such contact occurred, the waste would be released relatively slowly (if at a11) into the ground water.

3. Transport time of the waste from the point of burial to potential points where wastes could contact humans would be sufficiently long so that dilution, radioactive decay, and adsorption or precipitation of radionuclides in the geologic formations along the ground-water pathway would result in very low, if any, doses to humans.

The predominant strategy in selecting waste disposal sites and designing waste disposal systems has been to use multiple barriers against waste release to achieve items (1) through (3) above. Further effort has gone into the characterization of several potential host rock formations throughout the United States. Similarly, considerable effort has gone into the development of waste forms with low leach characteristics and waste packages that provide high integrity and high resistance to corrosion.

The Civilian Radioactive Waste Management (CRWM) program (formerly the National Waste Terminal Storage [NWTS.] program), under the direction of the United States Department of Energy. (DOE), has the responsibility for the identification and development of high-level waste disposal systems within the United States. At present, the CRWM program is focused on four prime media: 
basaltic rocks in the northwestern portion of the United States, geologic tuff in the southwestern portion of the United States, bedded and domal rock salt in the southeastern and southern central portions of the United States, and granitic rocks in the north central, northeastern, and southeastern portions of the United States. The studies within the CRWM program have indicated that all of the above-mentioned rock types offer a high probability of providing adequate isolation of the radioactive wastes over the long time periods during which such isolation is required.*

Similarly, studies of potential waste forms and waste package designs have resulted in package configurations which appear capable of providing low radionuclide release rates from waste packages to the ground water, should contact occur as mentioned in Item 2 previously.

The combination of siting and engineering factors which characterize waste disposal systems (geologic repositories) for the systems presently under consideration result in a very high likelihood of successful waste isolation and the continued protection of humans. Analyses of potential repository systems have shown that adequate levels of isolation should continue in spite of potential untoward geologic, extraterrestrial, and long-term climatic events, or processes that could adversely act on repository systems.

\subsection{HUMAN INTERFERENCE}

The successful isolation of high-level radioactive wastes over long periods of time, however, requires not only that the wastes be unaffected by natural events and processes, but also that waste isolation be satisfactorily independent of future activities of humans. Considerable concern has been voiced by a number of individuals and organizations that at some time after the repository has been sealed, perhaps far in the future, humans may engage in some type of activity at or near the repository site that would cause waste isolation to be

\footnotetext{
*Isolation means segregating wastes from the accessible environment (biosphere) to the extent required to meet applicable radiological performance objectives, e.g., U.S. Environmental Protection Agency (EPA) or U.S. Nuclear Regulatory Commission (NRC) standards. Isolation periods of several thousand years are generally considered adequate to reduce most radioactive species to safe levels (DOE, 1980).
} 
severely diminished (DOE, 1980). There are two basic types of human interference activities that are of concern, direct interference and indirect interference.

Direct interference activities are those that would somehow breach the actual repository facility and initiate a waste release. The most commonly hypothesized form of direct interference is direct intrusion into a sealed repository by means of a shaft or borehole while exploring for, or attempting to recover, resources (Figure 1-1). Direct intrusion could range from a borehole passing through the repository and establishing hydrologic continuity with one or more aquifer systems, to the actual mining by conventional or solution techniques of naturally occurring materials in the repository rock formation.

Indirect interference refers to activities that could take place at some distance from where wastes are actually emplaced (i.e., offsite), but that could adversely affect waste containment or isolation (e.g., short-cut the hydrologic transport path).

War, terrorism, and sabotage have also been postulated as potential human interference events. However, as stated in the U.S. Department of Energy's Statement of Position on the U.S. Nuclear Regulatory Commission Waste Confidence Rulemaking (DOE, 1980), the risks from war, terrorism, or sabotage should not be significant due to the depth, design, and difficulty of access of a sealed repository. For example, although a repository could be severely damaged by a direct attack with powerful (nuclear) weapons, the indirect effects on people of such an attack, due to releases of radioactivity from the repository, would be much smaller than the direct damage inflicted by such weapons. Similarly, the depth of the repository, the relative immobility of radionuclides within the waste form, and the distribution of waste packages within the large volume of rock comprising the repository would make postclosure terrorist or sabotage activities both unlikely and ineffective.* Repositories should, therefore, be unattractive targets for war, sabotage, or terrorism.

*Each waste package would be individually sealed in the rock formation, making each package relatively independent of any other package. 


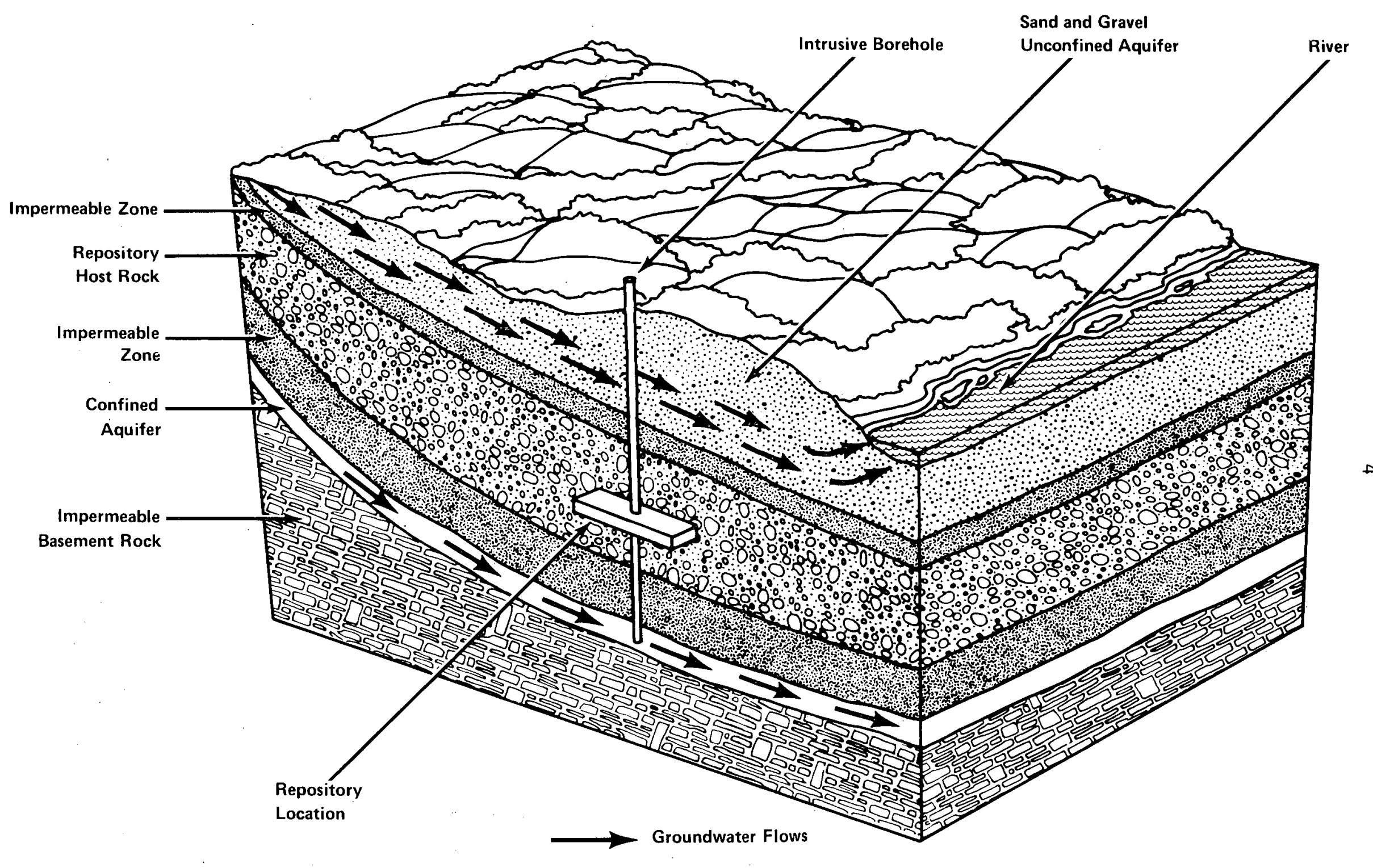

FIGURE 1-1. DIRECT INTRUSION BY EXPLORATORY DRILLING AND RESULTING CONNECTION OF AQUIFERS 


\subsection{SIGNIFICANCE OF HUMAN INTERFERENCE ACTIVITIES}

The significance of potential human interference activities is measured by the potential those activities are calculated to have for increasing the radiological dose to humans from the repository. As discussed previously, repositories offer a relatively passive form of protection from the emplaced radioactive waste; i.e., the combination of the rock mass, the hydrology, the repository design, and the waste form will be chosen to impede the dissolution and migration of radioactive waste for a well-designed and properly sited repository system. The release of any wastes to the biosphere in significant amounts is unlikely; the increase in radioactivity in the biosphere, if any, would be very small compared with radioactivity levels from naturally occurring sources (DOE, 1980).

Over the past several years, various analyses of human interference have been performed on hypothetical repository systems. The results vary widely depending upon the parameters used, the physical processes taken into account, and the purpose of the analysis. Analyses performed on a realistic basis (e.g., using solubilities, circulation rates, and geometries representative of current solution mining practices), have resulted in calculated doses that were a fraction of the natural background dose, usually a few millirems or tens of millirems (Office of Nuclear Waste Isolation [ONWI], 1981). Where assumed human interference scenarios resulted in waste releases to an aquifer system, calculated doses to humans are normally fractions of a millirem. In all cases, the actual magnitude of the calculated doses is strongly assumption dependent with "realistic" analyses generally resulting in relatively low doses.

Although the calculated releases resulting from human interference are relatively small for reaiistic and even reasonably conservative analyses, human interference may well be the dominant contributor to post-closure risk analyses due to the relative immunity of repository systems to naturally induced releases. 


\subsection{PROTECTING AGAINST HUMAN INTERFERENCE}

The protection afforded by the repository design, the waste package, and the repository site is expected to adequately mitigate the consequences of the release of radionuclides to ground water, whether the ground-water/waste contact is due to natural or human induced causes. Insofar as analyses of hypothetical systems show the likelihood of human interference to be greater than the likelihood of natural events or processes breaching a repository system, however, prudence dictates that methods directed at reducing the likelihood of such interference be evaluated.

The general societal trend of continuous technical advancement makes it unlikely that human interference could be precluded by design measures; i.e., technical advances are likely to render protective systems put in place by one generation vulnerable to the technology of subsequent generations. If future generations elect to apply their technology to gaining access to the waste repository, they are likely to succeed with reasonable planning and at considerable cost (see Section 2, ground rule 2). The U.S. Department of Energy has taken the position that: ". . although this generation bears the responsibility for protecting future societies from the waste that it creates, future societies must assume the responsibility for any risks which arise from deliberate and informed acts which they choose to perform" (DOE, 1980, p. II-189). However, at the heart of the human interference issue is the concept of releases from the repository taking place because those societies that caused or could be affected by the releases were uninformed.

This task force endorses the Department's position and, therefore, adopts as its main focus the reduction of the likelihood of uninformed human interference with repository systems. There are three primary mechanisms for reducing the likelihood of human interference. These are (1) reducing the incentive for human interference, (2) designing the repository to increase the difficulty of interference, and (3) communicating the existence of the repository to generations far into the future. For the reasons discussed in this report, the task force focused on the third mechanism. The approach and the logic used by the task force to analyze the problem and to arrive at its recommendations are discussed in Section 2 of this report. 


\section{HUMAN INTERFERENCE TASK FORCE APPROACH AND FINDINGS}

\subsection{HUMAN INTERFERENCE TASK FORCE APPROACH}

The U.S. Department of Energy (DOE) convened the Human. Interference Task Force in 1980. It consists of a group of experts selected from several organizations (see Appendix B). Their expertise included political science, sociology, environmental sciences, law, high-level waste management, nuclear regulation, and nuclear engineering. The group developed the overall analytical logic and methods for addressing the human interference issue. Additional areas of expertise considered critical to the analys is were identified, and in those disciplines experts whose work seemed particularly relevant were consulted. The areas of expertise identified included linguistics, semiotics, anthropology, behavioral psychology, public policy, nonverbal communication, materials science, climatology, and archaeology.

A variety of methods were considered by the task force in developing the analysis of human interference issues. After considerable discussion, the task force reached a consensus that a logic flow diagram (see figure 2-1, p. 13) presented a reasonable and structured approach to developing and analyzing the issues. The logic flow format chosen provided a clear presentation of the many factors involved in analyzing human interference and provided direction in developing measures to resolve those issues. That approach and the subsequent activities undertaken in its implementation have been reviewed by peers representing relevant technical disciplines and found, thus far, to" be reasonable.

Before discussing the logic flow format, however, the premises bounding this study or "ground rules" must be examined.

\subsection{PREMISES BOUNDING THE STUDY}

In developing the approach in this report; the task force formulated basic ground rules and assumptions to reasonably bound the issue of human interference. The ground rules and așsumptions are consistent with proposed objectives for siting and developing a high-level waste repository as well as with existing and proposed regulatory requirements. The ground rules, assumptions, and related considerations used by the task force are discussed below. 
1. Present society's responsibility is to dispose of radioactive wastes in a manner that is safe, is environmentally acceptable, and does not require long-term maintenance or surveillance. This ground rule is consistent with the objectives in the U.S. Department of Energy's Statement of Position in the U.S. Nuclear Regulatory Commission (NRC) Waste Confidence Rulemaking (DOE, 1981) and with a proposed U.S. Environmental Protection Agency (EPA) criterion that would limit reliance on active institutional controls to a 100 -year period after repository closure (EPA, 1982a).

A premise for this ground rule is that since present society is deriving a tangible benefit from nuclear power production, and since the means to dispose of the waste is within the technical capability of the present society, then a moral obligation exists for present society to safely dispose of its waste. This obligation includes taking reasonable steps to reduce the likelihood of inadvertent interactions between future humans and the repository. The objective is to minimize, to the extent practicable, the likelihood that a future human would unknowingly decrease the effectiveness of the repository. Repository systems must be sited and designed to mitigate the consequences of both natural and human-induced reductions in the effectiveness of waste containment or isolation. Adopting reasonable measures to reduce both the likelihood and potential consequences of human interference is prerequisite to assuring any subsequent exposures of future humans to be at as low as is reasonably achievable levels.

2. Future societies with knowledge of the existence and location of the repository, its contents, and the risks of interference, bear the full responsibility for any of their actions that can reasonably be expected to adversely affect the performance of the repository. This ground rule is also consistent with the U.S. Department of Energy's Statement of Position in the NRC Waste Confidence Rulemaking (DOE, 1980). There are two basic premises for this ground rule. First, it is improbable that any structure or system would withstand a determined, perhaps technically superior, future societal effort to overcome it. Second, although certain potentially valuable materials (e.g., heavy metals in high-level waste) may be deemed unsuitable for recycling at present due to economic or political reasons, the legitimate use of such materials by future generations should not be precluded. However, societies electing to take actions that would knowingly decrease the 
effectiveness of the repository in isolating waste (by such measures as attempting to recover the waste or to modify the ground-water flow regime or chemical composition) must assume responsibility for any risks that result from those actions to either their generation or later generations.

This society's obligation should be discharged by providing a secure isolation system that would continue to function if left undisturbed, by avoiding probable causes of disturbance, and by transmitting knowledge of the repository to future generations, thus allowing them to plan their activities accordingly. The principal concern is to avoid a situation where interference activities take place with no, or insufficient, knowledge of the existence and significance of the repository so that the consequences proceed unchecked.

3. Present society should make all reasonable efforts to transmit to future societies information about the repository, its contents, and the risks of interference. A virtual'ty endless range of future conditions on earth, future customs and levels of technology, and future resource needs can be postulated. Because repository design cannot with certainty prevent human interference nor can the potential motivations for interference actions be known with certainty, all reasonable efforts should be made to develop and implement long-lasting mechanisms for transmitting to future generations information about the repository, its contents, and the presently perceived dangers of interference. The mechanism for transmitting such information should be designed to persist for as long as possible in order to continuously prevent intrusions into the repository, i.e., intrusions that would not have occurred had the existence and location of the repository been known. This ground rule is consistent with the philosophy adopted by the NRC in 10 CFR 60 (NRC, 1983) and prepared by the EPA in 40 CFR. 191 (EPA, 1982a).

4. The focus of this report is on future societies having the technology required to disrupt a repository. Two aspects of level of knowledge/ technology are important in developing measures to inhibit human interference. These include: the general level of societal knowledge and technology, and the specific level of knowledge or awareness of the repository and its contents.

Potential states of future societal knowledge/technology represent a continuum that ranges from inferior to far advanced. If technology significantly regresses, the ability to penetrate through layers of 
saturated* rock to the depth of the repository will not exist, making it unlikely that a repository could be significantly affected. Consequently, of major concern in this study is a general level of societal knowledge and technology sufficient to disrupt a mined geologic repository. This minimum level of knowledge and technology may vary depending on the method of interference (see ground rule 5). Direct interference by a society with an inferior level of knowledge would require the technology necessary to successfully penetrate several hundred meters of overlying strata, including aquifers, to reach the repository. However, indirect interference activities may be possible by a society with knowledge and technology inferior to that required for direct interference. Indirect interference could occur, for example, through large-scale irrigation or reservoir projects in the repository vicinity which adversely affect ground-water flow patterns over extended periods of time.

The range of possible interference activities, direct and indirect, for societies with advanced knowledge and technology is limitless. As forecasts penetrate farther into the future, the range of potential interference activities increases as knowledge and technology advance. Fortunately, the knowledge of how to protect against the release or impacts of buried wastes, radioactive or otherwise, should likewise increase. Finally, one cannot completely discount the probability of an historical continuity with present society (and its level of knowledge and technology) and cont inued knowledge of the repository, with or without the measures discussed in this report.

The level of awareness of the repository and/or the waste might alter the conduct of the interference in several ways. For example, any action in which materials could be brought to the surface from the repository is likely to be monitored more closely, if the presence of the repository is known. Similarly, actions likely to release radioactivity to the environment would be avoided. Thus, in cases where communications are effective in raising the level of a future society's awareness of the repository or the waste, the prevention of a disruption of the repository could be enhanced, or the consequences of a disruption lessened. The limiting case would be one in which

*The presence of ground water complicates the process of very deep mining. Several repository concepts under evaluation would place the repository below one or more water-bearing strata, however, which could help prevent human interference. 
there is no awareness of the repository and all communications have failed. In this limiting case, only the design features and site characteristics would mitigate the effects of interference.

This ground rule is consistent with the NRC's philosophy regarding the credibility of anticipated processes and events related to human intrusion (NRC, 1983).

5. The method used to communicate information to future societies must be effective for both direct and indirect interference activities. Either direct or remote interference activities could influence the effectiveness of the repository. The means used to transmit knowledge, therefore, must focus on communication techniques that are applicable for either type of interference. For example, the surveillance methods used by persons planning to undertake activities that are potentially disruptive (drilling, mining, etc.) may take a variety of forms and cover a large range of technological capabilities. The mechanisms for alerting such individuals should be sufficiently diverse to cover a reasonable array of pre-interference survey options (e.g., ground surveys, airborne surveys, visual or geophysical survey techniques).

6. The emphasis for transmitting information will focus on the first 10,000 years after repository closure. This period of time considers both the decreasing degree of risk of radioactive exposure over time and uncertainties due to natural phenomena. First, the radioactivity hazard associated with the nuclear waste diminishes over time. Relatively rapid decay of fission products occurs during the first 1,000 years after closure. Slower decaying transuranic elements would reach levels that approximate background radiation after ten to thirty thousand years: Second, the time frame considers the uncertainty in evaluations due to climatic changes (heating, cooling, and rainfa11) on earth over periods of thousands of years.

This period of time is consistent with the U. S. Department of Energy's Statement of Position on the NRC Waste Confidence Rulemaking (DOE, 1980).

\section{Present languages are likely to change over the time frame of} interest. One can reasonably postulate that over a 10,000-year time frame, languages will be replaced or significantly modified, making any single language unreliable by itself as an effective device for communication.

8. A basic knowledge of atomic physics is likely to be possessed by future societies. Although nuclear technology and radiology as known today 
may not be used by distant future generations, the knowledge of basic atomic physics is unlikely to be lost by a society that has the technological capability to disrupt a repository. Basic atomic physics (e.g., atomic structure, nuclear interactions with matter) is an essential part of many sciences and technologies (communication, chemistry, medicine, electronics, etc.) and is likely to remain a basic building block for technologies far into the future.

\subsection{LOGIC FOR ANALYZING HUMAN INTERFERENCE POTENTIAL}

With the ground rules in mind, the analytic logic structure can be discussed. The analytical logic shown in Figure 2-1, which is discussed in detail throughout this document, is the framework of premises, assumptions, and requirements for the study of human interference. Figure 2-1 indicates conditions that would need to be met to provide long-term protection against human interference. The two most basic elements in the logic are to protect future societies by (1) reducing the likelihood of human interference, and (2) reducing the consequences of human interference. The likelihood can be reduced by considering human interference factors in siting a repository, by effectively communicating warning messages to future societies, and by designing repository systems to make physical access possible only with great difficulty.

To reduce the consequences of human interference, the repository system can incorporate natural and engineered barriers, including the waste package, engineered repository backfills and seals, and natural isolation features provided by the surrounding geologic environment. For the most part, the measures already planned and documented in Civilian Radioactive Waste Management (CRWM) literature to mitigate the effects of natural phenomena would be effective in mitigating the consequences of phenomena induced by human interference. Ample information is available in the CRWM literature to evaluate Box 7 in Figure 2-1: the efficacy of natural and engineered barriers in mitigating the consequences of human interference.

The major part of Figure 2-1 addresses the issues of reducing the likelihood of human interference by (1) site-related considerations (Box 4), 


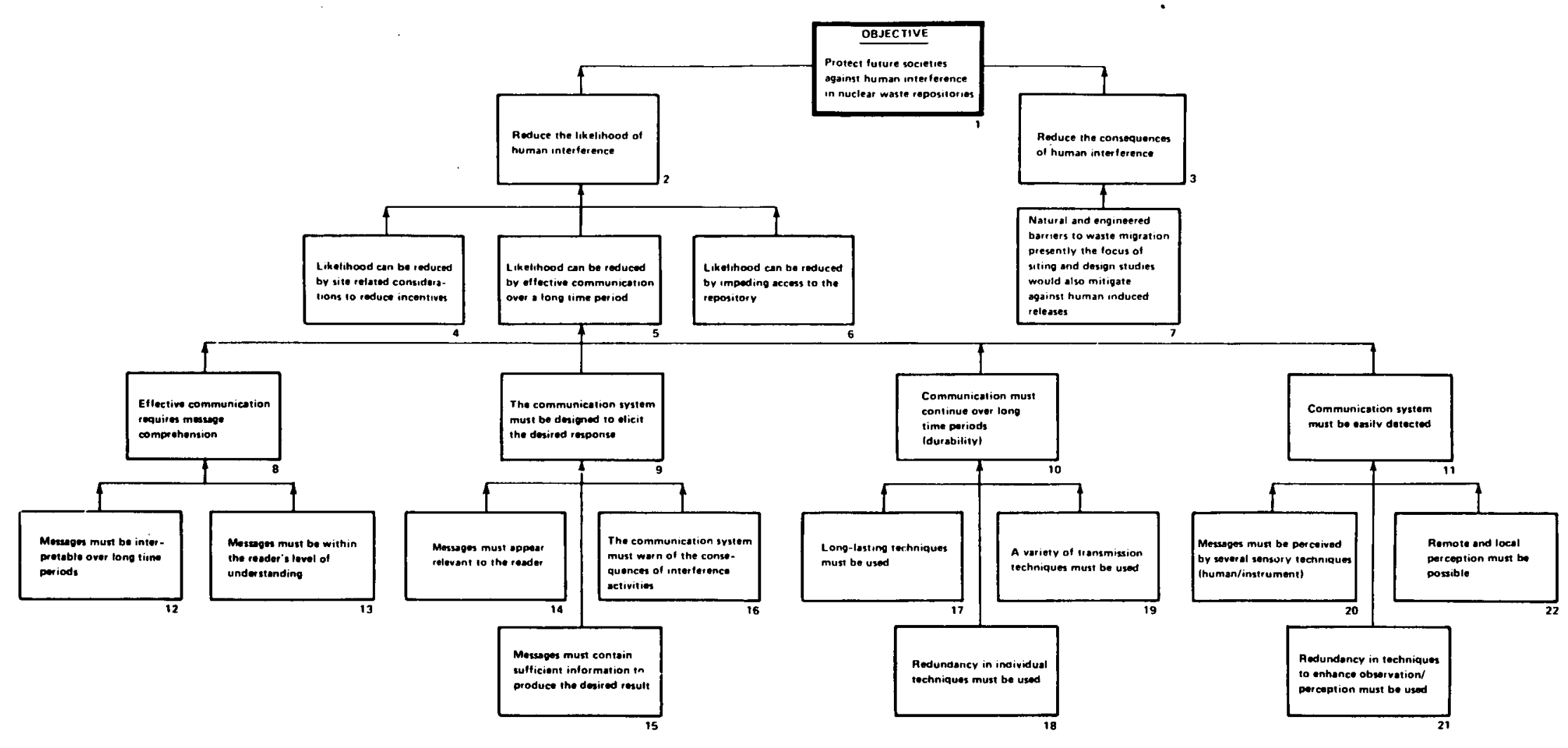

FIGURE 2-1. HUMAN INTERFERENCE LOGIC FLOW

\begin{tabular}{|c|c|c|c|c|c|c|c|c|}
\hline - 1 & 11 & 1 & -1 & 11 & 19 & 1 & ; & 1 \\
\hline D. & 11 & 11 & $\because$ & $R 1$ & $: 1$ & 1 & 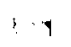 & 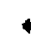 \\
\hline I & 11 & 11 & $\cdots$ & .1 & 1 & ' & $:$ & 1 \\
\hline I & ' & $\cdot$ & $\mathrm{me}$ & $\rightarrow$ & 1 & $\therefore 4$ & $\therefore-1$ & , \\
\hline
\end{tabular}


(2) effective communication (Box 5), and (3) impeding access (Box 6). Siting and land use considerations and repository design factors to reduce incentives for interference and to impede access are discussed in Section 3 and have been documented in other CRWM literature. This report emphasizes long-term communication (as expanded in Figure 2-1) as a primary method to reduce the potential for human interference.

This report indicates how the communication elements in the logic diagram (Figure 2-1) can be achieved by applying an understanding of linguistics, psychology, materials sciences, archaeology, and other appropriate disciplines. The options discussed for achieving the elements of the logic diagrams are used as the basis for one possible reference communication system at a hypothetical site (Section 7) to illustrate one possible combination. Some of the measures described are extensive and could, perhaps, be considered excessive. Whether measures to reduce the likelihood of human interference need be as extensive as options described in this report allow, is a matter of regulatory discretion, site-specific conditions, and further research. In practice, the communication system chosen would vary with site-specific conditions and regulatory requirements.

\subsection{HUMAN INTERFERENCE TASK FORCE FINDINGS}

On the basis of its studies, which have been carried on over a period of approximately two years and which have culminated in this report and several reports prepared by consultants to the task force, the task force makes the following findings, categorized into the areas of (1) siting, (2) repository design, (3) communications, (4) system effectiveness, and (5) applicability.

\subsubsection{Siting}

Human interference should be considered in the siting of repositories from the perspective of indigenous natural resources, the existence of natural features which could be used in marking the repository, the potential for future land uses, and the depth and geohydrological regime which characterize the repository. This is consistent with proposed DOE Siting Guidelines (DOE, 1983 ) and the NRC's high-level waste management regulation, 10 CFR Part 60 (NRC, 1983). 


\section{Resources}

A repository should be sited to avoid necessary and valuable resources that might become attractive targets for future exploration or recovery. Due to uncertainty regarding the economics of recovery and the resource requirements of future technologies, total reliance cannot be placed on the avoidance of presently identified resources as a means of preventing human interference. Similarly, the existence of marginally recoverable resources or of resources that are widely available in other locations should not be used to declare a site unsuitable; other measures described in this report, in particular, the communication measures, are believed by the task force to prove more important to protecting against human interference than will the avoidance of resources.

\section{Natural Features}

Based on its studies, the task force places very heavy emphasis on the use of long-term markers to communicate the existence of a repository. As discussed in the report, markers carved into existing rock outcroppings or cliff faces have survived for very long periods of time. Other things being equal, a site offering surface features which are amenable to transformation into long-term markers should be considered as an advantage.

Land Usage

Future land use should be considered from the perspective of avoiding areas that may lead to indirect interference activities such as the creation of reservoirs that could adversely affect ground-water flow regimes. Conversely, certain land uses could help promote the continued knowledge of the repository and/or protection of a repository from interference. For example, if the repository were to be subsequently included within lands under federal protection for other purposes (e.g., national park land*), advantages might be

*The proposed DOE Siting Guidelines (DOE, 1983) would consider siting adjacent to an existing national park to be potentially adverse. Making an existing repository into a national park at some future date, however, would not violate the guidelines. 
realized relative to the long-term protection of the repository from human interference.

Depth and Geohydrologic Regime

Protection from the effects of war, sabatoge, and terrorism are derived largely by the difficulty in obtaining access to the repository, e.g., protection by overburdens. Similarly, interference scenarios involving technically inferior societies show that a minimum level of knowledge is required to overcome the problem of gaining access to the repository horizon when mining through water-bearing strata. Therefore, a depth of several hundred meters and a location under water-bearing strata are considered advantageous.

\subsubsection{Repository Design}

The repository design may be highly effective in mitigating the impacts of human interference activities. For example, multiple barrier systems incorporated to protect against natural processes and events could be equally effective against human-induced events. Repository systems should be assessed on a site-specific basis to determine the types of interference activities that could be encountered and to ascertain that the repository design includes features to prevent such scenarios.

\subsubsection{Communications}

The likelihood of human interference can be reduced by communicating knowledge of the repository through a multiplicity of communication mechanisms. The capability exists to develop and implement long-term communication systems. Messages must be durable, detectable, comprehensive, and able to elicit the desired response.

Message Durability

Message durability depends on the ability of the material used to transmit the message to withstand the environment in which it is placed and 
the malicious acts of humans. For permanent onsite markers, monolithic (single piece) designs have been found to be more durable than jointed construction markers due to their ability to withstand the effects of weathering. Marker materials having low economic value and a poor potential for recycling should reduce economic incentives leading to human interference with the marker system. Similarly, very large markers which are difficult to remove, deface, or destroy are considered to be advantageous.

With regard to written records, linen, papyrus, ceramic materials, metallic plates, and acid-free paper can be used to record messages too complex for inclusion on surface markers. Such materials may be long-lived but may require a controlled environment to ensure longevity.

Detectability:

Both onsite and offsite communication channels are recommended to increase the likelihood of message survival. Onsite markers should be designed to be easily distinguishable with different designs used for detection from land or from an elevated position, by direct visual means or by instruments. offsite records should be retained in a variety of forms and locations to promote their continued existence and their detection by persons not specifically looking for those records.

Comprehension

Because the knowledge levels, backgrounds, and purposes of future readers are unknown, repository messages should be designed to convey varying levels of meaning, from rudimentary to complex, and from general to specific. Several levels of messages are recommended, ranging from symbolic caution messages to reasonably detailed descriptions of what should be avoided. To account for changes in languages over long periods of time, identical messages should be repeated in several widely used languages as well as in pictographic form. Consideration should be given to the response of the reader to the message, the desired response being one of taking caution prior to engaging in potentially disruptive activities rather than fear of the repository site. of particular use would be a message structured to cause future generations to 
(1) take it upon themselves to protect the repository, using whatever means are most applicable to their times, and (2) to re-encode the message to account for future language changes whenever necessary (e.g., establish a message relay system).

Multiplicity

A variety of channels (techniques) should be used for message transmission to protect against destruction and to promote detection. For onsite message channels, options worth considering include:

- Peripheral markers spaced to be within eyesight of one another

- Central markers

- Earthworks

- Messages carved into natural rock outcroppings. For offsite messages, options worth considering include:

- Record archives

- Libraries

- Inclusion in reference books and maps.

\subsubsection{System Effectiveness}

The effectiveness of systems and measures to protect against future human interference must be considered on a site-specific basis. Systems must be designed to withstand a variety of anticipated conditions and to reach a variety of potential readers. Determinations of system effectiveness should be based on evaluations of the multiplicity of communication methods used and of the probable effectiveness of each measure as a function of time. Although the use of stochastic (probabilistic) techniques to evaluate system effectiveness may entail a number of difficulties, such techniques would likely present a more comprehensive and realistic analysis of system effectiveness than could be obtained on a strictly deterministic basis. The use of fault and event trees to describe the occurrence of human interference scenarios encountering a highly redundant communication system would show the continued effectiveness of such a system even though some elements may fail. 


\subsubsection{Applicability}

Although the studies by the Human Interference Task Force were performed under the auspices of the former National Waste Terminal Storage program, significant inferences can be drawn relative to other types of waste disposal activities, both nuclear and non-nuclear. The task force considers the single most important item for protecting against future uninformed human interference activities with any type of buried biohazardous waste to be the transmittal of an unambiguous, easily understood message stating, "CAUTION BIOHAZARDOUS WASTE BURIED HERE" (see Section 5). With this simple message, received and understood, future humans should (for reasons of selfpreservation), be encouraged to either avoid areas so marked or take steps to learn sufficient additional information about the areas so that they may safely engage in whatever activities they deem prudent.

Nuclear waste is but a very small part of the biohazardous wastes buried throughout the world. The problem involved in communicating the messages deemed necessary for nuclear waste are no greater, and perhaps less, than the problems that need to be considered for other more shallowly and readily accessible buried wastes having infinite lifetimes and high biological risk factors.

The global adoption of a symbol uniquely structured to mean "CAUTION BIOHAZARDOUS WASTE BURIED HERE" will, because of the large numbers of times and locations the symbol would be used, provide the highest possible assurance that this basic cautionary message will be remembered regardless of changes in languages, customs, and political boundaries.

The channels described in this report for transmitting messages were designed to be excessively comprehensive due to the high perceived risk associated with high-level waste disposal. The incorporation of extremely large markers and monuments for other biohazardous waste disposal grounds is not recommended (even though the actual risk attributable to those wastes may far exceed the risk associated with high-level waste disposal) due to the very large economic impact associated with establishing such extensive warning systems. The task force believes that adequately durable marker systems can be developed to convey long-lasting cautionary messages without unreasonable economic penalties. The synergistic effect of using a universal cautionary 
symbol for a 11 biohazardous waste would provide the needed assurance that future societies will be aware of the existence of such waste and adopt the measures they deem necessary to protect themselves and their descendants from harm. 


\section{SITING, LAND USE, AND INSTITUTIONAL CONTROLS}

Various methods are available for reducing the likelihood of human interference with high-level waste repositories. Figure 3-1 identifies three approaches that have the potential for preventing such disruption over a long period of time. This section examines siting, land use, and institutional controls regarding their ability to prevent human interference, and identifies the limitations of these methods.

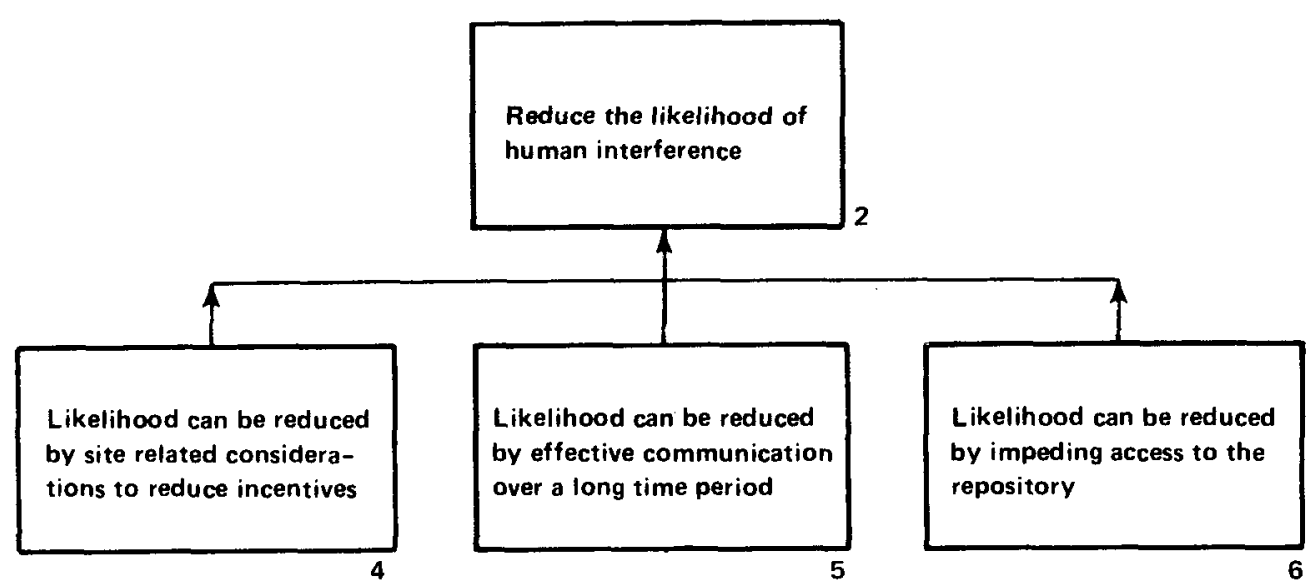

FIGURE 3-1. REDUCING THE LIKELIHOOD OF HUMAN INTERFERENCE

\subsection{SITING CONSIDERATIONS}

Various siting criteria have been proposed by federal agencies and interested organizations (U.S. Nuclear Regulatory Commission [NRC], 1983; U.S. Environmental Protection Agency [EPA], 1982a; U.S. Department of Energy [DOE], 1981; DOE, 1983) to assist in determining acceptable sites for a high-level waste repository. These criteria were developed to meet the problems of radionuclide migration, disruption by natural forces, and minimization of human exposure. Some of the criteria also directly and indirectly influence the probability of human interference. 
The U.S. Nuclear Regulatory Commission rule, 10 CFR 60 (NRC, 1983) requires that the repository be sited on lands under the jurisdiction and control of the Department of Energy or on lands permanently set aside for repository purposes. In addition, a control zone surrounding the geologic operations area is to be established. Jurisdiction and control of surface and subsurface uses are to be maintained to prevent adverse human actions. These rules require institutional controls, which will be discussed in this chapter.

Proposed criteria (EPA, 1982a) would require siting a repository away from areas that contain valuable or unique natural resources, as the presence of potentially valuable or exploitable minerals, water, or energy resources (e.g., geothermal) might attract adverse human activities, e.g., extracting resources or drilling through the repository to reach the resources in a manner that would affect the integrity of the host rock formations. Such criteria are directed at reducing incentives for, and therefore the likelihood of, human interference.

While the use of such site selection factors to reduce the likelihood of human interference appears quite reasonable, the factors' effectiveness relies on predicting resource needs of societies far into the future. Such predictions over long time periods are of doubtful validity. As technology advances, the economics of recovery change, as do the nature/characteristics of materials considered to be resources. For example, the change in the resource value of uranium just within this century clearly illustrates that the value of, and need for, natural resources depends upon economic and technological conditions (Merritt, 1978). Due to our limited ability to correctly predict demand and need for particular resources, resource-related siting criteria appear prudent but not sufficient to adequately protect against interference.

Population density criteria have been considered by DOE and NRC relative to repository siting. Such potential criteria do not appear to have any significance in protecting against post-closure human interference.

\subsection{LAND USE}

After closure of the repository, the problem of human interference begins. Two approaches are available for utilizing the site to minimize this 
problem. First, the use of the site and its vicinity can be developed to discourage direct and indirect interference. The second approach would promote the use of the site for other purposes that would enhance the likelihood of successful isolation.

The first approach could be implemented by developing a new community (rather than siting near an existing town). Adjacent communities would tend to perpetuate knowledge of a repository and prevent a11 but the most minor disturbances to the land. Violations under or near a city would be more subject to recognition and prevention than those in remote areas. Such considerations would need to be balanced against the potential for increased real or perceived risks due to having a repository near a population center. If such risks are acceptable, the development of a community near the site may prove to be a useful measure.

If the repository site could be co-located with activities which are conducive to long-term recordkeeping but not detrimental to the repository's function, a favorable synergism could be established as suggested by the second approach. An example would be to co-locate nuclear repositories with other waste material storage/disposal systems (e.g., similar site but distinct disposal areas) to provide additional incentives for knowledge retention. Designating such areas as sources for materials for which there is no present need, but for which a future need may arise, may result in their voluntary inclusion on the future equivalent of U.S. Geological Service or Bureau of Economic Resources maps.

A final point to be made relative to land use is that the lessons learned by our progeny from their ancestors will include the fact that certain areas have been used for purposes which require careful consideration. For example, salt domes are used for a number of purposes such as salt mining, petroleum storage, and natural gas storage (Griswold, 1981). Given that a large number of domes have been already exploited for such purposes, entrepreneurs scrutinize existing records to determine past commercial uses of the dome prior to investing the large amounts of capital required for the commercial use of a salt dome. Prospective users will continue this practice and will be forewarned if the area has been used as a repository. Thus, the use of unique geologic formations which have competing commercial uses may enhance the likelihood of an interference-free repository. 


\subsection{INSTITUTIONAL CONTROLS}

The third factor that offers an alternative method for reducing the likelihood of human interference is generically referred to as "institutional controls". In this report, "institutional controls" refers to active and passive measures undertaken by organizations and groups that are directed toward protecting or informing other people about the waste and repository. This method is composed of a variety of techniques that rely on different institutions for implementation. The existence of one institutional method does not preclude control being exerted by another institution. The dynamic quality of this method is also evident in that an institution may change its method of authority over time.

Active institutional measures are governmental actions primarily aimed at preventing or impeding access and unauthorized activities at the repository site and surrounding areas. These measures are often associated with the operation and decommissioning of the site when access to the site must be restricted for health and safety reasons. Active controls are considered to be costly and a difficult method to continue over long periods of time. The U.S. Environmental Protection Agency at one time suggested that a 100-year period be established as the maximum time period after closure upon which active institutional controls may be relied (EPA, 1982a). Under those proposed federal guidelines, DOE would be the governmental agency responsible for guarding and protecting the site during the development, operation, and the first 100 or more years after closure.

Active controls could include fences, guards, surveillance techniques and licenses to control activities at the site. These institutional measures will change over time as previously suggested; e.g., jurisdiction over the site may fall under the authority of another federal agency (for instance, the U.S. Department of Interior, which is currently the lead agency for public lands), state agency, or private corporation after closure of the repository.

Passive institutional measures, i.e., institutional measures which are a by-product of other activities taking place, will also be effective in protecting the repository from human interference. Such controls could be governmental, societal (oral tradition), or organizational (university or fraternal groups). For example, the federal government will for some period 
of time control the surface and subsurface land rights (NRC, 1983). Recording of the federal ownership will occur at the federal, state, and local levels. The county courthouses will probably provide the most accessible and complete land records of the site. The deeds of the site will notify subsequent property owners of adjoining lands about the repository and inform future developers of subsurface minerals about the location of the waste. The retention of such records will occur independent of the repository; however, the repository will be protected as a secondary benefit of such records. Additional examples of passive institutional measures include:

- Federal, state, local, and private company maps will identify the location of the repository.

- The nature of the repository will result in the scientific community conducting research and publishing its results.

Such records are likely to invoke a more passive type of institutional control based on each succeeding generation's self-interests.

The effectiveness of institutional measures depends upon the type of institutional control, the incentives for using the controls, and the durability of the institutions. Active institutional measures require a government agency that is funded to implement the controls. The government will be interested in continuing these controls during the near term because of the presence of higher levels of radioactivity. Although the EPA at one time asserted in a draft regulation (EPA, 1982a) that the maximum time period that active institutional controls can be relied upon to isolate wastes from potential human actions is 100 years, there seems to be 1 ittle evidence to limit the influence of active institutional measures to one century. As long as the waste is considered to have the potential of being harmful, the likelihood exists that state and federal agencies will provide active institutional controls to protect the public health and safety. Many laws, rules, and court decisions place a heavy burden upon government agencies to safeguard the public welfare.

Institutions are likely to apply passive measures as long as they do not conflict with their primary goals, and as long as the secondary goals of protecting the waste and educating people about the repository are considered to be important. An example of this situation is that the recording of deeds will continue for the long term since our economic system is closely tied to 
1and ownership. Acknowledging the presence of a repository in the land records will exist for as long as this information is considered relevant to the buying and selling of land.

In summary, the continuation of institutional controls depends upon the perceived need for them and the existence of a government or organization. Successive generations will institute appropriate controls if twentieth century concerns relative to radiation persist. Assuming the need exists, the question then centers around the survivability of institutions.

Historians (Durant, 1954) have traced over 5,000 years of more or less continuous history of civilizations, including their institutions and governments. The oldest include Egypt (5,500 years), India (3,000 years), Japan (2,600 years), and the Near East (5,200 years), while the Greek and Roman histories cover over 2,000 years. Contemporary religions offer other examples of institutions that have existed for thousands of years. Thus, institutions, including governments, have the potential for surviving long periods of time. The structure for active and passive measures will be available if society determines that they are needed to protect the waste and to educate people about the repository. 


\section{COMMUNICATION AS A MEANS OF REDUCING THE LIKELIHOOD OF HUMAN INTERFERENCE}

Communicating information about the repository and its contents is the primary means of reducing the likelihood of human interference. A major issue in developing the information communication system is maintaining its effectiveness for up to 10,000 years. Ensuring that repository related information will be maintained over such a long time period (one-third longer than the span of our 7,000-year recorded past) is the primary requirement in designing a. communication system and in determining factors important for its effectiveness. The objective is to provide continuous communication throughout the 10,000 -year period by using a variety of media and methods to convey the same message at different levels of sophistication and in different forms.

This chapter discusses basic message elements and the requirements (Figure 4-1) necessary for effective long-term communication.

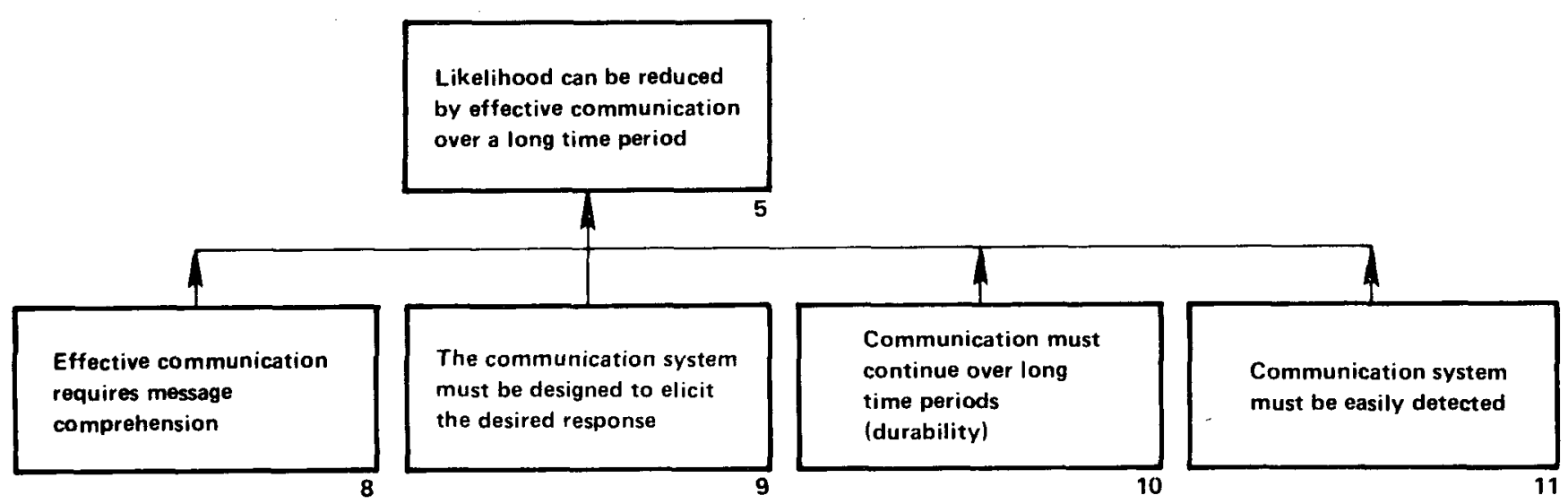

FIGURE 4-1. ELEMENTS OF EFFECTIVE LONG-TERM COMMUNICATIONS

\subsection{BASIC ELEMENTS OF MESSAGE COMMUNICATION}

The basic communication elements, shown in Figure 4-2, consist of a source (message sender), a channel (the medium through which a message is 
transmitted), and a destination (message receiver). The message sender* formulates and encodes the message and then transmits the message to a receiver who decodes and interprets the message. Surrounding this message transaction is the "context" in which the transaction occurs. Context is often crucial to interpreting and resolving the significance of a message, even to the extent of determining whether the receiver (destination) wi11 believe a message (Sebeok, 1984).

Figure 4-2 indicates the interrelationship and interaction that occurs between the communications elements. In formulating repository-related messages and in selecting channels through which to transmit such messages, these relationships must be considered and attention be given to determining the requirements necessary for the receiver to actually receive, understand,

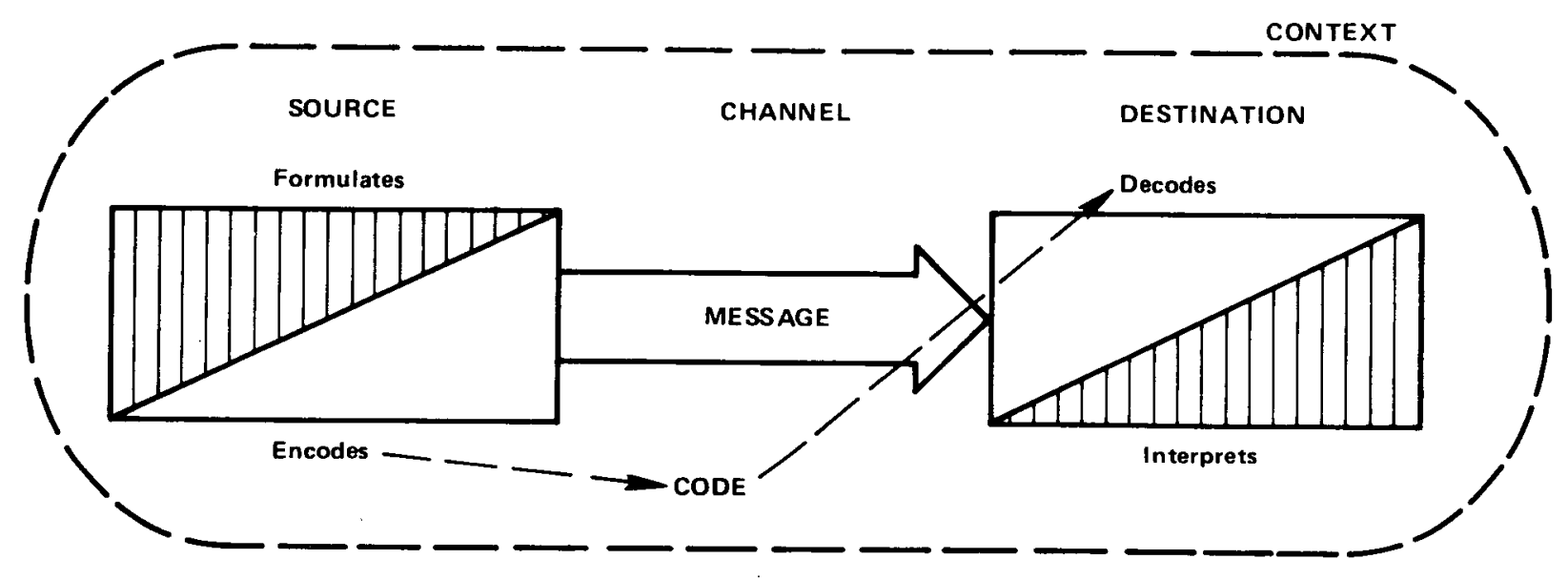

FIGURE 4-2. BASIC ELEMENTS OF COMMUNICATION

(Adapted from Sebeok, 1984)

*In the case of high-level waste disposal, the U.S. Department of Energy $(D O E)$, as the sender or source of the message, is responsible for formulating and encoding the message and transmitting that message to unknown receivers (destinations) in the immediate and the distant future. 
and favorably act on the message. These requirements shown in Figure 4-1 include:

1. The message must continue to exist (Box 10); that is, it must be on or of durable material.

2. The message must be observed (Box 11); that is, it must be accessible and detectable by the receiver.

3. The message must be comprehensible to the receiver (Box 8); that is, the receiver must know and understand the Code* used to transmit the message.

4. The message must elicit from the receiver an appropriate response (Box 9). In this case, the receiver should respond by heeding the warning message and avoiding any disruption of the repository.

\subsection{MESSAGE DURABILITY AND DETECTABILITY}

The most important requirements in transmitting information over long periods of time are ensuring that the messages (1) continue to exist in accessible locations and (2) are detectable by people with the potential or opportunity to interfere with the waste repository.

\subsubsection{Durability}

Durability is the physical ability of the message medium or material to last over time. For this study, it is defined as the ability to withstand or be protected from natural or engineered processes for up to 10,000 years. Figure 4-3, a part of the logic diagram of Figure $1-1$, shows the elements in terms of the materials used to carry messages (Box 17) and the methods by which messages are transmitted (Box 19). Message redundancy (Box 18), as it relates to the effectiveness of the entire communication system, is discussed in Section 4.5 .

*The term "code" refers to the language or symbols used to communicate the meaning of the message. 


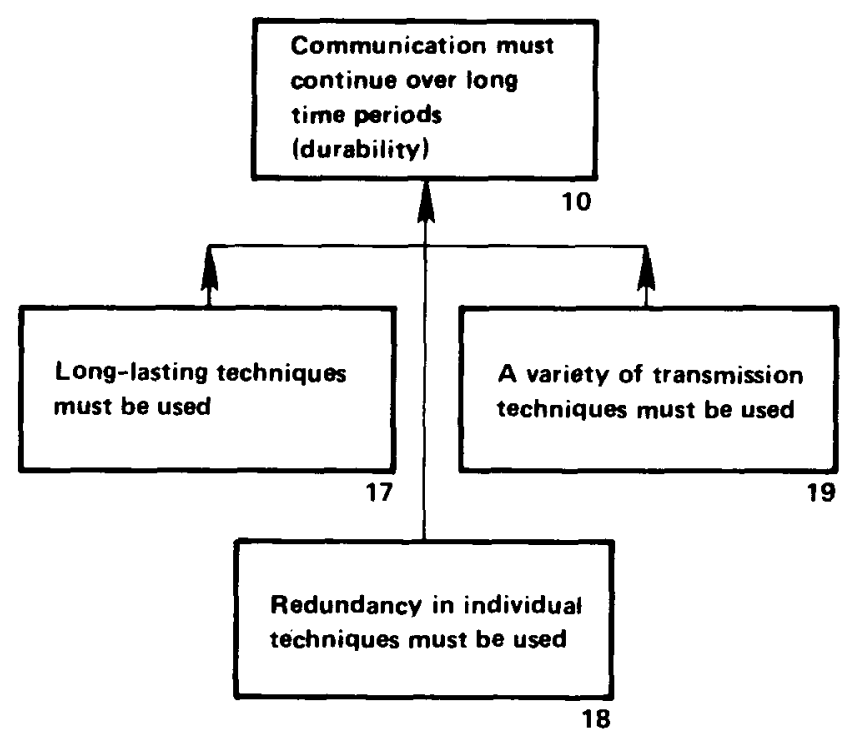

FIGURE 4-3. MESSAGE DURABILITY

The durability of materials has been examined through reviews of archaeological and historical data (Kaplan, 1982a) and through controlled deterioration tests on a number of materials (Berry, 1983). Both perspectives clearly demonstrate that durability depends on the environmental weathering to which materials are exposed and on their potential to be removed by people for recycling or direct use.

The environmental factors considered to be important to the weathering process are climate, air quality, soil type, and the degree of protection from exposure. Moisture appears to be the most critical element in the degradation process (Berry, 1983).

In determining the environmental conditions to which the repository message may be exposed, it is necessary to consider potential climatic changes over the period of interest. According to certain theories, for example, the climate in the next 10,000 years may shift from interglacial to glacial, with increases in floods, flash floods, slope erosion, and landslides; the accumulation of wind-blown loess and sand; and increased areas subject to freezing and thawing (Kukla, 1977, 1981). Hence, possible long-term climatic changes 
and their effects must be considered in selecting message media, designs, and materials.

The construction of message media can affect their ability to withstand unfavorable environmental conditions. Single-piece (monolithic) construction is more durable than jointed construction, since joined surfaces are more affected by freeze-thaw cycles.

The economic resource value and the potential for recycling of materials used for message transmission also affect durability. Among the materials that are likely to survive 10,000 years of surface or subsurface exposure are precious metals (such as gold and silver). However, their high economic value gives them a low effective durability because these materials are likely to be sought and removed (Berry, 1983; Kaplan, 1982a). Historically, even nonprecious metals (such as copper and bronze [Muhly, 1980l) and stone building materials (such as limestone) have been removed because they could be reused (Thompson, 1981). Monolithic and megalithic markers and engraved messages have been more durable (Kaplan, 1982a) because they are difficult to remove and are resistant to tampering.

Ceramic materials, metais, and synthetic stone have also been investigated for durability. Glass and pottery, while dating to 1,500 B.C. and 6,000 B.C., respectively (Kaplan, 1980) are more susceptible to weathering. Like metallic objects, many of the ancient glass and pottery objects that have survived did so because of favorable environmental conditions (Berry, 1983). Because oxides are already the end product of metal deterioration, they generally cannot deteriorate any further. Sintered stable oxides have been only recently developed, and no weathering data are available; however, some accelerated tests indicate good performance for these materials. In fact, natural rocks that are structural analogs of Synroc (a synthetic rock) have been known to survive 20,000 to 2 million years in a variety of geochemical environments (Berry, 1983).

Concretes and plastics can also withstand weathering. The performance of concrete, however, depends on its composition and preparation, and the plastics that have survived weathering have been used in relatively undemanding circumstances (Berry, 1983; Ringwood, et a1, 1979).

Studies of library materials indicate that certain acid-free papers may survive a millennium under reasonable conditions (Fisher Scientific, 1964). 
Paper from cotton or linen fibers has lasted up to 1,000 years, while papyrus has survived from Egyptian times. Considering that such long-term survival has been under favorable environmental conditions (Berry, 1983), materials suitable for detailed written messages would probably require storage in protected environments.

\subsubsection{Detectability}

Message detectability reflects the ease with which repository information can be perceived, sensed, observed, and/or obtained. Figure 4-4 shows the logic elements necessary to ensure that messages are detected by readers over very long time periods. Both the location of messages and the method by which they are transmitted affect their accessibility and detectability. Messages must be located where potential repository interference actions are most likely to occur, and where messages are most likely to be encountered during a survey process that may precede an interference action. Both onsite and offsite message locations are desirable in order to reach site visitors and to promote general regional knowledge of the existence of the site.

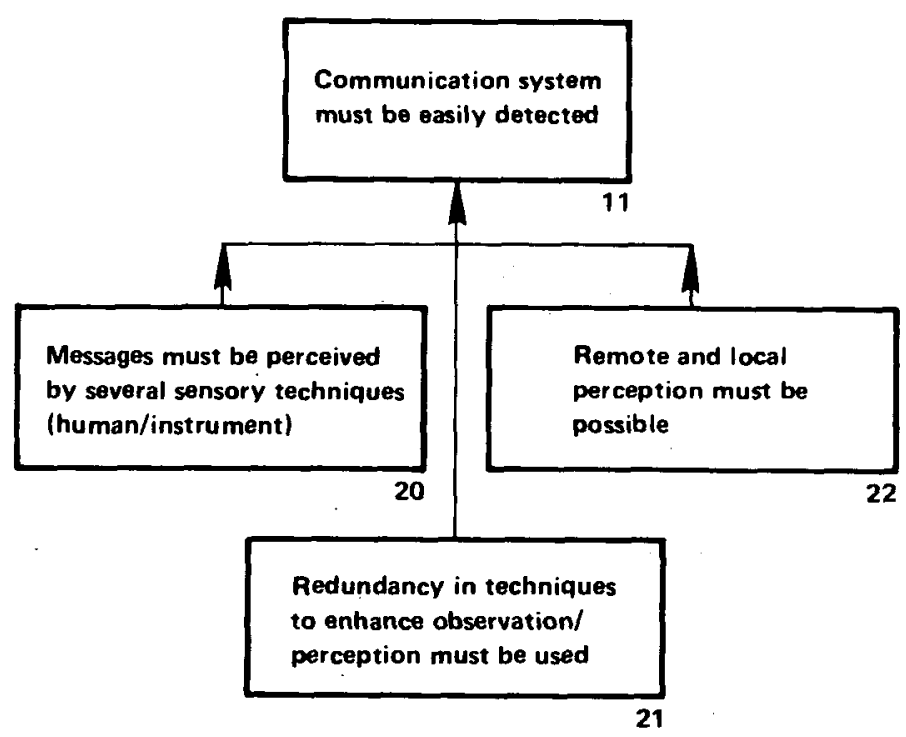

FIGURE 4-4. MESSAGE DETECTION 
To increase the probability of detection, messages should be simultaneously transmitted by a variety of media, some capable of being detected by human senses and some by instrument sensors. A written message on a marker is an example of the former; a magnetic or thermal sign is an example of the latter. Both types of media have advantages. Written markers are easily detected by a casual survey; magnetic and thermal signs can be made to be highly immune to surface conditions.

A multitude of carefully chosen locations and media would increase the durability and detectability of the overall communication system and enhance the quantity and the quality of information transferred (see also Section 4.5). A system of surface (visible and instrumentally sensed) and subsurface (instrumentally sensed) markers on and near the site could, for example, indicate the existence and nature of a repository site, define the boundaries of the repository, and provide detailed information about the repository.

\subsection{MESSAGE COMPREHENSIBILITY}

The message must be presented in such a way that it can be understood for up to 10,000 years. This section discusses the elements needed for message comprehension (see Figure 4-5).

In general, the following sequence of events takes place when communication occurs between any two parties.

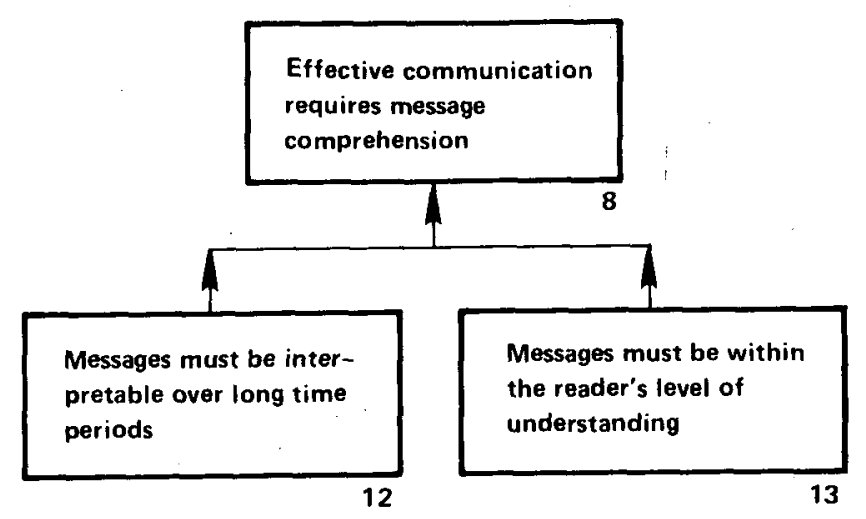

FIGURE 4-5. EFFECTIVE MESSAGE COMPREHENSION 
1. The message sender formulates a message and encodes it for transmission (e.g., puts an idea into words, the words being the code; alternatively, a person could conceive of a gesture or action to convey the message).

2. The message sender transmits the message (e.g., speaks the words or makes the gesture).

3. The message receiver receives and decodes the message (e.g., hears or sees the message and uses knowledge of the code to interpret the meaning of the message).

The comprehension of such messages thus depends on the extent to which the sender and the receiver share a common code, such as an alphabet and a language. This society cannot predict what cultures or societies will exist several hundred or several thousand years from now, the level of knowledge or technology those societies may possess, or the specific codes that they will use. Therefore, the information system must possess the following characteristics (Figure 4-5):

- The message must be interpretable over long time periods; that is, it must, to the extent practical, be crosscultural and amenable to a variety of decoding devices.

- The message must be within the receiver's level of understanding; it must address receivers with the minimum level of knowledge or technology needed for disruptive activities.

Messages can be transmitted as iconic, indexical, symbolic signs (Sebeok, 1984), or combinations thereof. An iconic sign resembles some segment of the real world to which it refers. Drawings and photographs are commonly used icons in our culture; there is a correspondence in form (isomorphism) between the pictorial representation and the thing represented*. An indexical sign "points to" an object or is a sample of it. A verbal example is the word "I", which refers to the person saying it. A symbolic sign is one whose relationship to the item it represents is largely arbitrary, but whose message is

\footnotetext{
*Care must be exercised in choosing icons to strive for crosscultural understanding as, in some cases, an assumed isomorphism may be only fully grasped by those already informed of the code or convention being used (Sebeok, 1984).
} 
understandable because social conventions assign a specific meaning to the symbol. For example, the skull and crossbones is a commonly used symbol in the United States to warn of poisonous substances. It is also a symbol recognized as representing pirates. Highly formalized visual symbols are termed "emblems". An example of an emblem is the seal of the President of the United States.

Historically, iconic representations like the carved animals in Germany's Vogelherd cave, and the Spanish Levantine pictographs of hunting scenes, have been deciphered. Even the more complex Egyptian funerary art that details social, political, and agricultural activities in pictographic sequences is understood (Givens, 1981; Smith, 1965; Ha1lo and Simpson, 1971). The key to accurate deciphering appears to be visual realism as well as the absence of details unnecessary for comprehension.

Each message type, iconic, indexical, symbolic, has advantages and disadvantages for long-term communication. One potentially important factor in correct message interpretation is the context in which the message is situated and perceived. For example, a hand-drawn map of an island, recognizable by shape, with an "X" at the base of a recognizable natural feature, would be decoded as a possible "buried-treasure" map if found among some recently discovered possessions of a long-deceased pirate. Conversely, the map would probably be meaningless if found on a street corner in a distant part of the world where its meaning would not be aided by the context of its surroundings. To increase the likelihood of accurate decoding by the receiver, messages could consist of all three types to the extent possible. In the example given, had the map included the name of the pirate, a picture of precious gems and metals, words to the effect that it was a treasure map, and been written on an obviously ancient parchment, it would be likely to attract sufficient attention so that the finder would seek further information, even if the conditions surrounding its discovery did not make its purpose obvious. For repository communications, this discussion would suggest using a combination of message types arranged in a manner that would readily suggest a relationship between the message and what lies below the repository land surface.

An important consideration in long-term communications is the effect of language changes. The ability to interpret extinct languages is directly related to the degree of relationship between the language to be recovered and 
comparable known languages (Gelb, 1973). Thus, although many people cannot read 01d and Middle English, scholars have little difficulty in translating them because of the close relationship to Modern English. Communication with future generations was probably not the purpose of the Egyptians who made the Rosetta Stone*, but the tablet was, nevertheless, the key to deciphering ancient hieroglyphics (Budge, 1929). Because the Greek version was immediately translatable, it was used as a "code breaker" for the Egyptian hieroglyphs. The senders, the Egyptians, had no way of knowing that Greek would survive longer than their own language. The important lesson is that the repetition of the message content in several languages allowed the message to be understood thousands of years later. Therefore, the ability to decipher written records should be enhanced (see Section 4.5) by repeating the message in several languages, some of which may persist for a long time.

There is a question of which languages, if any, will persist over the time frame of interest. The size of the populations using certain languages and the numbers of books and records in certain languages increase the likelihood that widely used languages will be translatable by future generations. History indicates that even though present languages are likely to undergo major changes over the time frame of interest, most of the literature and important records will be reencoded to facilitate future use. $\star \star$

Furthermore, some ancient languages remain widely read and understood. The Hebrew Torah, for example, is read and understood in the original Hebrew. The sacred writings of Hinduism continue to be read by scholars and devout Hindus in the original Sanskrit, a language that has not been spoken for hundreds of years. In the western world, similar examples can be seen in ancient Greek and Latin. The use of the latter by the Roman Catholic Church is particularly interesting because people of many races, cultures, and

*Although many markers have survived from our distant ancestors, they do not appear to be determined attempts to send messages to people in the distant future, but rather, are intended for destinations or receivers in the time of the encoding population. Thus, ancient recordings, chronicling devices, and commemorations, such as the late-Paleolithic cave paintings $(28,000$ B.C.) Sumerian cuneiform records (3,000 B.C.), and Stonehenge (2,500 B.C.), were probably designed for their contemporary audiences (Givens, 1981).

$\star \star H i s t o r i c a l$ examples are ancient Greek literature, 0ld English Literature, the Bible, and numerous other ancient works. 
countries used it as a liturgical "code", although they did not speak or understand it. The use of several widely used languages, pictographs, and widely used symbols should provide a number of reasonably reliable avenues for correctly reading and interpreting the meaning of repository messages.

Because the knowledge levels, backgrounds, and purposes of future readers are unknown, repository messages should also be designed to convey varying levels of meaning, from rudimentary to complex and from general to specific, in order to best exploit available channels and encourage reading. One approach would be to provide all possible information about the repository. However, this is not always physically possible because of space limitations in a given channel, nor is it necessary; all readers must receive an informative message, but not a 11 will be able to understand a technical message. To accommodate varying information needs and message channel properties, a system that can provide messages with different technical information levels and varying details of information is preferred. Messages that transmit several levels of meaning can enhance future understanding by technology - from less sophisticated knowledge and technology (rudimentary, general information) to superior knowledge and technology (complex, specific information).

\subsection{RESPONSE TO MESSAGE}

The final requirement for effective communication is related to the effect of the message on decoders. Once the message has survived, been noticed, and correctly interpreted, it must then elicit a specific response that of heeding the message by avoiding activities that would compromise the integrity of the repository. Figure 4-6 presents the part of the logic diagram that illustrates the elements necessary to elicit the desired response, that of heeding the message. The message must include sufficient information to produce the desired result (Box 15), be relevant to the recipient and appear to have a factual basis (Box 14), and convey the potential consequences of interference actions (Box 16).

\subsubsection{Message Information}

In selecting the information to be included in the messages, important considerations are the clarity of the message and the knowledge necessary to 


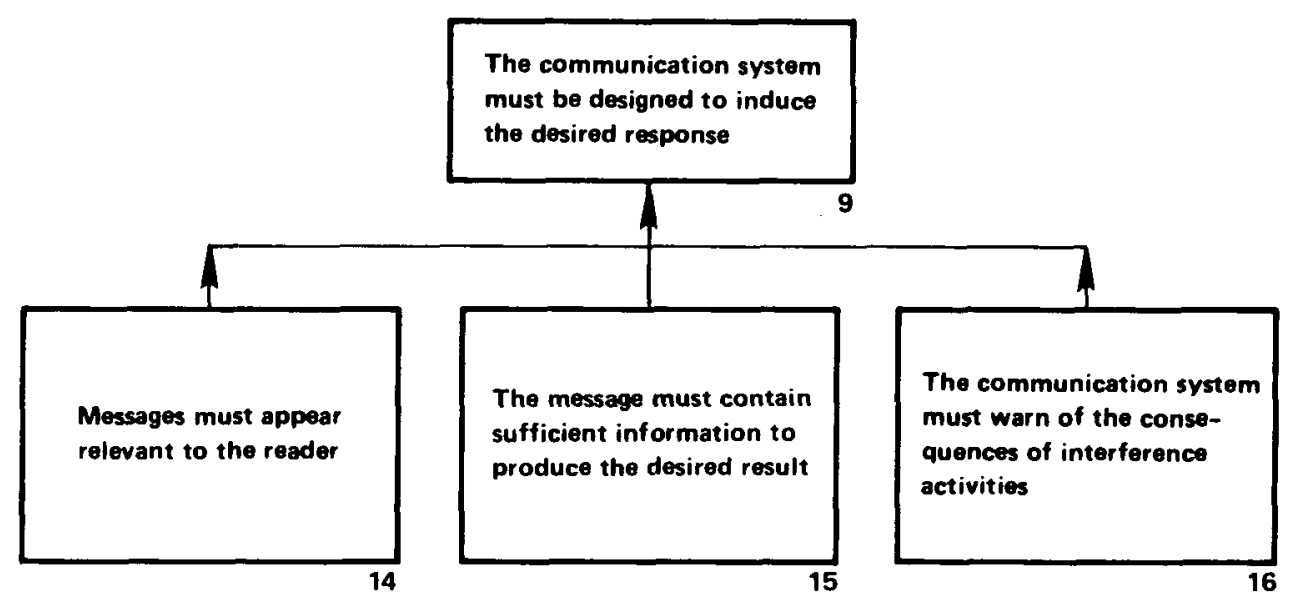

FIGURE 4-6. RESPONSE TO MESSAGES

understand the message. As in all communication, the two requirements may be antithetical: a simple message may be clear but lack detail. This trade-off suggests a system of messages with varying levels of information and complexity. Each level would denote a minimum message of warning and connote the presence of the waste. Higher-level, more complex messages would also transmit increasing amounts of pertinent information. The concept of levels of messages is discussed in more detail in Section 5.

\subsubsection{Message Relevance}

A person's inclination to heed a message is influenced by the apparent relevance of the message, that is, the reader's perception of a cause-andeffect relationship between the message and the reader. Experience indicates that people warned of dangers generally avoid them. There are exceptions, because certain individuals are attracted to danger (Tannenbaum, 1984), particularly danger associated with challenge. Such exceptions, however, do not relate to repositories because of the depth, design, and the type of hazard associated with repositories. Therefore, a warning of danger could provide the relevance required. A consideration of "danger" messages presents two important questions: 
1. Should the message express "extreme danger" or merely mark the existence of a repository?

2. Should the message be directed toward only those with the potential to dri11, mine, or excavate to the depth of the repository (approximately 500 to 1,000 meters)?

An "extreme-danger" message will likely elicit a stronger response from the recipient because of fear. However, as time goes on and the presence of the repository becomes an historical fact, people may realize that there is no danger to a person on or near the site at the surface, and the message may lose its significance. Furthermore, marking the repository with danger messages may instill in the present generation a fear of repositories when, in fact, there is no reason to fear them. People may be bewildered to learn that a repository, found by the government to be safe, is marked with danger warnings.

At the other end of the spectrum is the simple informational message that "there is a repository at this site". A message like this, one that carries no connotation of hazard but merely conveys information, would be less effective, and possibly not effective at a11, if future generations perceived no relevance and dismantled al1 surface markings.

A prudent middle ground between these extremes appears to be a warning message system that advocates caution and indicates the possible consequences of disruptive actions. Such a message could attract the attention of people encountering the markers without conveying a false notion of imminent danger. Since the danger will exist only if interference actions disrupt the repository, warning messages should also denote the nature of the hazard and the types of activities that should be avoided.

The second question is whether the message should be directed toward only those who are capable of interfering with the repository. Here the question deals not with the level of knowledge possessed by a society (ground rule 4, Section 2) but with the capability of people receiving the information. Should the message, for example, be keyed to an engineer or a scientist conducting a site survey? Messages that are understandable and perhaps interesting to the average adult (and inscribed on durable material) are more likely to succeed over long periods because of the potential for broader dissemination of message information. If more people know and understand the message, 
the message is more likely to reach those capable of interference and those capable of preventing interference; furthermore, the message is more likely to be perpetuated.*

\subsubsection{Factual Basis}

Because the context of a message influences the interpretation and the response to that message, messages marking the repository should appear to have a factual basis and be important, qualities essential to making the messages believable (Sebeok, 1984). The message will indeed have a factual basis to the best of this society's knowledge. The problem lies in structuring the message in such a way that the future recipient is immediately convinced of the factual basis or is prompted to verify it by checking. To accomplish this objective, the message should be such that the potential recipient perceives that the sender was knowledgeable and considered the message sufficently important to take steps to ensure its survival.

\subsection{MESSAGE REDUNDANCY}

Information tends to degenerate over time in durability, detectability, comprehensibility, and impact. If a message is repeated in a variety of media, forms, and levels of sophistication, it is more likely to persist, be noticed, and be perceived and interpreted correctly. A single message is often perceived by the receiver with some distortion because the sender and the receiver interpret all or part of a message in different ways. However, a message repeated in many forms, through many media, and at mány locations is likely to be eventually understood with minimum distortion.

Redundancy should be introduced into each communication requirement discussed in Sections 4.2, 4.3, and 4.4. The durability and detectability requirements would be met by using a variety of media for message transmission (e.g., stone, preserved archival materials); by distributing messages in a

*Each succeeding generation should be encouraged to institute its own controls over waste sites. Protection against human interference would then be provided by eliciting a renewed response from each succeeding generation, each striving to protect its own welfare from this and other potential risks. 
number of locations, both at the site (above and below the surface) and elsewhere; and by using a variety of methods to transmit messages (e.g., markers, written records, archives, oral communication). Redundancy directed at comprehensibility could be achieved by using a diversity of message types and a diversity of message codes.

Messages structured at several levels of detail, as discussed in Section 4.3, result in redundancy. Should any particular channel convey an incorrect impression, the correct content of the message could be perceived when the recipient encounters the message in another form or hears about it from other recipients.

Another approach to providing redundancy would be a "relay system" for information transmission in which a message would be periodically reencoded as necessary to account for language changes. ${ }^{\star}$ In the case of repositories, the relay concept could consider the 10,000-year time to be a series of time units each of perhaps a few hundred years. Some onsite and offsite channels would be designed to transmit messages at least through the first time unit. The caution message would be supplemented by a second "meta-message". The second message would provide instructions for renewing and updating the message by methods most efficient and effective at the time of receipt, for transmission to the next time unit. The reencoded message would include similar instructions for renewing the message for the next unit, and so on through the 10,000 years and beyond. Such a relay system offers the possibility for continuously updating repository-related information through the best available knowledge and technology if succeeding generations share our concern about radioactive waste. The important factor is that this meta-message would be added to the message system rather than replacing the existing one. Thus, as the "codes" of future generations change, the information system would expand to include new codes; if instructions to do so are followed (Sebeok, 1984).

\footnotetext{
*For example, religious texts like the Bible or the Hebrew Torah and Talmud have been translated many times over into contemporary languages. Our generation's understanding of these contemporary texts is immediate. However, if there is some question as to the exact or original meaning of a phrase, old versions of the texts are available for scholars to review.
} 


\section{MESSAGE STRUCTURE AND CONTENT}

As discussed in Chapter 4, the ability to communicate to people is directly related to message comprehension. Successful communication of repository related messages far into the future requires that the messages be interpretable by people from many cultures and be within the level of understanding of people in societies having the capability to interfere with the repository. Figure 5-1 focuses on effective communications over a long period of time using redundant message systems.

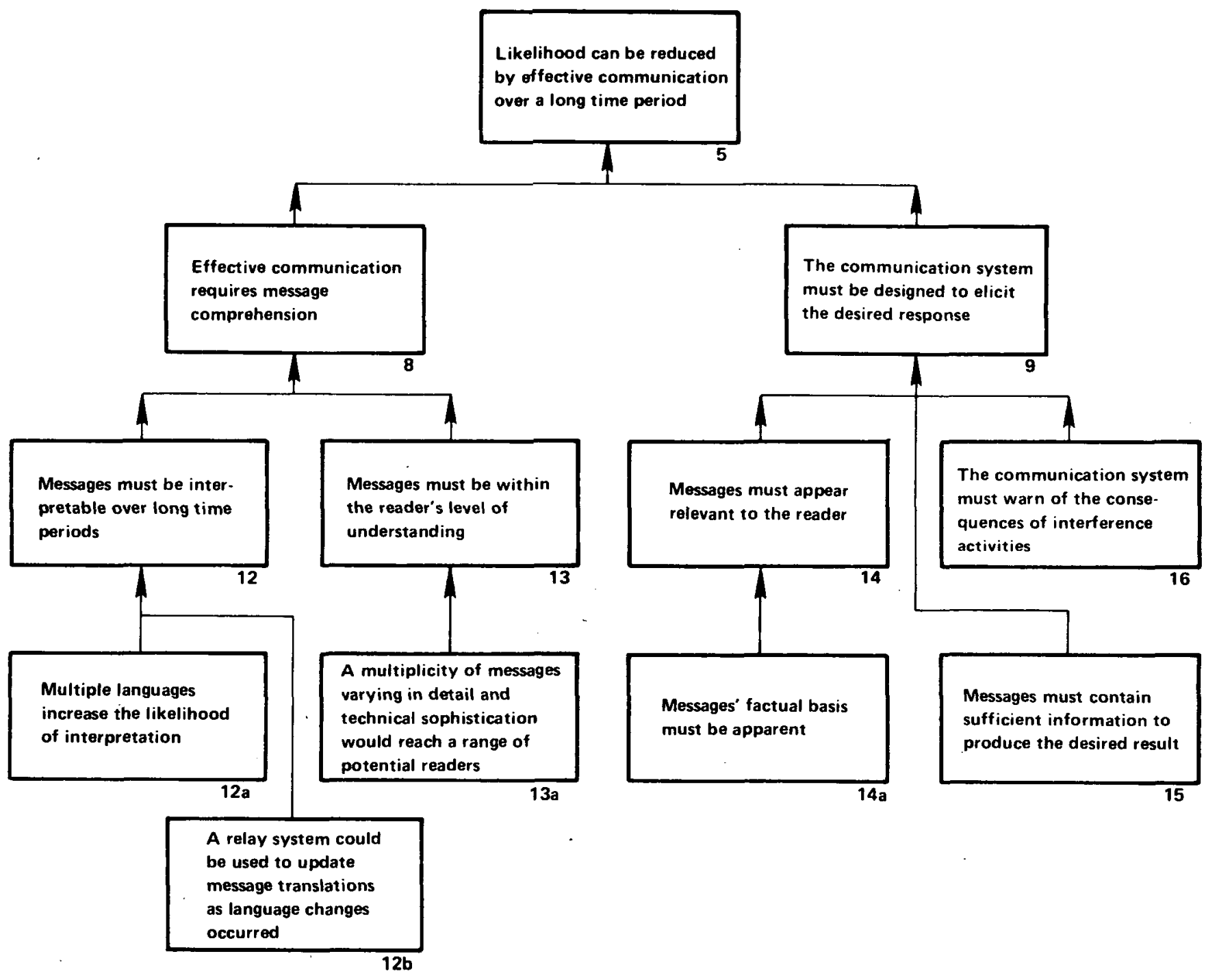

FIGURE 5-1. COMPREHENSION AND RESPONSE 
Requirements for comprehension (Figure 5-1) must be met within the structure and content limitations of the message channel. Although it may be considered ideal to physically provide the maximum amount of information to future readers about the repository, it may not be possible (e.g., space limitations on markers).

A message can convey varying levels of meaning and information. A hierarchy of message levels can communicate rudimentary to complex information by various methods. Simple messages are more easily conveyed and understood, and are more amenable to highly stable transmission methods. Complex messages offer more definitive explanations and may result in more knowledgeable actions. Complex messages are more difficult to accurately convey, however, and are more limited relative to long-lasting materials of conveyance. A combination of messages, varying from simple to complex and detailed, could address a range of potential future message recipients.

If the only action taken to mark a repository site were to provide a marker but no message, the most basic (rudimentary) conclusions reached by future visitors to it, in the absence of any structured attempt at long-term communication, would be that "something made by humans is here". To the future observer, some meaning or purpose might be conveyed by the object, but what the meaning of the marker would be interpreted to be is not clear. A message of this simplicity is not likely to produce the desired response. In fact, it might provoke inquisitive interference.*

The following sections identify four possible levels of messages above the rudimentary level that may be used with geologic repositories to achieve reasonably accurate, long-term comprehension of the message and to effect the desired response to the message. Each successive level would contain additional information relative to preceding levels about the repository. The message channels (Section 7) are structured to make it very likely that a meaning beyond the most rudimentary level will be in evidence over the period of concern.

\footnotetext{
*Consequently, permanence of the message is construed as being of equal importance to permanance of the marker if each marker is taken as an isolated case. Were messages to survive on some markers, but not on a11, at the same site, the bare markers could serve an additional purpose relative to boundary identification.
} 


\subsection{CAUTION MESSAGE (FIRST LEVEL)}

The simplest message to be conveyed is "CAUTION - BIOHAZARDOUS WASTE BURIED HERE". This simple message should discourage interference before further investigation. The basic warning message could be transmitted using several message types to facilitate comprehensibility: iconic, symbolic, and linguistic. For each channel, the message could be conveyed by as many methods as space and inherent channel properties allow.

\subsubsection{Iconic Message}

Certain iconic signs can be so directly related to an image or attribute that their referential meaning is apparent; consequently they may not have to be learned and would therefore require a minimum of processing for comprehensibility (Tannenbaum, 1984). Iconic forms can convey a message without reliance on a language; an arrangement of such signs (a pictograph) could be used to convey a relatively complex sequence of ideas. Thus, a pictograph depicting a series of sequential events or actions could be used to convey certain elements of the message without dependence on existing or future languages. Pictorial representations can be designed to use the smallest number of units needed to convey the greatest amount of information by strictly adhering to visual realism and, simultaneously, excluding details unnecessary for complete understanding (Givens, 1981). One suggested method of presenting a pictograph repository warning message via iconic representations on the repository marker system is shown in Appendix $A$.

\section{1 .2 Symbolic Message}

Development of a recognized symbol to transmit the basic warning message could enhance long-term comprehension. Signs that are common within a culture become comprehensible due to continued exposure and familiarity without the need for formal learning. Signs that are important to human health and safety (e.g., traffic signs) are most likely to be perpetuated by special training beyond simple knowledge gained through exposure to the signs (e.g., driver training or license examinations). In any case, for a symbol to gain meaning 
and usage in ordinary communication, it must be commonly used and group sanctioned (Tannenbaum, 1984).

There are likely to be only two to five high-level waste repositories in the United States, not a sufficient number for "common usage" learning. If the caution symbol is used for other radioactive wastes as well (low-level wastes, uranium mill tailings), the number of sites displaying it could increase to, perhaps, hundreds, still not large enough to ensure familiarity. There are potentially many thousands of sites for all biohazardous waste disposal in this country (Pishdadazar and Moghissi, 1980). A symbol used for all biohazardous waste disposal sites* in this country would be quite common. Two additional benefits would accrue. First, the symbol would be highly unlikely to be forgotten because of its widespread continuous use; there are too many perpetually biohazardous waste disposal sites distributed throughout the country. Second, a symbol would provide useful protection to the public from a11 biohazardous disposal sites, many of which, by virtue of their proximity to populated areas and the accessible environment, will continue to pose a more immediate hazard than radioactive waste repositories. The development of an internationally accepted symbol that could be used for a 11 biohazardous wastes would further increase its usage and fortify its recognition as a warning message. Because of its relevance to health and safety, the symbol could also be perpetuated through education.

In developing the symbol, the primary concerns are:

- It should be noncontroversial, so as to be easily accepted (adoption of a presently accepted international symbol should resolve this concern).

- It should be artistically simple to avoid tendencies to stylize or simplify it with time and usage.

- It should be iconic, to the extent practical, to assist in comprehension.

- It should be uniquely applied to biohazardous materials disposed of by burial.

\footnotetext{
*This suggestion relates only to the use of an international symbol to help offset language changes. The total communication system discussed in this report is not intended to be universally applied to all biohazardous waste disposal sites.
} 
- It should attract attention.

- It should be legible.

Such factors as size, color, shape, contrast, and spatial relationships affect legibility. For purposes of attention, a bold, distinctive symbol should be used in a variety of situations, preferably with some degree of variation in form and with the ability to stand out from its surroundings as much as possible. Certain shapes and colors also claim more attention than others (Tannenbaum, 1984).

A proposed warning symbol for biohazardous waste burial is shown in Figure 5-2. The symbol consists of a triangle around a large arrow pointing downward; the arrow contains the international biohazard symbol.* The triangle is currently used internationally in a variety of signs to denote caution. Although a directional arrow is normally used to encourage movement in that direction, placing the hazard symbol within the arrow countermands that implication. The caution message can be reinforced by using colors. Yellow, often used to indicate caution, could provide the background for the symbol. The black biohazard symbol would stand out from the background of the arrow. Yellow and black are preferred colors for enhancing visibility (Tannenbaum, 1984).

A symbol can be used with a number of channels. For instance, the symbol can be placed on markers and monuments, constructed as a large earthwork, be outlined in materials suitable for detection by survey instruments, and be used on documents. The size of the symbol will be governed by the ability of the viewer to comprehend it. For example, a very large symbol could be used for detection by air reconnaissance.

\subsubsection{Verbal Message}

Information transmitted at the first level also announces the need for caution in verbal form. The message content at this level, "CAUTION BIOHAZARDOUS WASTE BURIED HERE", is identical with the desired connotation of

\footnotetext{
*The basic symbolic message could be supplemented with other symbols commonly used for specific types of hazardous materials, such as the trefoil for radiation, to provide more specific information regarding the type of waste materials buried.
} 


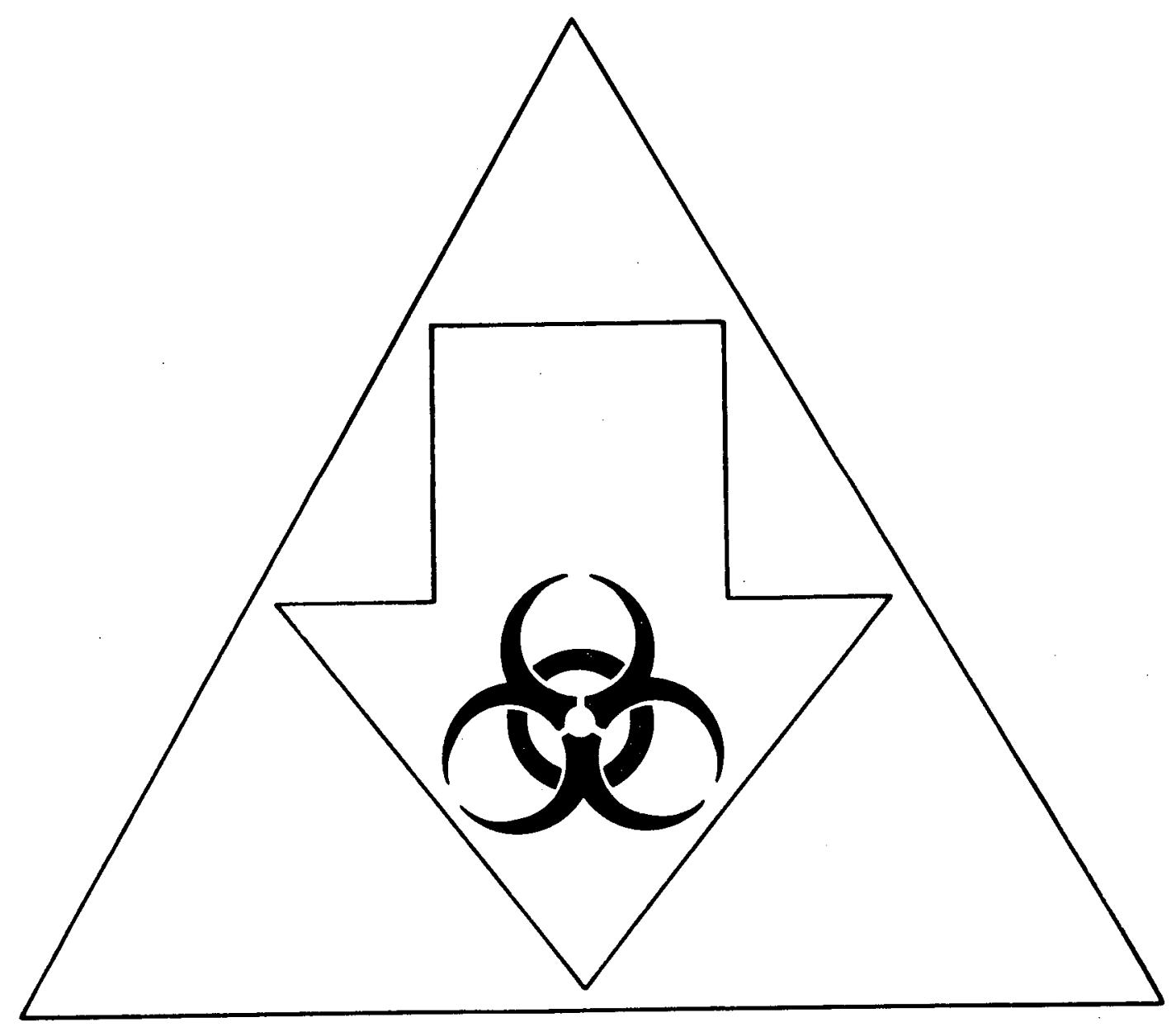

FIGURE 5-2. SYMBOL, "CAUTION - BIOHAZARDOUS WASTE BURIED HERE" 
the symbol. This content, while still providing only minimal information, transmits a warning and indicates the reason for caution. This basic caution message could be transmitted in several languages to provide redundancy, as discussed in Section 4.

\subsection{WARNING MESSAGE (SECOND LEVEL)}

The previous level is directed solely toward communicating caution about the presence of biohazardous waste buried by people, while the second level message would convey both a warning that the waste is radioactive and the location where the waste is buried at the site. Both messages about the site and the waste would be directed toward people at the site.

The amount of data would be limited to the space available in the message channel. The following factual information would be presented:

- Warning message

- Type of waste

- Depth of waste

- Repository boundaries.

This amount of data need not aly be transmitted either symbolically, iconically, or verbally; the message could rely on a combination of these methods. In addition to the warning symbol and the verbal caution statement, the message should state that the waste is radioactive. Data about the depth of waste, size of repository, and how the repository is marked could be communicated by words and drawings. A map of site markers and a drawing of the waste below the surface could be provided to limit the need for words. The message would also direct the reader to a location where further information can be found.

In summary, the second level message would include the warning symbol and words such as these:

CAUTION - BIOHAZARDOUS WASTE BURIED HERE.
Radioactive wastes are buried __ meters
below the surface within a hectare
area bounded by __ markers. Further
information located

along with a map of the marker areas and, perhaps, a cross-sectional drawing of the waste buried below the surface. 
To ensure that the message can be interpreted, the written information should be given in a multiplicity of languages, such as the six languages officially used in the United Nations.*

\subsection{DETAILED MESSAGE (THIRD LEVEL)}

The previous two levels of meaning attempt to convey nontechnical information about the site and the waste. The third level would provide additional detail about the type and the amount of waste and the characteristics of the site. The message would provide at least the following information:

- Repository dimensions and depth

- The contents of each waste package and the number of packages

- Characteristics of the waste

- Type and structure of engineered barriers

- Actions to be avoided to ensure safety.

The written version of this information would be equivalent to a few pages of text.

One of the limiting factors regarding this level is the uncertainty concerning technical. knowledge of the audience receiving the message. Because the purpose of this level is to transmit data for public information, the message must be comprehensible to adults with little or no knowledge of the site and the waste and no special background in physics and chemistry. The information must be at least technical enough to convey the nature of the potential waste hazard yet simple enough to be understood by an average adult. An example of such a message is presented in Figure 5-3. The last paragraph in Figure 5-3 illustrates an example of the "relay" message discussed in Section 4. Iconic representations, which were used in transmitting first and second level messages, would also be part of the third level message. In addition, pictographs and diagrams of the repository layout, waste package design, radioactive decay chains, and other matter suitable for pictographic or diagrammatic presentation could be used to enhance comprehension of the message.

*The decision on languages would be made at the time of repository decommissioning. 


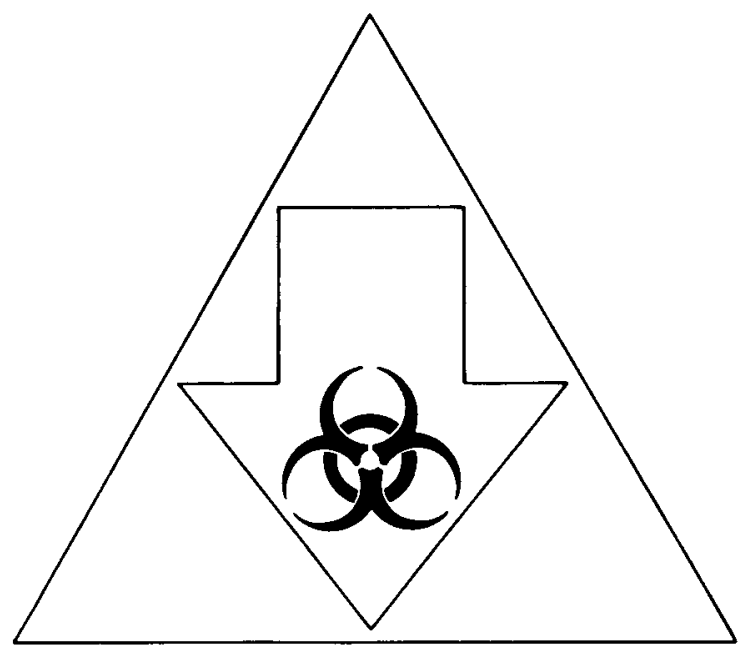

The United States of America, in the year , buried metric tons of radioactive waste below this area. The surface of the land is safe, but the buried material could be dangerous if it were improperly moved or if the repository is damaged.

The buried radioactive waste was produced by the fission of uranium to generate electricity. The waste includes radioactive elements, such as plutonium, uranium, and cesium. The radioactive waste was stabilized in a glass material that has been packaged in metal canisters.

There are waste canisters, buried meters below the surface. These canisters have been emplaced in a (type of rock) formation in rows meters apart, _ canisters per row, and meters from adjoining canisters. The canisters are located over an area _ meters long and _ meter's wide.

The radioactive waste has been buried at this location and in this manner to ensure that the waste does not become dissolved in circulating ground water. If ground water contaminated by the waste were to reach the outside environment and enter a food chain, it could possibly harm living creatures. The potential for harm decreases significantly over the first 500 years, but the waste should continue to be left undisturbed if possible. Proper instructions for moving the waste or using the land above it without affecting these wastes can be found. More detailed information has been placed at other major libraries and archives.

These messages should be translated into languages common to your time. Future readers will be better able to understand and follow these messages if they are changed to the current language.

FIGURE 5-3. EXAMPLE OF THIRD LEVEL MESSAGE 


\subsection{DETAILED TECHNICAL INFORMATION (FOURTH LEVEL)}

The fourth level message would be a written, comprehensive discussion about the repository that would be widely disseminated. Besides detailed written information, mathematical data, tables, figures, maps, and diagrams would provide currently known important information about the repository and the waste. This level of information would also include a reproduction of the signs or symbols displayed on the site markers and monument. Complete relay and cross-referencing instructions and the precise geographical locations of the repositories would be included. Such information, being less durable than that in the previous levels, should be disseminated widely to increase the likelihood of survival. Repetition of the detailed technical information in many languages and locations throughout the world would promote survival and comprehension of the message.

Two versions of the fourth level information are envisioned: complete and comprehensive discussion in English,* contained in technically oriented documents of approximately 500 to 1,500 pages, and a more condensed version (about 200 pages) available in multiple languages.

\subsection{SUMMARY}

A summary table of the message levels discussed in this chapter is provided in Table 5-1. The likelihood of effective long-term communication would be enhanced by using a multiplicity of both communication codes (written languages, pictographs, and a symbol), and message contents keyed to the reader and the channel of communication, and by encouraging a retranslation relay system.

\footnotetext{
*English is the predominant written and spoken language of the international nuclear community.
} 
Table 5-1. Summary of Message Levels

Message Leve 1

Description

Rudimentary

Simple connotation that something made by humans is at the site.

1

Caution message: "CAUTION - BIOHAZARDOUS WASTES BURIED HERE."

2

Simple written message: "CAUTION - BIOHAZARDOUS WASTES BURIED HERE. Radioactive wastes are buried meters below the surface within a hectare area bounded by __ markers. Further information located

3

4

Detailed message: nature, location, and emplacement time of wastes along with information regarding why actions are to be avoided (Figure 5-3).

Detailed technical information: approximately 500 to 1,500-page technical description of the repository and the risk of potential human interference. 


\section{MESSAGE TRANSMISSION}

For successful transmission of messages over very long time periods, the message channels must be durable and detectable by future societies. Durability requires a careful matching of materials and designs to environmental and usage conditions. Detectability requires designs and locations that will be observed by people who could influence the likelihood of human interference.

Detectability and durability are closely related. The options available for creating detectable systems are limited to those that have the required durability. Similarly, the designs and locations chosen for detectability establish the environmental and usage conditions considered in designing for durability. Figure 6-1 shows the logic flow for ensuring durability and detectability.

One method for determining the durability and detectability of message channels is to investigate several ancient monuments. This section begins with a description of various markers that have lasted at least one thousand years. The remainder of this section discusses the considerations important to, and the potential options available for, designing durable and detectable message channels that were learned from these markers and other archaeological sites, as well as from current research. The discussion is keyed to two general message-channel types; marker systems designed to transmit first, second, and third level messages (Table 5-1) and written messages, which could convey any level of message but would be of particular importance to fourth level messages. The former were considered the most likely to be used at the site,* whereas the latter could be used at or away from the site. In addition, the oral transmission of information is discussed.

\footnotetext{
*The first through third level messages for which the markers would be designed would all indicate "...waste buried here", thus implying onsite marker locations.
} 


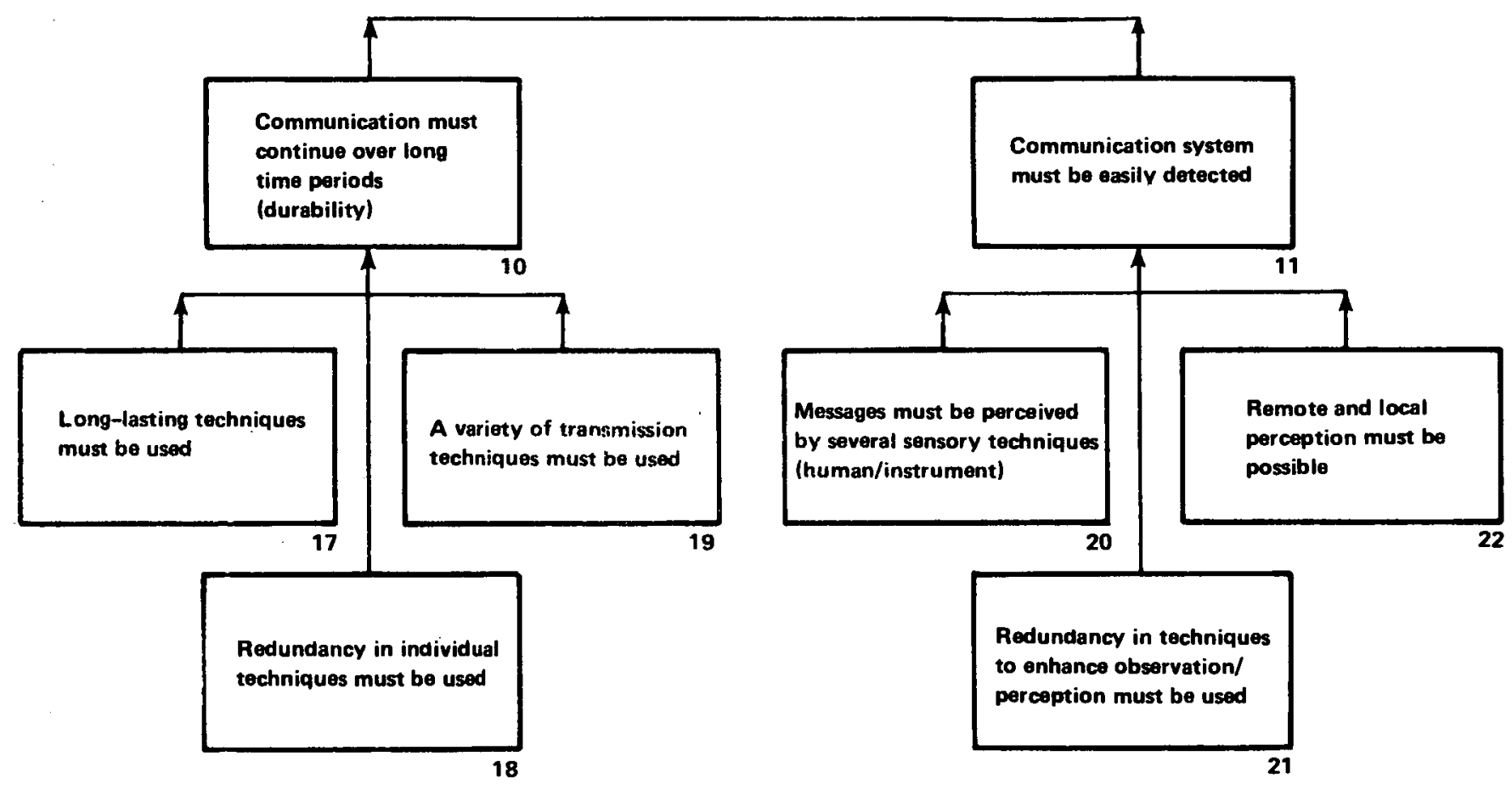

FIGURE 6-1. DURABILITY AND DETECTABILITY 


\subsection{ARCHAEOLOGICAL INFORMATION}

\subsubsection{Ancient Monuments}

The ability to communicate ideas to future people is a skill not limited to contemporary people. While earlier civilizations may not have been attempting to send messages into the future, examples of their work to designate sites, protect themselves, or pray to their gods have lasted for thousands of years and carried messages to us about their ideas, beliefs, and values. These monuments provide existing examples of how to transmit messages that are durable and detectable over long periods of time. Selected markers, chosen to represent a variety of cultures and climates, are described to provide information and background that can be used in designing a repository communication system.

The Pyramids, Egypt

The three very large pyramids at Giza near Cairo are tombs for the three rulers of the Fourth Dynasty of Egypt (approximately 2,600-2,500 B.C.). They stand from 450 feet ta 11 and 750 feet on a side to 218 feet tal1 and 356 feet on a side. These pyramids were made of a local limestone core and finished with a white limestone or granite layer (Fakhry, 1969; Bratton, 1968).

While the contents of the tombs have been looted in antiquity (Smith, 1965) and nearly a 11 the casing of finer stones and part of the cores have been quarried, these actions have only had a minor effect on their immense bulk (Kaplan, 1982a). Knowledge about the pyramids was transmitted through Greek and Roman writers. (Bratton, 1968) and Arab historians (Hassan, 1953).

Stonehenge, England

The general consensus is that the Bronze Age Britons were the people who built Stonehenge, a monument of large standing stones arranged in a ring of upright stones with lintels, an inner ring without lintels, and two horsehoes of upright stones (Kaplan, 1982a). Due to the absence of written records, the purpose of the site is still being debated, including such suggestions as its 


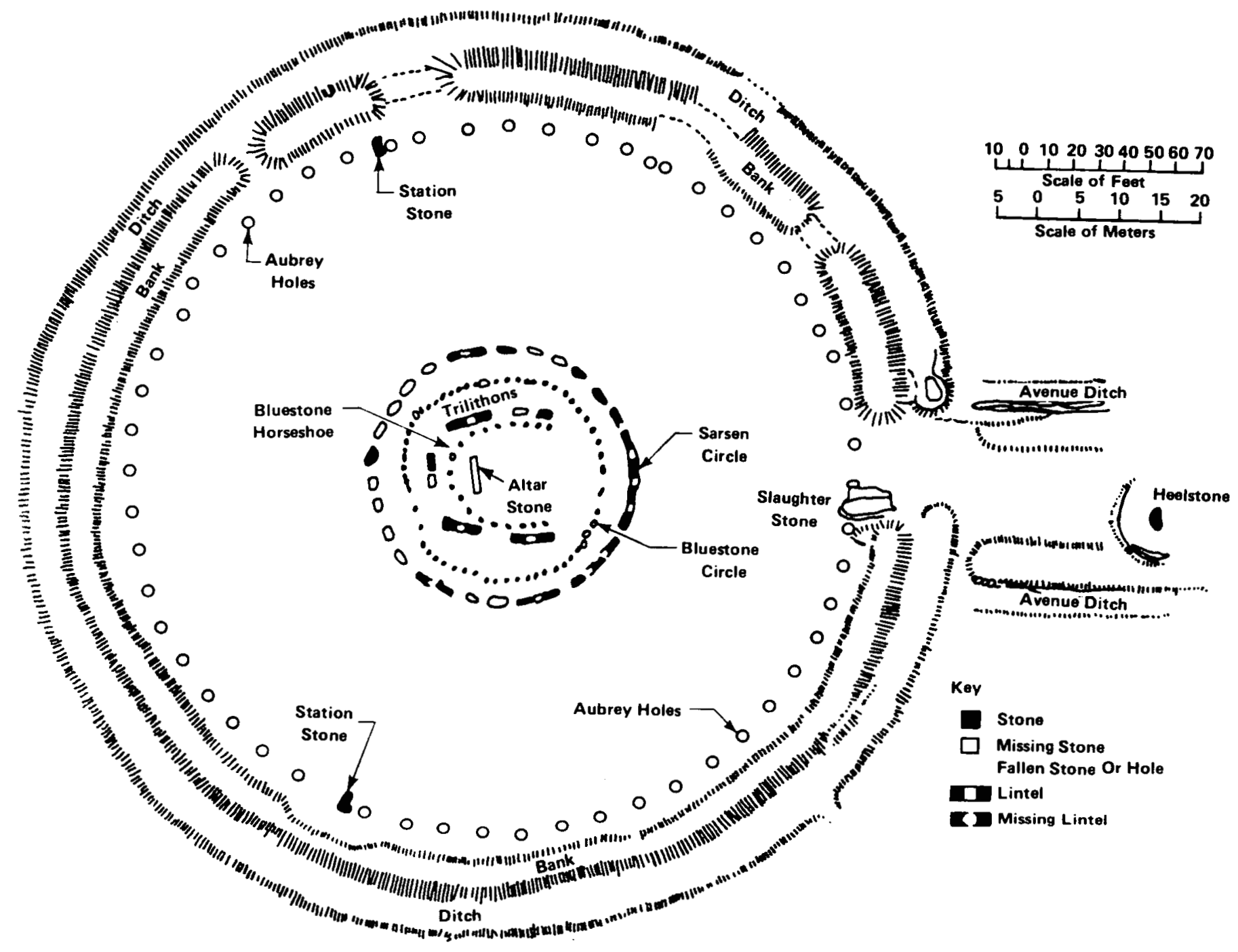

FIGURE 6-2. STONEHENGE 
having some astronomical function or being a ritual enclosure for meetings (Bur 1, 1976).

Stonehenge has withstood invasions into Britain, wars, and visitors who used to be allowed to chip off mementos (Hawkins, 1965). Two-thirds of the upright stones survive and remain in position (Figure 6-2); several of the stones have carved figures from the Bronze Age on them.

Nazca Lines, Peru

The Nazca Lines are a collection of lines, geometric forms, and seminaturalistic figures created by humans, and made possible by a particular set of geologic circumstances, including the decomposition of rocks and the deposition of oxides on their surfaces. The lines were created on a large scale (with one figure measuring 500 feet in length and a single 1 ine extending more than 6.5 miles) by turning certain pebbles over to take advantage of the color contrast between the oxidized and the nonoxidized sides (Hawkins, 1969).

Comparison of figures on pottery to the figures on the desert floor and carbon dating have established the origin of the lines at 200 B.C. to 600 A.D. (Isbe11, 1978; Broecker, et a1; 1956; Ralph, et al, 1973). The purpose of these lines is unknown although there have been some suggestions that they could be astronomical sighting lines, pictures to be viewed by the gods, religious or ceremonial pathways, or mechanisms to balance the resources and population.

Serpent Mound, Ohio

The Serpent Mound, an embankment of earth in the form of a snake in the act of uncoiling, consists of two parts, the serpent and an oval wall (Figure 6-3). The serpent is 1,254 feet long, fitting within an arc of 737 feet, with a height of about 4 to 5 feet, tapering to 1 foot high at the termination of the tail. The oval wall has diameters of 125 and 60 feet, rising 4 feet high (Greenman, 1970).

The form of the serpent and oval are clear but the interpretation of the site is still uncertain. Although no artifacts were found at the monument, artifacts at a burial mound within 400 feet of the serpent belong to the Adena 


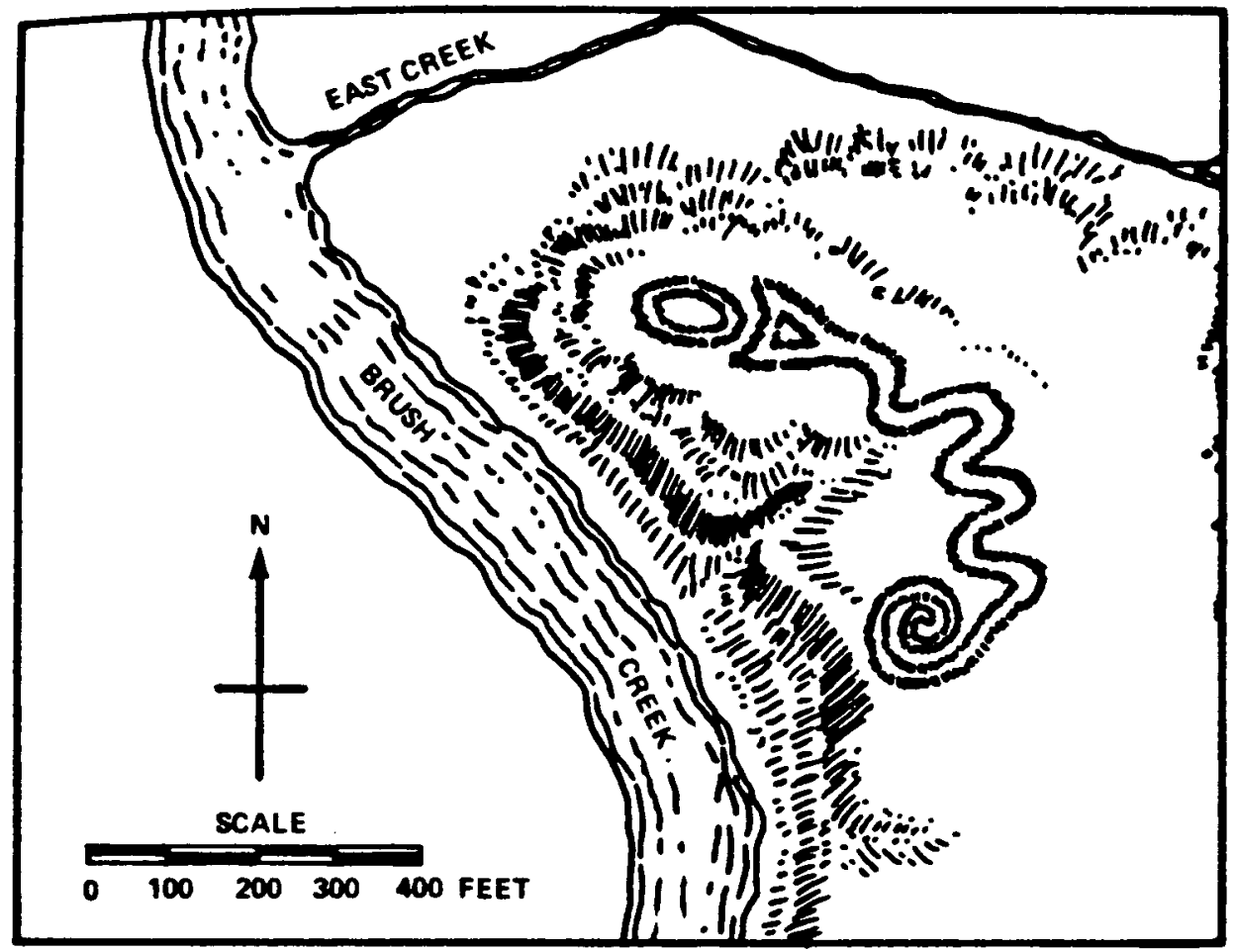

FIGURE 6-3. SERPENT MOUND 
Indians who lived in Ohio between 1,000 B.C. and 700 A.D. The burial mound and the Serpent Mound are considered to be built by the same people (Greenman, 1970; Putnam, 1890).

The Great Wall, China

Begun in 221 B.C., the Great Wall originally spanned a distance of about 1,850 miles, but later additions, loops, and inner walls have nearly doubled its length. The Wall was completed in 210 B.C., incorporating about 1,300 miles of walls previously built. The materials used for the construction vary according to the local building materials (e.g., dry tamped earth, stone, bricks) (Gei1, 1909; Silverberg, 1965; Fryer, 1975). The Great Wal1 has been maintained and rebuilt over the centuries. Parts are in excellent condition, while other sections have deteriorated as a result of the construction techniques used (Kaplan, 1982a). In addition to the written history of the Wa11, a vast literature has developed about the Wa11, including poems about its beauty and stories of the hardships of the people who built it. The Great Wall is an integral part of Chinese military and cultural history (Silverberg, 1965; Fryer, 1975; Lum, 1960).

\subsection{MESSAGE DURABILITY}

\subsubsection{Onsite Markers}

The durability of onsite markers will depend mainly on resistance to natural forces (weathering, seismic ground motion), resistance to tampering and vandalism, and the lack of incentives for removal. The marker must therefore be built of very hard, stable materials that are resistant to corrosion, oxidation, and erosion. The marker must also be difficult to dismantle and remove and have little recycling value.

A number of material and design options were studied from the perspective of historical precedent and modern materials science (Kaplan, 1982a; Berry, 1983). The earliest copper artifacts, for example, were made 7,000 years ago and have been found in archaeological excavations (Tylecote, 1976). Some have survived in excellent condition in favorable environments such as dry tombs or 
caves; e.g., a collection of copper vessels and a table were found in a 4,000year-old Egyptian tomb (Aldred, 1965). As noted in Section 4, however, most metals have historically been regarded as useful commodities and the historical trend to remove them from markers results in an overall low effective durability for exposed metals.

Glass and ceramic materials were also investigated. Glass and pottery, while dating to 1,500 B.C. and 6,000 B.C., respectively, can sustain significant damage from weathering (Kaplan, 1982b) and physical shock. The ancient artifacts that have survived did so under favorable environmental conditions (Berry, 1983). To be of value as message-channel materials, therefore, glass and certain ceramics would need to be protected from direct exposure to the elements; thus, they should not be used on the exterior surfaces of markers. other ceramic materials, such as aluminum oxide compounds, can be formulated to have properties that would resist external weathering over the time period of interest (Berry, 1983).

Concrete and steel construction offers high strength and design flexibility. Certain concretes can last millennia (Malinowski, 1979). Concrete reinforced with stainless steel could, therefore, be considered for marker construction. Concrete surfaces are less resistant to direct weathering than some other materials, however, and would not be expected to survive 10,000 years of exposure.

There are many examples of ancient stone markers and monuments that have survived to varying degrees with legible messages. A review of archaeology reveals that hard crystalline rocks, such as granite and basalt, proved suitable for resisting both people and the elements. Softer stones are too easily damaged by erosion, abrasion, or intentional disfigurement to make desirable markers. Marble and limestone were commonly used and lasted reasonably well, but they have recently shown severe deterioration from industrial pollution, especially sulfuric acid in the atmosphere (Bouras, 1979). Markers might, therefore, be created from quarried granite or basait sculptured into the desired shape.

The durable properties of natural rocks could be also obtained from synthetic rock formed into the desired shape and size. One such material that has received considerable attention as a potential waste form matrix, and 
might also be suitable for markers, is Synroc.* The advantage of a material like Synroc is that it combines the design and fabrication flexibility of engineered materials with the proven long-term durability of natural materials.

Size and the type of construction appear to be major factors for survival. The stones used in Stonehenge weigh 4 to 50 tons each. Although some of the smaller stones have been removed, the larger stones remain (Atkinson, 1956). The same is true of the pyramids: some of the smaller facing stones have been removed while most of the larger ones have been undisturbed. Also, the number of stones is so large that an attempt to dismantle one of the pyramids was halted due to the expense (Fakhry, 1969).

Survival also appears to be enhanced by single-piece (monolithic) construction. A marker built of component parts appears to have two disadvantages when compared to a monolith. First, the use of a mortar or a binding agent between the components sets up a materials interface that is more susceptible to deterioration in freeze-thaw cycles. Therefore, as seen at the Great Wall of China, maintenance is required for long-term existence. Second, markers built of separable parts are easier to tear down and reuse. Many blocks from ancient buildings and markers were removed for building new structures (Kaplan, 1982a).

One possible course of action would be to form a hard, durable shell of natural or synthetic rock to carry the message and resist surface damage, and to pour within the shell a structurally sound reinforced-concrete* core for mechanical strength and stability. Long-lasting quasi-monolithic structures could be created through present design and materials ${ }^{\star \star \star}$ techniques, by interlocking she 11 components to each other and to the core. Complex joints (e.g., tongue and groove) sealed with durable bonding materials could be used to exclude moisture. A schematic diagram of two possible arrangements for bonding the shell and the central core are shown in Figure 6-4.

\footnotetext{
*Synroc is a synthetic rock developed to simulate the long-term wear properties of certain natural rocks. It consists of a number of oxides (including hollandite, perovskite, and zirconolite) formed in a hotsintering process at approximately 1,300 C (Berry, 1983).

$\star \star A$ chemically compatible reinforcing material would be required for marker lifetimes of thousands of years. Common steel reinforcing materials would cause deterioration.

$\star \star \star$ Further work would be required to demonstrate the apparent feasibility of fabricating the shell components from Synroc.
} 


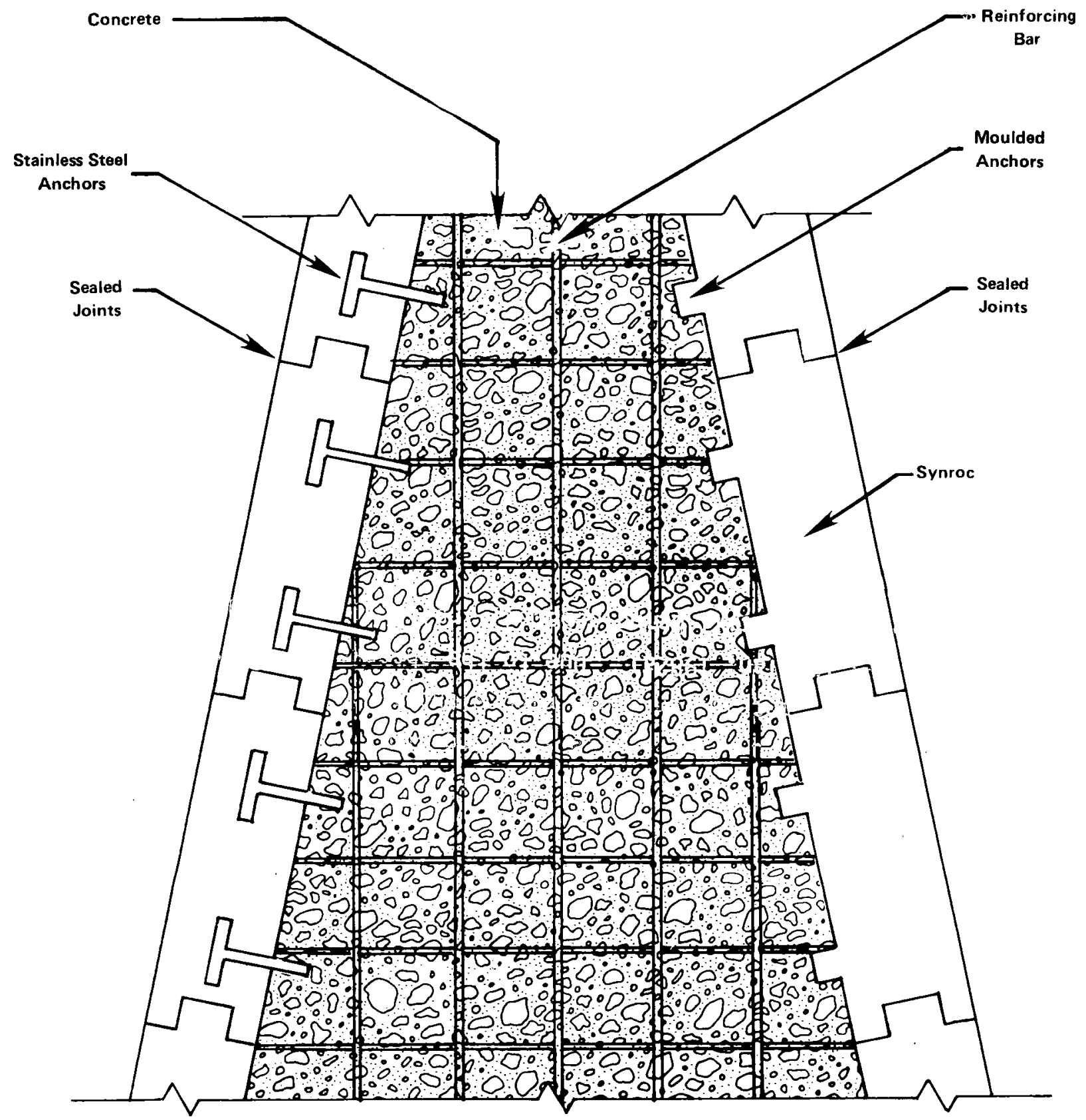

FIGURE 6-4. TWO POSSIBLE CONSTRUCTION METHODS FOR A QUASI-MONOLITH 
If conditions permit, markers could a1so be created from natural features at the site, such as rock outcroppings or cliff faces. Several archaeological examples - among them the Egyptian Sphinx and the Behistun Inscription of Darius - demonstrate the durability of this technique. The Sphinx was sculptured from rock outcroppings remaining after quarrying had removed surrounding rocks more suitable for building the pyramids. In spite of being cut from a relatively soft stone it has survived several thousand years with only occasional maintenance (Fakhry, 1969). The Marker of Darius was constructed on the side of a cliff in approximately 500 B.C. for King Darius of Persia. Its inscriptions have remained legible for 2,500 years (01mstead, 1951). The feasibility of using indigenous markers for repository purposes would depend, of course, on the existence of suitable site features. The potential advantage of such markers is that, being created from natural features, they could be of a large size and perhaps have a societal value that would protect them from human activities.

Markers could also be created from excess materials mined during repository construction* (earthworks) or by impregnating the site with materials that, being anomalous at the site, could be detected visually or by instruments during the course of a survey.

There are many archaeological examples of earthworks that have survived for a long time. The earthworks at Stonehenge (banks and chalk-filled pits) have existed several thousand years (Renfrew, 1973). The Serpent Mound in Ohio is approximately 1,500 years of age (Greenman, 1970). Excess rock from repository excavations could be used to create very sizable earthworks in the shape of a first level symbol. Stabilization could be enhanced by establishing a vegetative cover on the earthwork surface or by covering the earthwork with highly durable and stable asphalt compounds (Asphalt Institute, 1977). The large sizes possible (several hundred meters on a side) and the nature of the message ${ }^{\star}$ would allow considerable weathering to be tolerated without impairing message transmission. Also, the relatively grand nature of such an

* Excess materials are mined rock remaining after repository backfilling. Only about 50 to 60 percent of the rock removed can be used for backfill because of packing-density limitations.

**The message would be transmitted by the general shape of the earthwork, not by inscriptions on the earthwork. 
earthwork would probably give it considerable aesthetic appea1, which might enhance survivability by creating a visitor attraction that might be sufficiently valued by future generations to become a protected area.

The second method of transmitting first level messages is to create anomalous site conditions in the shape of the biohazardous waste symbol which would be detectable by instrumentation. Anomalies could include surface materials with different heat absorption properties than those of the indigenous ground cover and soil, in order to create infrared images detectable by aerial/satellite surveys. Also, the ground could be impregnated with iron ore or magnetite in the shape of the symbol to provide a magnetic anomaly. The latter method could be used below the surface to afford protection from weathering and to enhance long-term durability.

An additional requirement for markers using inscriptions to convey messages is long-term inscription durability. The planar surfaces of markers would be suitable to carry messages in symbolic and/or written form. Messages should not be affixed to the marker (e.g., plaques) because they would be too easily removed, nor should they be applied to the marker (e.g., paint) because a surface coating can be too easily scraped off, painted over, or weathered away. A preferable option would be to engrave the marker itself with the message (Kaplan, 1982a). A point to consider here is whether the lettering or symbols should be raised from, or cut into, the surface of the marker. Most ancient inscriptions were cut into the stone or metal. Raised figures were generally reserved for artistic works. Cutting the message into the stone created crevices subject to weathering effects. Conversely, raised letters were more susceptible to vandalism - it was easier to chisel off an inscription than to hack it out because less stone had to be removed. In general, engraved rather than raised letters are considered more suitable for long-term durability, the human factor being more difficult to overcome than long-term weathering.

If synthetic materials are used for markers, the message could be cast into the surface by using letters of another material. For example, letters of a durable material, like a sintered aluminum oxide compound several centimeters thick, could be cast into a concrete surface or hot-pressed into Synroc during formation. Either method would produce a message as durable as the marker. 
Resistance to movement by natural or human forces is important to durability. The markers can be made sufficiently large and sufficiently well anchored to make removal difficult. A reasonable fraction of the marker would need to be below the surface, possibly anchored to bedrock. At a minimum, a relatively deep poured concrete footing would be required to protect against settling and to discourage removal.

Designing markers to provide aesthetic appeal would further discourage removal or destruction. Contemporary society, in general, does not follow past practices of removing or destroying ancient markers even though it is within its power. Future technical societies are anticipated to have the same ability to damage site markers, but they may continue current practices of preservation if they consider the site monuments to possess positive aesthetic, cultural, or historical qualities.

\subsubsection{Written Records}

The preceding section was concerned with the durability of messages on large monolithic markers located at the repository site. Practical space limitations on markers would render them unsuitable for fourth level messages. Such messages would need to be transmitted in a written form on a medium suited for several hundred pages of information. Also, messages about the site must be written to explain the purpose of the site. Due to the absence of written records about Stonehenge, its purpose is obscure, particularly the astronomical theories associated with it (Bur1, 1976). In contrast, the historical records about the pyramids explained their purpose (Bratton, 1968). Such messages could be located on or off the site. If located on the site, the messages must be accessible when needed but removed from unnecessary exposure to potentially damaging natural or human forces. Because reference to the message would be required from time to time, hermetically sealed timecapsules* would not be suitable for protection. Also, recorded messages (e.g., magnetic tapes) and microfilms do not appear to provide sufficient

\footnotetext{
*Time capsules are essentially single use channels. Once opened, a new or redundant capsule would be required for subsequent readers.
} 
longevity (Berry, 1983). Archaeology indicates that linens, papyrus, clay tablets, and metal plates have survived for thousands of years, normally because of fortuitously favorable environments that protected them from chemical and mechanical forces (Berry, 1983; Kaplan, 1982a). Messages engraved or made part of ceramic plates may last thousands of years if protected from direct exposure to weathering and malicious mischief; examples are cuneiform tablets (Gelb, 1973). Metallic plates could offer longevity with more resistance to breakage than ceramic tablets, but they must be protected from recycling. Modern acid-free papers may also be chemically stable for thousands of years in protected environments (Fisher Scientific, 1964). For example, if suitably sealed into transparent durable protective cases through which they could be read, and if protected from direct human contact, acid-free papers could conceivably exist for thousands of years.

The key to the survival of onsite written records would appear to be:

- Transcribing the message onto a reasonably durable material that would be chemically and physically stable for thousands of years.

- Protecting the durable message medium from direct environmental exposure to the extent feasible.

- Allowing human access to the message when necessary, but only with significant difficulty* so as to avoid whimsical or malicious damage.

For offsite written records, the above media may again be suitable. In addition, microfilm, tape (e.g., computer, video), or other electronic information storage methods may be of significant value if located in record archives and maintained or replaced periodically. Although the likelihood of any given document, tape, or film surviving would be low, given a very wide distribution of documents and a wide variety of forms in which the material was documented, ${ }^{\star \star}$ a statistically significant number of references to the repository may survive. One important factor of document survival is the importance posterity places on protecting the public from biohazardous wastes.

*Vandalism or theft cannot be prevented, but prudent design (Section 7) may reduce its likelihood.

$\star \star$ Maps, texts, and reference works including relevant information about the repository are examples. 


\subsection{MESSAGE DETECTABILITY}

Message channels need to be designed to attract attention and to be accessible to readers. Onsite channels would most likely either be markers or be associated with markers. Offsite channels would most likely be associated with archives, libraries, or other written-record repositories. Two major limitations must be considered in designing for detectability: (1) limitations imposed by the durability requirement in the choice of materials, methods of construction, or environments; and (2) space requirements for message encoding into the channel. This section discusses a number of potential options for onsite and offsite message channels for a 11 message levels. The list of options is not complete, but it is indicative of the measures that could be brought to bear. Each option could be implemented in a number of ways. Section 7 suggests one way that the options considered in this section could be developed for a particular site.

\subsubsection{Peripheral Markers}

For some distance around the area where wastes are actually emplaced, there will be an annular control zone where drilling or deep excavations should be prohibited because of the potential for direct intrusion. The radius of the control zone will be specific to the site, depending on (1) residual uncertainties related to geologic characteristics; (2) the local ground-water regime and its reactions with the host rock (e.g., dissolution); (3) the potential for angular drilling (whipstocking) to pierce the repository; and (4) the nature and location of potential resources.

One reasonable method of delineating the extent of the control zone would be to place markers around its perimeter, taking care that:

- The disposal area is defined with reasonable accuracy.

- The spacing of markers allows a person at one marker to see the next marker on either side.

- A sufficient number of markers are used so that the placement pattern can be identified even if some markers are destroyed.

The actual placement of the markers will be determined by the terrain and indigenous vegetation at the site because each marker must be visible from another. 
The option of simply using four markers to mark the cardinal points of the area may not be acceptable for several reasons. For example, the distance batween markers would probably be too large to permit other markers to be seen, and people would, therefore, have difficulty in visualizing or recognizing the pattern. Furthermore, the loss of any one marker would destroy the pattern, placing a portion of the repository at risk. For example, the Sarsen circle at Stonehenge had 30 standing stones (Figure 6-2). That was a sufficient number of markers to reconstruct the pattern, * even though some of the stones were destroyed or carried off to museums (Atkinson, 1956; Hawkins, 1965).

The markers must be sufficiently large to carry the required message and be clearly visible and distinguishable on or near the site. Clearly, the size would be tailored to the site, but in general, markers would be 3 to 10 meters high and provide a surface area of approximately 5 to 10 square meters on each side for the message. The marker should contrast with the background, and the message should clearly contrast with the marker surface (by color or relief). The shape of the marker should also provide contrast, but take aesthetic values into account within reason, the prime mission being visibility.

\subsubsection{Central Monument}

Peripheral markers are most likely limited to conveying first and second level messages because of space limitations. Detailed inscriptions on surfaces exposed to weathering would be more prone to damage than the large coarse lettering used for simple messages. For third and fourth level messages a central monument would provide a reasonable channel. The monument would need to be large enough to convey third level messages on its surface and have provisions for containing fourth level messages in a protected portion of the monument. The monument could be constructed to accommodate third level messages on either external or internal surfaces. The latter option, which implies a structure that would be entered or looked into by readers, would protect the message from weathering.

\footnotetext{
*The plan of Stonehenge can be reconstructed, even though more than a third of
} the stones have disappeared over the last 5,000 years. 
The monument would need to be readily visible from anywhere on the site. It could also provide a first level symbolic message by virtue of its general shape from an aerial or distant view, thereby attracting attention and inviting investigation.

If the monument were to have a third level message on interior walls, then those walls could be above or below grade. Below grade walls have more stability and resistance to freeze-thaw effects, but are more subject to water damage. The monument could be a conventional rectangular structure with vertical walls and pillars; it could be of a shape chosen for durability, such as a dome or a pyramid; or it could be a bunker. The latter would be less suitable in a rolling terrain since it would blend into the landscape and sacrifice visibility. The durability advantages of domes and pyramids would probably be a strong consideration. The pyramids are similar to a naturally occurring geologic shape that endures for long periods of time (e1-Baz, 1981).

The fourth level message, transcribed onto some durable medium suitable for several hundred pages of information, would need to be protected within or by the monument. Numerous time capsules could be used to carry the message, thus providing a number of discrete message transmission possibilities (one per capsule). There would be a high risk, however, that a 11 or many of the capsules would be opened by one or a few readers to cross-check contents. There is also some rationale to making access to the fourth level message reasonably difficult by using a reversible* process so that access could be gained with difficulty, the message read, and the enclosure holding the message resealed to preserve the message for the next reader. A prime concern in either case would be vandalism or theft.

For central monuments, the options for redundancy are limited. It would be unreasonable, for example, to provide more than one large monument per site. Redundancy could be provided by multiple message locations within or on the monument (e.g., identical messages on several walls or free-standing sur-. faces or by including several sealed enclosures for fourth level messages).

\footnotetext{
*For example, sealing the message within a vault by means of an extremely
} heavy lid that could be removed and replaced only with heavy machinery. 
Continued awareness of the repository could be enhanced if the monument were designed for a utilitarian purpose. The monument could be used as a U.S. National Geodetic Survey marker or for mounting surveyor transits. If the monument is reserved for similar purposes, international control and maintenance may continue even if public concern for the waste is minimal. Another device for encouraging use and awareness is to make the site and the monument aesthetically and/or educationally attractive. There is some risk that developing monuments with secondary utilitarian purposes may detract from the significance of the warning message.

\subsubsection{Earthworks and Anomalies}

As mentioned previously, earthworks and anomalous materials arranged in geometric patterns could provide a durable and highly detectable means for transmitting first level messages. Either could be arranged in the general shape of the symbol given in Figure 5-2. Both would be recognizable by surface, aerial, or satellite reconnaissance - earthworks visually and anomalies by instrument readings. While large structures may be desirable to increase their detectability by offsite measurements, the earthworks should also be discernible by site visitors. The Nazca Lines, while clearly visible from the air, are difficult to track on the ground because of their size.

The Serpent Mound in Ohio, the earthworks surrounding Stonehenge, and the Nazca Lines in Peru are all examples of earthworks that form patterns and have survived more than 1,500 years (Greenman, 1970; Atkinson, 1956; Isbe11, 1978). The anomalies have no archaeological analogs (the instruments for detecting such anomalies are modern inventions); however, anomalies appear to be a reasonable extrapolation from the earthwork concept.

\subsubsection{Offsite Written Message}

Repository messages and information could be stored off the site in a variety of national and international archives, libraries, and municipal record repositories (e.g., town halls, state and federal record archives), and incorporated into mapping systems. Materials for such records would be 
printed on conventional materials* and on special long-lived materials like acid-free paper. They would be stored in controlled environments.

Because these written materials would not be at the site, an unambiguous reference to their exact location would be necessary. The primary purpose of such records would be to reach persons researching an area for some personal or business reason (e.g., historians, resource entrepreneurs, and land developers). Wider public dissemination would be possible near the time of repository closure but would not be sustained over very long time periods. Nonetheless, knowledge of the repository could be perpetuated by references in carefully chosen records or texts associated with the geographic area where the repository was located.

Such references would be designed to lead the researcher to the fourth lever message.

Large numbers of libraries and archives have been established in the United States and abroad for the use and preservation of documents, and the maintenance of the accumulated knowledge of civilization receives considerable attention. The redundancy inherent both in distributing and archiving important information provides assurance that knowledge of the repositories can survive for a very long time. The effort and care that is expended on maintaining and adding to existing collections is substantial and has been a major societal activity, certainly for the past 500 years.

By striving for international distribution, potential periodic losses of repository information within certain political boundaries could be offset by the information being preserved and reentered into the records of the affected region from an unaffected political region. The same logic would hold for destruction of records by acts of war, civil violence, or natural catastrophes.

The "detectability" of offsite messages can be made extremely high by widespread international distribution and purposeful incorporation into records/texts that have a high likelihood of continual reproduction and translation.

Incorporating the location of a repository on widely distributed maps is a method of transmitting messages for offsite perception. The creation and

*Conventional paper would be suitable for records that are periodically updated or maintained. 
use of maps has a long, documented history in human societies and has, with modern technology and communication methods, become very widespread and commonplace. Maps are used by large portions of society and represent a unique means of conveying the repository locations to many people, both in the present and in the future. Private organizations and public institutions can facilitate any repository mapping program that may be chosen. The mapping, charting, geodesy, and surveying activities in the United States today, both public and private, represent a very large commitment of people and financial resources. Combining the public and private annual map production with a conservative estimate for the fraction retained would yield a number on the order of 100 billion for the quantity of maps in existence in the United States at a given time (Weitzberg, 1982). The physical lifetimes of the maps would range up to several hundred years, depending on their use and the care afforded them.

In addition to developing geologic and cartographic data and producing maps and charts, the U.S. Geological Survey has established the National Cartographic. Information Center to collect and disseminate information about maps and the data and materials used to compile them.* Map information from 180 different sources, including federal, state, and local government agencies and private companies, is accessed, indexed, and stored in computerized data bases. The Center also provides information about many current and out-ofprint map products. Moreover, there is also a large distribution of private maps through automobile clubs, oil companies, and other channels. Special maps, such as infrared or other color-enhanced composites produced from the Earth Resources Technology Satellite program, could uniquely show the repository location. Following repository closure, detailed surface and underground maps of the repository would be appropriately sent to the federal repository responsible for maintaining maps of abandoned mines (Edgerton, 1974).

\footnotetext{
*The U.S. Geological Survey: has also established the EROS (Earth Resources Observation Satellites) Data Center near Sioux Falls, South Dakota, to receive, process, and file the large amounts of data generated by satellite missions over the United States. This provides another independent large data base in which digital and visual records of repository locations could be recorded. Only a small percentage of satellite data may ultimately be converted into maps, but photomosaics, orthophotomaps, and digital data tapes will add another dimension to the diversity of repository locators.
} 
In addition to the conventional storage of documents in archives and libraries, the relatively recent development of computers has led to a proliferation of machine-readable data bases, many of which contain information that could aid in preserving knowledge about waste repositories. For example, as of 1979, the USGS maintained over 200 separate data bases (USGS, 1980), covering a variety of subjects related to resources. There are information exchanges such as the NAtional Water Data EXchange (NAWDEX) (Edwards, 1979), which compiles data on surface and ground water and water quality for more than 600 organizations nationally. Its files contain information on more than 600,000 wells, with hundreds of millions of daily observations of stream flow, water quality, and ground-water level. There are also similar data files maintained by the U.S. Environmental Protection Agency, the U.S. National Oceanic and Atmospheric Administration, and state and local agencies. These independent information files, whether or not computerized, could provide many additional channels for preservation of information about waste repositories.

\subsubsection{Oral Transmission}

Oral transmission may be considered a potential repository message channe1. There is controversy among historians and folklorists over the efficacy of oral transmission as a method for accurately conveying information over long time periods (Monte11, 1970). Opinions range from "Folk Tradition as Historical Fallacy" to "Folk Tradition as Historical Fact", but even those who dispute the accuracy of folk tradition usually agree that folklore does have some basis in fact, although it must be regarded and used with care. Examples, cited by Monte11, of the many instances where historical information was preserved orally for many hundreds of years include:

1. The Southern Paiute Indians of Utah retained knowledge of history consistent with archaeological evidence 800 years old.

2. Native traditions from 1,400 A.D. regarding habitability in the area at Yakutat, Alaska, were confirmed by radiocarbon dating.

3. Archaeological findings in the west of England confirmed local traditions that a nearby cave had been occupied by Saint Ninias 14 centuries earlier.

4. The reliability of Icelandic family sagas dating to 930 A.D. was confirmed. 
Oral transmission may, through a synergistic relationship with permanent message bearing markers and records in archives, offer an additional channe 1 for dissemination of repository-related information. It can be expected that stories, poems, and legends will develop about the site in the same manner that oral tradition and history is associated with the Great wall.

\subsection{SUMMARY}

There are a number of options for creating durable and detectable channels, both on and off the site. The success of any given channel may vary, but the redundancy and synergism resulting from using a multitude of channels should create a high likelihood of successful communication. 


\section{COMMUNICATION SYSTEMS COMPONENTS AND THEIR APPLICATIONS}

Factors essential to the successful communication of repository-related information - including durability, accessibility, detectability, comprehensibility, message content, context and relevance, and message redundancy - have been discussed in preceding sections. The different levels of messages developed in Section 5 and the possible methods of their transmission discussed in Section 6, were devised specifically to meet as many of these requirements as possible, often in several different and redundant ways. This section describes a reference communication system for a high-level waste repository. The description contains sufficient detail to establish the preliminary feasibility of the conceptual design of the system and to assess its effectiveness. The discussion specifically addresses the question of ensuring that the messages sent by the communication system are observed by their ultimate recipients.

For a site-specific application, any chosen communication system would be thoroughly tested prior to and during its early phases of implementation. Symbols, messages, and pictographs would be tested for their comprehensibility content and relevance; the feasibility of marker and monument construction will be demonstrated; and the overall awareness of the local population of the correct location and hazards associated with the buried waste would be examined.

For this study the repository site was assumed to be in a remote, nonglacial* region of the United States. The immediate vicinity contains nothing of major significance or known value. The land is flat, with no dominant natural landmarks (i.e., rock outcroppings and/or cliff faces that could be used to transcribe messages are not assumed to be present).

To maximize the effectiveness of any communication system and increase its long-term survivability, two major classes of communication methods could be utilized: (1) site locators and descriptors, and (2) information dissemination and retention off the site.

\footnotetext{
* No glaciers would be expected within a 10,000-year period. Areas subjected to significant glaciation pose a unique problem with regard to surface marker longevity.
} 
The following sections describe how these two methods can be used to communicate the four levels of message presented in Section 5 . Throughout this discussion "it must be remembered that partial loss of the higher level message would still leave residual messages of lower levels of content.

\subsection{SITE LOCATORS AND DESCRIPTORS}

\subsubsection{Peripheral Markers}

One major communication system component could be permanent markers installed at the periphery of the repository. Markers for a nuclear waste repository could be as high as 7 meters* and would be spaced regularly within view of each other (a maximum separation of about 1,000 meters). For stability as well as symbolism, they would be shaped as triangular pyramids and would be constructed of granite. One potential marker layout, design, and construction scheme is shown in Figure 7-1.

To avoid settling and to increase the difficulty of removal or toppling, each marker would be secured to a piling anchored in bedrock. If bedrock was not within 30 meters of the surface, friction pilings of 30 meters could be used. The base of each marker would have a bored hole, which would fit closely over the top of the piling.

Peripheral markers would contain first and second level messages as described in Section 5. Three faces on each of about 10 markers would provide 30 redundant message locations. Each marker face would show the universal symbol for biohazardous buried waste (Figure 5-2), and a diagram of the repository site showing marker locations and the location of that specific marker (indicated by an arrow). Each marker face should also have a message inscribed in English, another official United Nation's language, or a pictographic message. The messages would be engraved into the surface of the

\footnotetext{
*Based on limitations in quarrying continuous (monolithic) rock slabs and assuming approximately one-third of the marker length to be below grade for stability.
} 


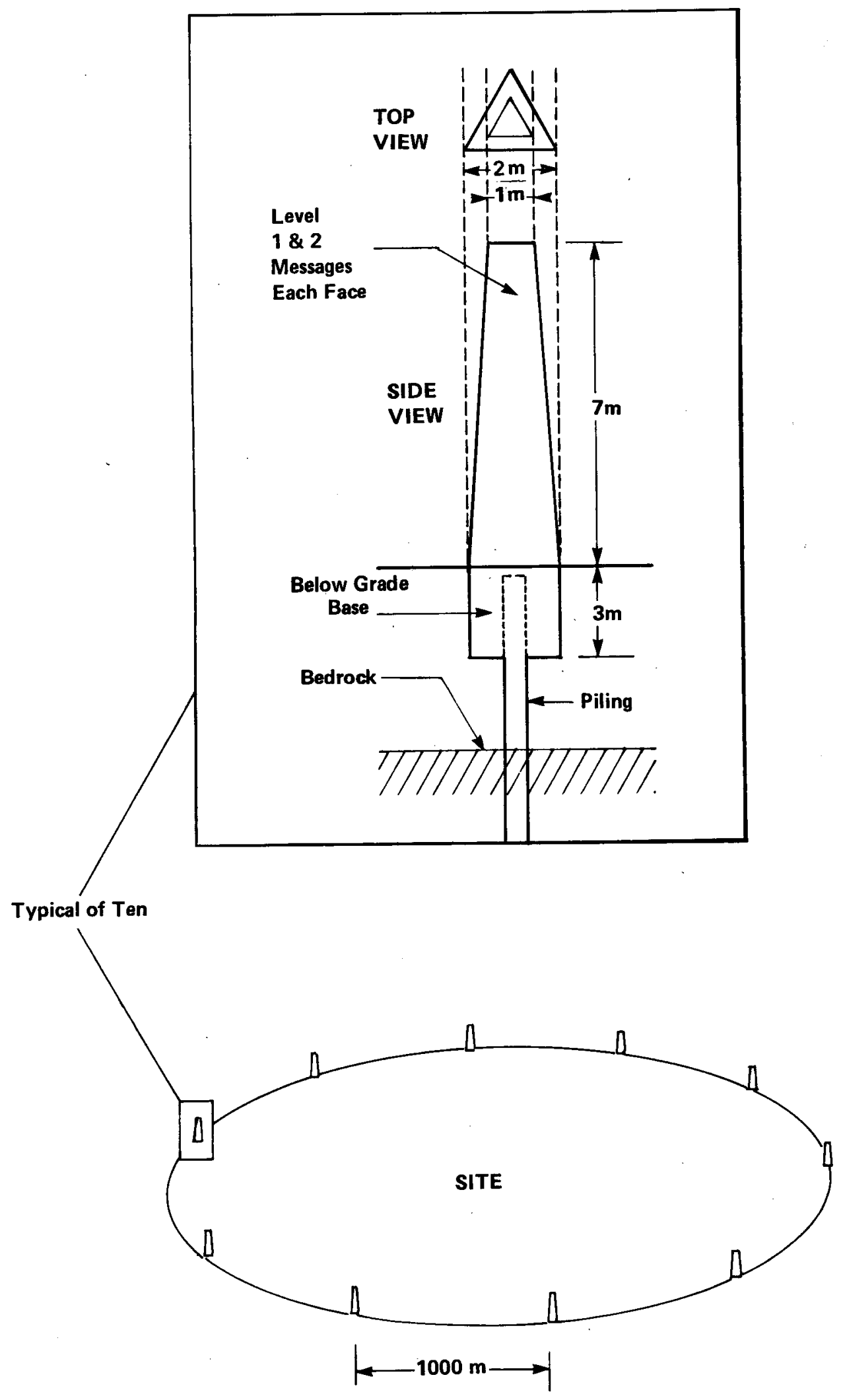

FIGURE 7-1. 'PERIPHERAL MARKERS 
markers. An example of a peripheral marker with first and second level messages is depicted in Figure 7-2.*

\subsubsection{Central Monument}

A central monument composed of a grouping of large markers centered on the repository site could be used to carry more extensive messages describing the use of the site as a radioactive waste repository. The arrangement shown in Figure 7-3 would consist of three larger markers and three document vaults placed to form a triangle. Present international symbolism uses triangles as warning symbols (Dreyfus, 1972).

Within the limitations*t imposed by the geology of granite, the size of the central markers has been selected for longevity (i.e., difficult to move or destroy), visibility, and ability to carry third level messages. A reinforced concrete base mat, 50 meters on each side and 5 meters thick, would be included for stability and to enhance visibility from above. The shape of the base mat, as shown in Figure $7-3$, is similar to the outline of the biohazardous waste symbol.

The large markers would be slightly tapered rectangular prisms roughly $2 \times 4$ meters in cross section. They would extend 7 meters above grade and 3 meters below. The document vaults (as shown in Figure 7-4) would be hollow granite blocks having $1.5 \times 1.5 \times 4$ meters outside dimensions with $30 \mathrm{~cm}$ thick bottom and sides and a rectangular lid also $30 \mathrm{~cm}$ thick. The tops of the side walls would be ridged to fit into a groove in the lid, and these would be sealed with asphalt or another long-lasting sealant. The lid would weigh about 5 metric tons and thus would preclude easy lifting and removal.

The construction of the central markers would be similar to that of the peripheral markers. Pilings would be driven to bedrock or, if bedrock was

*In addition to the second level message describing the waste repository and the potential hazards, the markers themselves, by virtue of their triangular shape, would convey a cautionary message.

$\star \star$ The largest monolithic granite blocks now being quarried in the United States measure approximately $2 \times 2 \times 10$ meters and weigh about 100 metric tons. Long horizontal fractures or joints 2 meters apart with less frequent vertical fractures are limiting factors in quarrying large monolithic granite blocks. Monoliths up to $2 \times 4 \times 10$ meters (200 metric tons) could be produced but these would be difficult to transport. 
RADIOACTIVE WASTES ARE BURIED 700 METERS BELOW THE SURFACE IN GRANITE WITHIN AN 800 HECTARE AREA BOUNDED BY 10 STONE MARKERS. FURTHER INFORMATION IS AT THE CENTRAL MONUMENT.

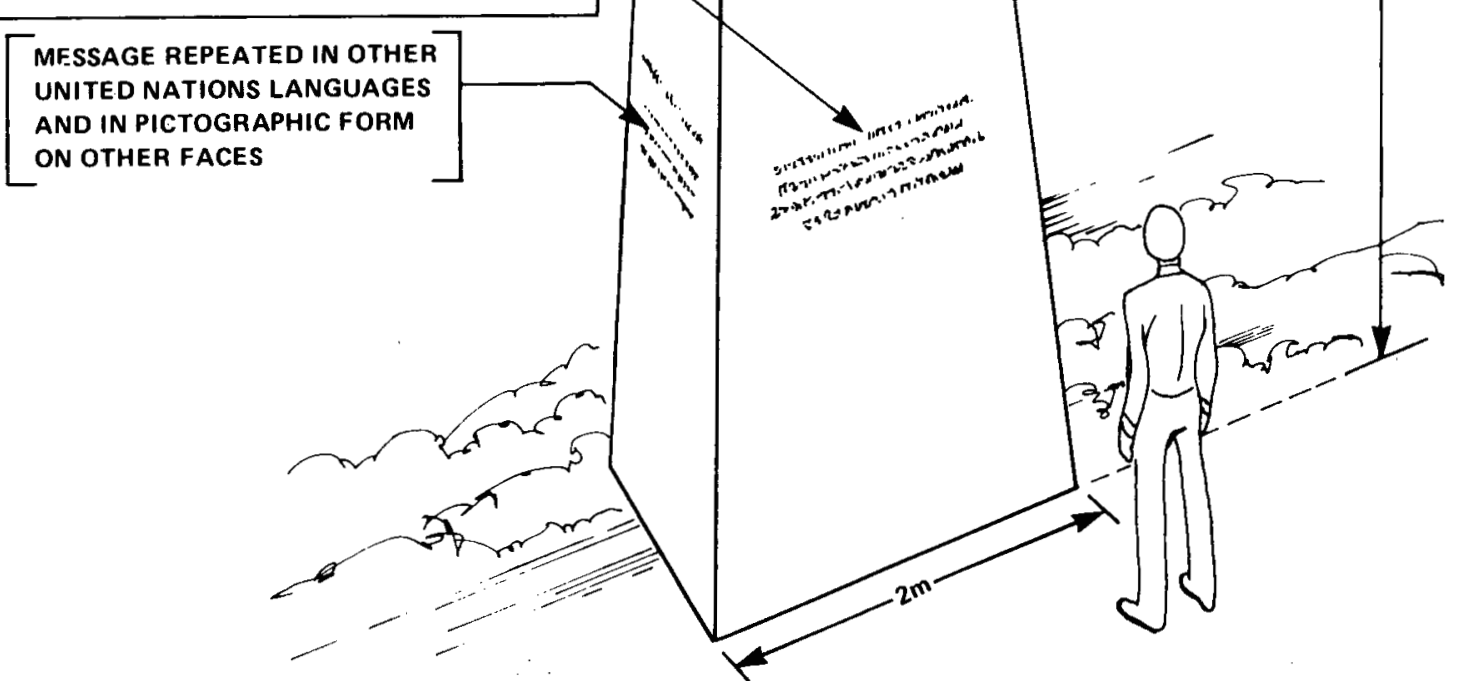

FIGURE 7-2. PERIPHERAL MARKER MESSAGE 


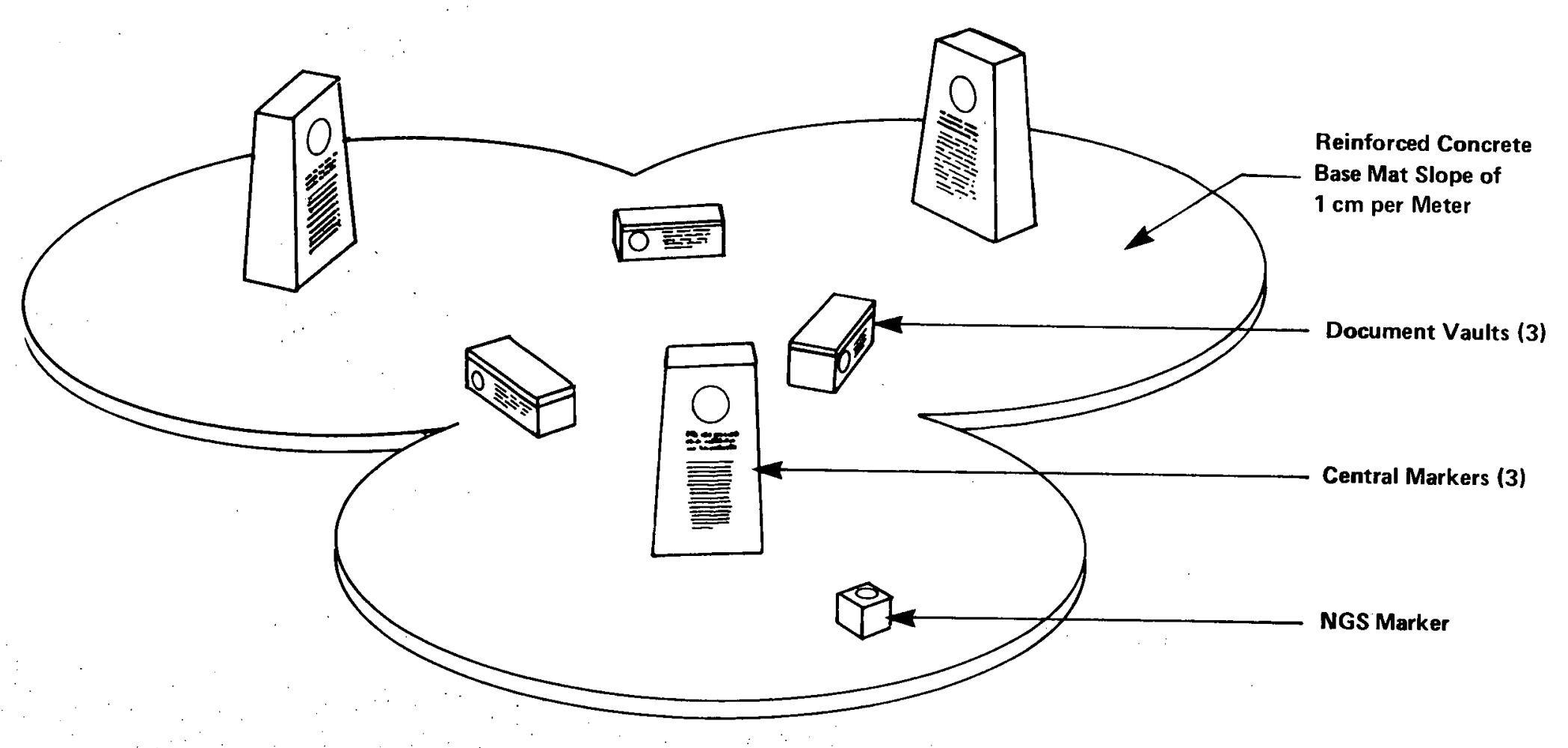

FIGURE 7-3. CENTRAL MONUMENT 


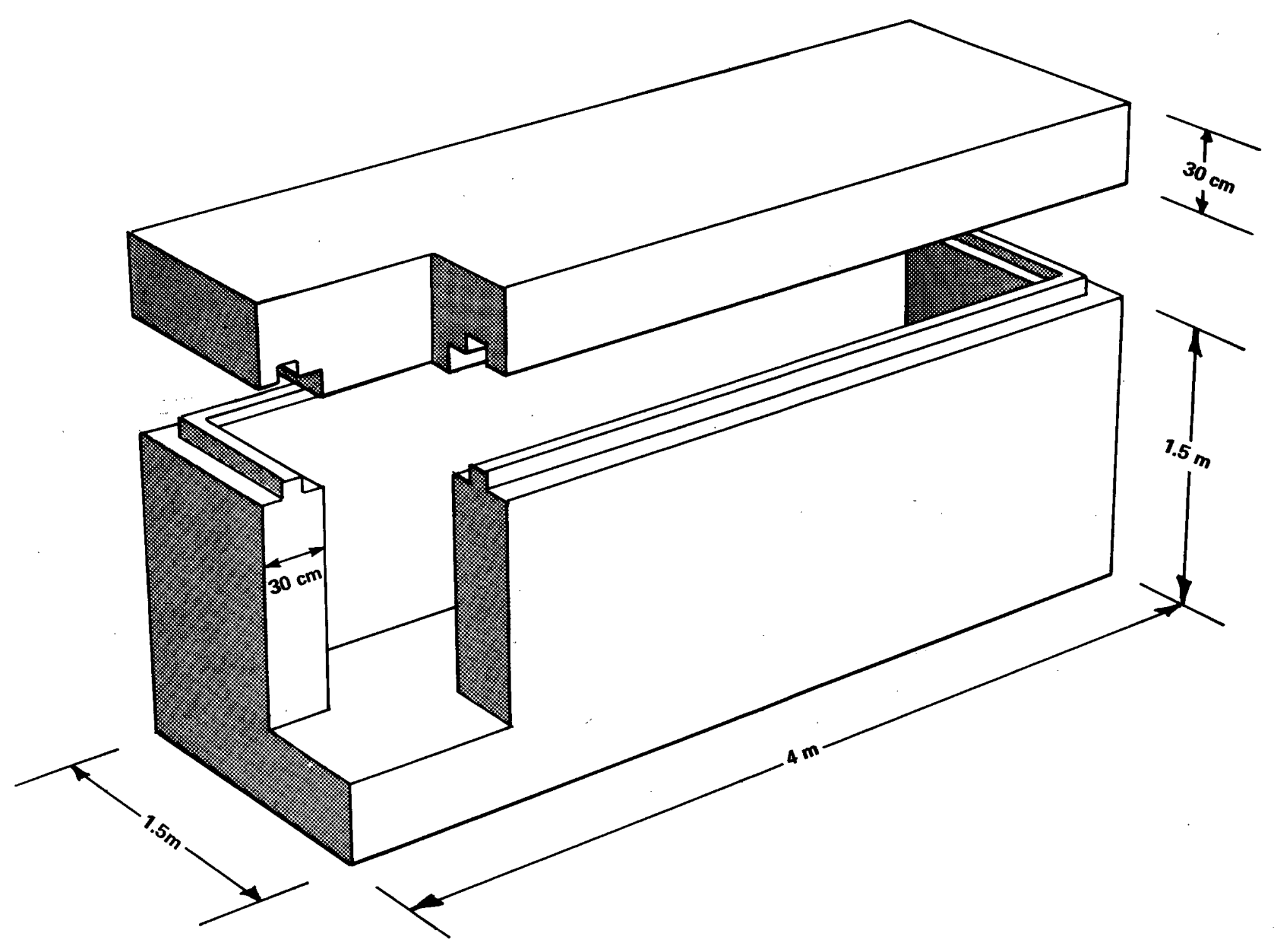

FIGURE 7-4. VAULT DETAIL 
not within 30 meters of the surface, friction pilings of 30 meters would be used. The stainless steel reinforcing bar for the base mat would be tied into the top caps of the pilings and the markers would have two bored holes in their bases, to fit over the pilings. The base mat would be poured as a single monolith.

As discussed in Section 6, longevity might be enhanced if the monument served a useful societal purpose in addition to its waste annunication function. Accordingly, a granite cube has also been included to provide a location for a U.S. National Geodetic Survey (NGS) marker as well as a base plane for mounting surveyor transits or theodolites in using the marker. The NGS marker would be a solid granite cube, 2 meters on a side, also placed on a piling.

The central monument group would contain messages at several levels of meaning. The surfaces of the markers would have first, second, and third level messages (Section 5.1, Figures 5-2, and 3) engraved in multiple languages. The sides of the document vaults would be marked to identify their purpose. The vault lids would be unmarked to eliminate places where water could collect. The vault contents, the fourth level message, would be in printed form doubly sealed to protect against atmospheric effects.

Were a larger central monument deemed more appropriate, a structure such as shown in Figures $7-5$ and $7-6$ could be constructed of reinforced concrete clad with Synroc. The interior walls would provide ample space for Level 2 and 3 messages and Level 4 messages could be placed in the three document vaults. The larger size would increase the visibility of the monument, but without further research its longevity is less certain than that of the granite monoliths. Ultimately the choice must be made based on the cost of the alternatives and the desired performance.

\subsubsection{Other Site Markers}

To enhance the prospects of future identification of the site, several additional measures could be taken to transmit first level messages. For example, substantial earthworks could be constructed, and anomalies detectable by remote-sensing techniques could be created in the shape of the warning symbol. 


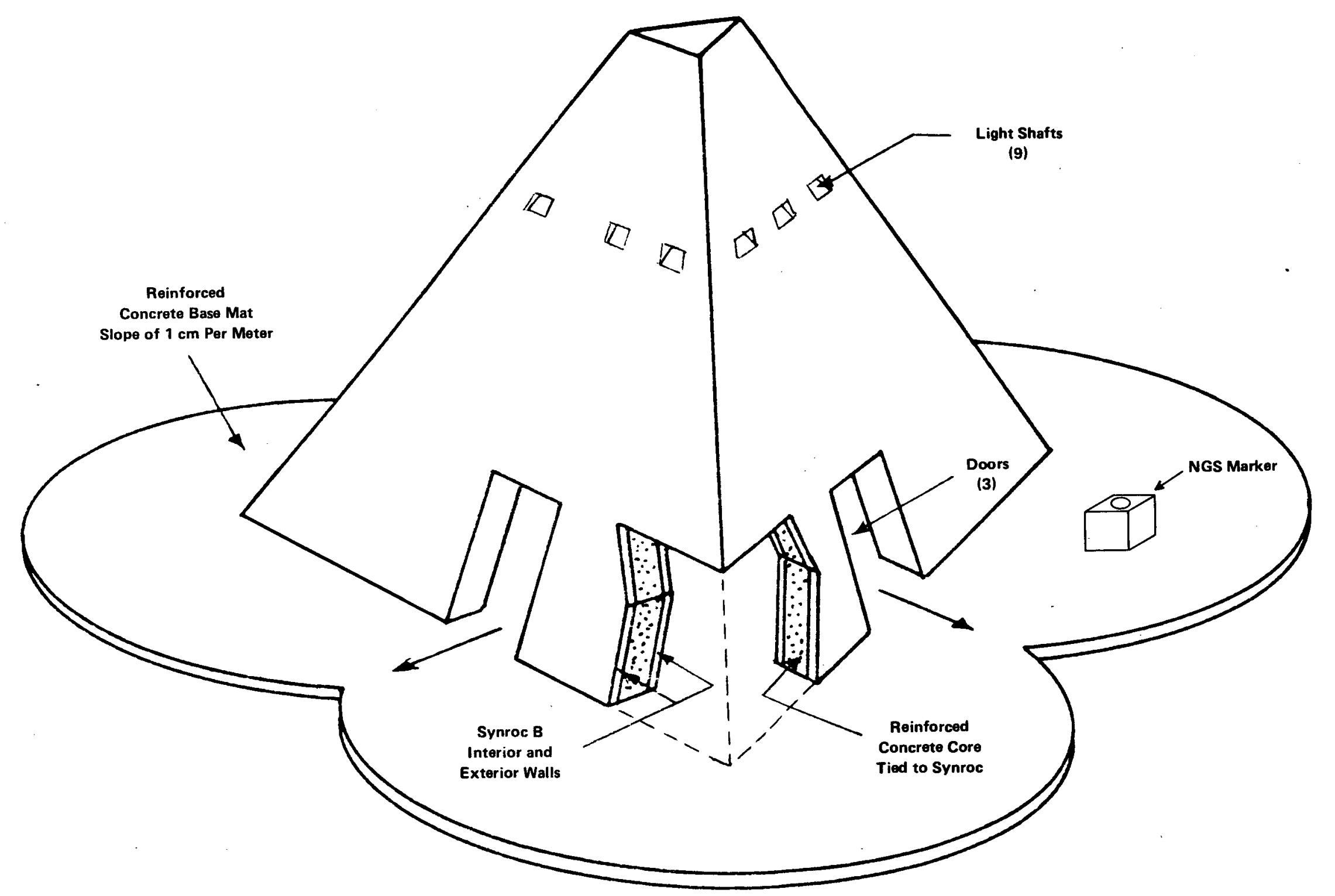

FIGURE 7-5. ALTERNATE CENTRAL MONUMENT 

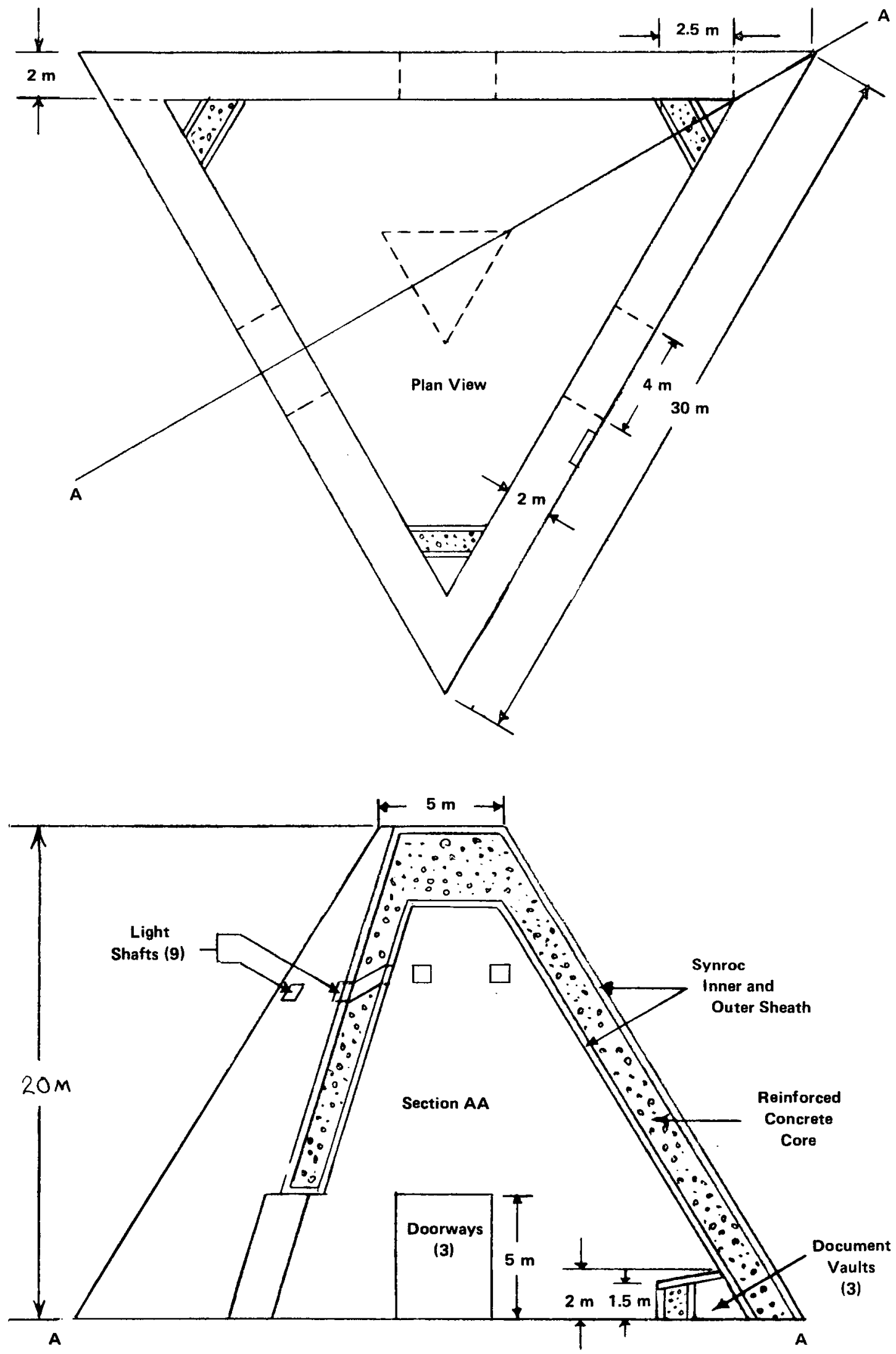

FIGURE 7-6. ALTERNATE CENTRAL MONUMENT DETAIL 


\section{Earthworks}

The site layout would include substantial areas for the storage of mined rock. These areas, initially delineated by dikes, would be used to store the overburden and mined rock during repository operation. During backfilling and repository closure, about half of this material would be returned to the repository, leaving about 4 million metric tons (about $2.5 \times 10^{5}$ cubic meters) for disposal. If the geologic medium is salt, much of it might be moved off the site to prevent damage to the environment. For other media, however, substantial amounts of material may be available for use as a permanent earthwork to mark the site.

For a typical communication system, the storage diking could be shaped to simulate the arrow form of the biohazardous waste symbol designed (approximately 100 meters across) to leave a level plaza several meters high after the repository has been backfilled and sealed. Surrounding the arrow shaped plaza at a distance of several hundred meters could be a segmented earthen berm, also several meters in height, forming the outline of an equilateral triangle.

The central monument and base mat described previously would be centered on the raised plaza, as shown in Figure 7-7, which would be first established and compacted. Figure 7-7 shows that the concrete base mat plus the earthen arrow and triangular berm, as viewed above, would form the biohazardous waste symbol (Figure 5-2).

To add to the durability of the plaza and berm, their surfaces could be sealed with a 15- to 30-centimeter layer of aggregate asphalt mixture, similar to that used for highway paving. Natural asphalts have been used since antiquity (Asphalt Institute, 1977) with residual evidence remaining to this day (Rosenfield, 1965; Hodges, 1971; Marschner and Wright, 1978). The asphalt mixture would be subject only to surface oxidation and weathering effects; it would therefore be expected to remain largely in place for several thousands of years without maintenance. Even if the sealing of the earthwork surface failed, substantial amounts of asphalt and aggregate would remain to mark the surface of the plaza and would also hinder the growth of vegetation for a long time. 


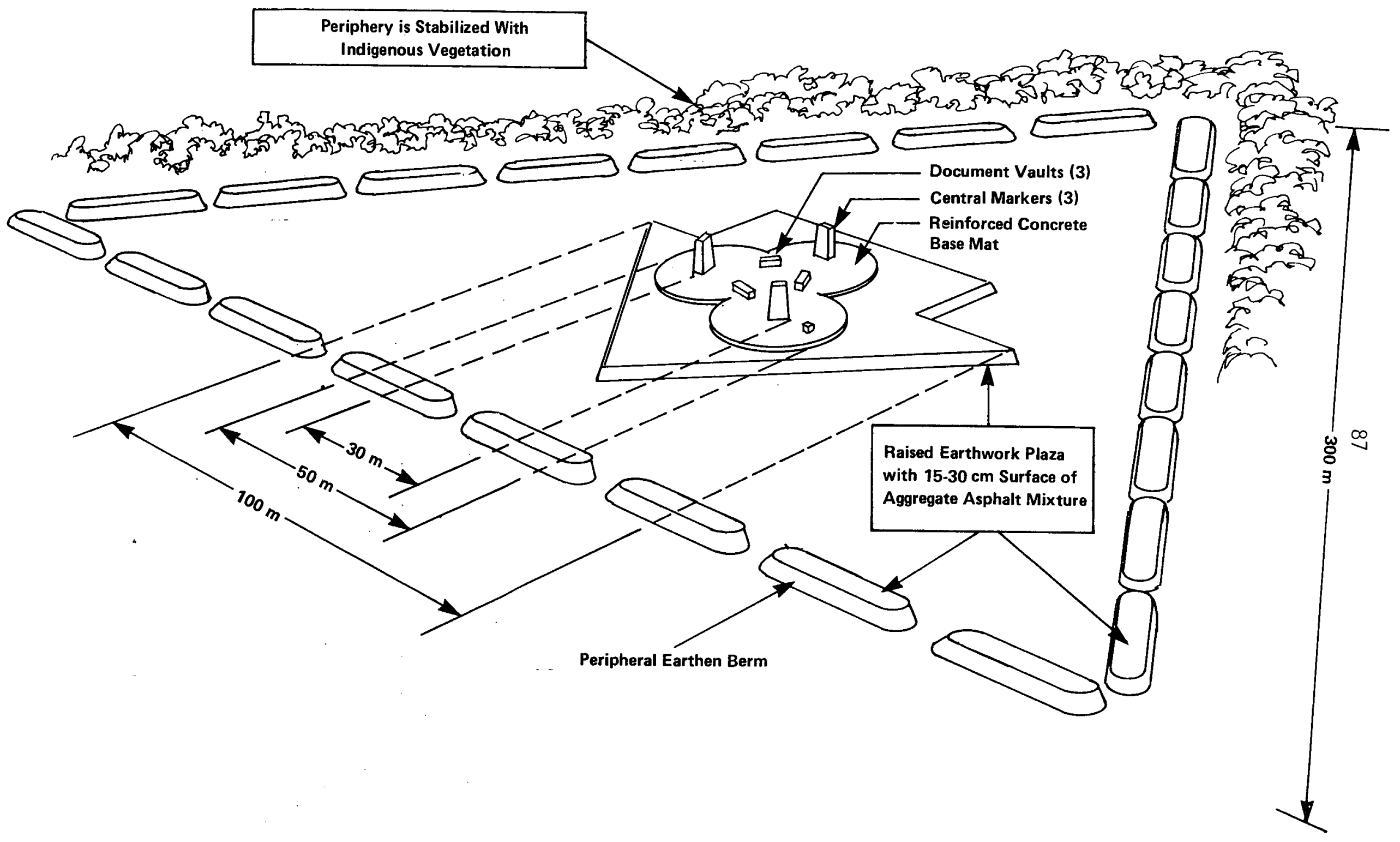

FIGURE 7-7. TYPICAL CENTRAL MONUMENT PLAZA 
Anomalies

The size of the central monument and earthwork plaza would help ensure their visibility even to remote sensors carried by satellites. Current technology (Foster and Hall, 1981; Watkins, 1981) offers resolutions ranging from 10 to 30 meters, which is more than adequate to discern the monument and the surrounding earthworks.

Because the monument, base mat, plaza, and peripheral earthworks would be constructed of materials with different surface textures and hence different absorption and emissivity characteristics, they would be apparent to visible, near-infared (IR), thermal IR, and certain types of radar detectors. In addition, the difference in thermal absorption between the aggregate asphalt surface of the plaza and the surrounding natural vegetation should result in substantially different radiant temperatures, discernible by present remotemeasurement techniques.

Thus, the central monument, the plaza, and the earthworks already planned to announce the presence of the waste repository, could also add anomalies recognizable by several remote-sensing techniques. These anomalies could be further enhanced during the final design of the structures.

\subsection{INFORMATION AND RECORDS DISSEMINATION AND RETENTION OFF THE SITE}

In addition to the physical markers and messages at the repository site, information about repositories could also be widely disseminated and placed in archives off the site. Mechanisms presentiy in existence for producing and distributing reports, documents, and maps would automatically cause their retention in archives in many locations. Similar mechanisms will be available and could be used at the time of repository operation and decommissioning. other methods that could be used include public relations activities and the inclusion of waste-management knowledge in educational programs. Thus, the knowledge of biohazardous waste sites and marking symbols could become established.

Any communication system as now envisioned would, at the least, contain the elements of land survey and land use records notification as practiced for hazardous and low-level waste sites (U.S. Environmental Protection Agency 
[EPA], 1982b). The use of the central monument as an NGS benchmark wou 1d also aid in precisely mapping the waste locations for the survey plats. Such measures would tend to perpetuate knowledge about the repository.

The sections that follow present a number of potential channels for offsite record dissemination and retention. Such channels could convey repository-related information without any additional planned activities, because of public needs and interest, education, and custom. The intent of the discussion that follows is not to indicate how a deluge of propaganda could be created, but rather to acknowledge that systems already exist for other purposes that would assist in the dissemination, retention, and continued transmittal of repository-related knowledge.

\subsubsection{Identification of Repository Locations on Maps and Charts}

Provisions could be made during the development of the repositories to accurately locate them on the base 7.5-minute-quadrangle topographical maps of the U.S. Geological Survey (USGS). The scale of the maps $(1: 24,000$, or about 2,000 feet per inch) would permit the identification of major site features and buildings as they are changed during the phases of repository operation and decommissioning. The aerial photographs used to generate these USGS maps would also provide a separate record of site activities. After repository decommissioning and the construction of the peripheral markers, central monument, plaza, and surrounding earthworks, the area would be rephotographed and the maps updated to reflect the final repository configuration. At that time the horizontal location and vertical elevation of the central monument would be precisely determined according to the standards of the U.S. National Geodetic Survey (NGS); the monument would then be established as an NGS benchmark and incorporated into the Survey's maps and data bases.

Concurrently with these mapping activities, the continuing use of earh reconnaissance satellites with their varied remote sensing capabilities would independently record the waste repository locations and activities many times over, without any special action being needed. As wifl be discussed in the next section, the existence of USGS maps, NGS charts and records, as well as the aerial photographs and remote sensing data records would provide the opportunity for much wider information dissemination and retention. In 
addition, the use of the biohazardous waste symbol to identify the repository location and maps will also aid in promoting its recognition.

\subsubsection{Distribution and Archiving of Documents and Maps}

Presently established organizations in the U.S. annually produce and distribute many millions of maps (Weitzberg, 1982). Because most of these can be traced back to the base topographic maps produced by the USGS, the locations of waste repositories could be readily incorporated into many other map products. The distribution of repository-related information in this manner could thus be reinforced during the years immediately after repository closure, when knowledge of the repository is widespread.

Reports and publications about repository locations, design, and operation, particularly fourth level technical information, would be routinely distributed by existing national and international agreements. The customary distribution to the 1,200 government and private libraries, as well as to foreign libraries through existing exchange agreements, could be augmented by distribution to libraries, school systems, universities, and governmental entities in the states near the waste repositories. Such local distribution could reinforce the public education effort described in the next section. For example, the same site plat and description could be kept in the county courthouse as a land use record, and be stored in the archives of the U.S. Federal Bureau of Land Management.

Important maps and documents are now stored for permanent use in many locations. Special requests could be made to all major libraries and archives to access the important repository-related information for permanent retention and to ensure that the bibliographic information is placed in all major library information networks, such as the OCLC.* To aid in the durability of the written material, special editions of the maps and publications for storing would be printed on acid-free paper that can last very long periods of

\footnotetext{
*The OCLC Online Computer Library Center, Inc. located in Columbus, Ohio, is perhaps the largest of the U.S. library information networks, currently servicing over 2,600 participating libraries. Its computer data base contains more than 7 million records and adds about 25,000 records weekly (OCLC, 1981).
} 
time. In addition, requests could be made to input important repositoryrelated information into many different computer data bases, particularly those dealing with water and mineral resources, land use, and hazardous wastes.

\subsubsection{Educational and Institutional Activities}

Public Relations and Education

The dissemination of repository knowledge into the public sector through the maps and documents described above, with varied levels of information presented to different segments of the population, would occur during and immediately after repository closure. Efforts could be concentrated on states near repository sites, but could include to a lesser degree a national program, preferably coupled with education programs related to all biohazardous waste sites. Conceptually, information could be distributed to school systems and universities, with requests for inclusion into appropriate science curricula. Information could also be disseminated through widely circulated publications and the news media. The present and likely future concern over environmental protection and the health and safety impacts of hazardous substances should serve to encourage this type of public education. The identification of waste sites on general purpose maps and on road maps could also serve to reinforce the awareness of actual repository locations as could the placement of information signs on highways near the repositories. In addition, the accuracy of the local population's perception of the repository as transmitted by oral and written means can be tested and, if needed, the educational activities could be modified accordingly.

\section{"Cal1 Before Dig" Institutions}

In the United States, there are now more than 100 private utility organizations for protecting underground installations from inadvertent damage by the public. These "one-call" systems are available in about 25 states and service more than 1,300 participating utility companies (Moore, 1978; American Public Works Association, 1980; Rifkin, 1980). These and similar systems 
that locate underground installations before any excavating activities are undertaken could be used in two ways to protect waste repository sites. For direct protection, federal, state, and local agencies with responsibilites in the areas adjacent to the sites could join existing "one-call" systems or encourage their formation if none exist. Petroleum or gas-transmission pipelines, as well as cross-country communications in the general vicinity of repositories, would benefit from the "one-cal1" approach. Local or statewide ordinances could be amended to require that, before any underground construction is started, the permit issuing process would check with the "one-call" system to see whether any underground installations would be threatened, including the waste repositories.

Indirect protection of waste repositories will be developed as the "call before dig" tradition becomes more generally accepted. The significant savings to the utilities, in money and labor required to repair damaged installations, and the reduction of risk and inconvenience to the public at large, should perpetuate the use of "one-call" systems, independently of any repository-related benefits. The growing use of "one-call" systems, supported in many areas by appropriate legislation (Courtney, et a 1, 1977), is steadily building the tradition that, in general, some risk is associated with any digging operation, and that it is prudent to check with others before proceeding. While the risk in urban areas is apparent, the use of intercontinental transmission pipelines has extended that risk even to apparently trackless deserts. By supporting the "call before dig" concept in regard to biohazardous waste sites, the tradition can be reinforced.

Since it is likely that underground facilities and waste sites will grow in number with the passage of time, it is likely that future societies will perpetuate activities and traditions that will reduce the associated risks.

\subsection{SUMMARY DISCUSSION}

\subsubsection{First Level Channels}

The first level messages (see Section 5.1) would be transmitted both by durable site markers, monuments, and earthworks, and by much less durable oral communication, maps, and records. However, the continued existence of durable 
site features will greatly enhance the likelihood of perpetuating and maintaining the oral transmission and the records. When the effects of all of the methods are evaluated together, the synergistic effects make each channe 1 more effective than when considered individually. For example, possible ambiguities about site location are reduced by onsite markers containing the same symbols and messages as the offsite or oral messages, and the oral transmission is reinforced by having a physical place identified as the area of concern.

Oral Transmission

Active public relations and educational efforts made while the repository is actively operating, and immediately thereafter, could promote a general awareness and promote ora 1 communication regarding the repository site and the associated hazards. The presence of long-lasting physical site markers greatly increases the likelihood that long-term oral communication would be perpetuated if it is indeed established. Following historical trends, there will probably be periodic resurgences of general public knowledge and oral communication about the repository, followed by periods of little oral communication.*

Although there are historical examples of oral transmissions lasting considerably longer than 500 years (Monte 11, 1970), the need for continuity of transmission is the week point of the oral communication for long-term reliance. A7so, the transmission would not be apparent to any visitors to the site, unless they were informed of them by the indigenous population.

Oral tranmission of the first level information** could take place by two primary means: knowledgeable individuals could inform the general population or the population could spread the information by word of mouth. Although understood, the message could be expected to eventually contain inaccuracies.

*This premise is based on the assumption that the causes that would promote oral communication regarding the repository would vary, both rising and falling in societal importance.

**In addition to the caution message, this could also include perpetuation of knowledge about a "special" place. 
These may be minimized by the reinforcing effects of the permanent site markers and messages. Inclusion of a caution message is important, even though the specific reasons for the caution may not be clear, since an individual's general awareness would be increased when warned. Oral transmission, in and of itself, may have little merit but its effectiveness would be substantially enhanced by the positive reinforcing effects of the site markers and other message channels.

Maps

As described previously, mechanisms are available for placing important geographical information, including such data as waste repository locations and hazards, on many map products and distributing them widely. Since surveying and mapmaking go back many thousands of years (Ingram, 1911; Richeson, 1966), similar activities will probably continue far into the future. Mapmaking, in general, is likely to be a continuing endeavor, with information transmitted and updated from one generation to another.* Individually, maps are less detectable and accessible than site markers, but collectively they would provide an effective message-transmission channel. Furthermore, the synergism between the maps and the use of the central monument as a U.S. National Geodetic Survey benchmark would aid in perpetuating knowledge of the repository, reinforced whenever any accurate surveying is performed in the area.

The information placed on maps would be very simple and only in one language, and although easily understood, the simple message would result in some uncertainty because of the absence of details and explanations. The effectiveness of widely distributed maps lies in their large numbers spreading the general communication that certain identified geographical areas contain buried waste. The technical information content of the maps would be negligible.

*There is an implicit assumption of information relay. However, there is a reasonable likelihood that some maps produced on modern acid-free paper could survive for thousands of years without the relay. 
Offsite Archives

The placing of documents and maps in archives was described in Section 7.2.2, with more detailed information contained elsewhere (Weitzberg, 1982).* The large number of archives, the care presently and previously shown for valuable documents, and the historical precedents of documents already surviving more than 1,000 years strongly suggest the long-term endurance of archives for all levels of message. There is also no likely scenario by which individual documents important to society, printed on long-lasting materials and placed in hundreds of archives throughout the world, can be postulated to be all destroyed.

However, the mechanism of dispersing the information, while ensuring its continued existence, also reduces its detectability to persons to whom the information would be relevant.

Earthworks and Anomalies

The central plaza and earthworks, as shown in Figure 7-7 and described in Section 7.1.3, would be massive, containing several hundred thousand cubic meters of earth and rock. Their size alone, which is larger than analogous ancient earthworks like the Serpent Mound (Kaplan, 1982a), would suggest their survival for thousands of years. Surface stabilization with aggregate asphalt would provide further resistance to weathering. The only possible mechanisms for the obliteration of the earthworks within the time frame of interest would be a massive planned human interference or the effects of glaciation. Since most of the contiguous United States will not experience glaciers during the next 10,000 years (Kukla, et al, 1981), the durability of the earthworks, together with any anomalies, is rated high. The detectability of the earthworks is also rated high because their arrangement and size would make them

\footnotetext{
*A distinction is drawn here between land use records, which would be stored and maintained by the local land authority, and records in archives ma intained as part of a larger, multipurpose information storage system. For example, the same site plat and description would be considered a land use record when kept in the county court house and an archive record when stored by the U.S. Bureau of Land Management.
} 
readily visible from the repository site and from the air. In addition, they would be detectable by thermal, infrared, and radar sensors.

The earthworks and anomalies present only the biohazardous buried waste symbol without any accompanying text. Although the symbol could be perceived by several means, its message content and relevance would be low since its form is likely to be perceived only from a distance and its apparent relationship to the viewer would be tenuous at best. However, considering that knowledge of the symbol has been widely disseminated in other ways, it should be recognizable.

Peripheral Markers

The peripheral markers, described in Section 7.1.1, are granite monoliths, 7 meters high. Natural granite formations have survived up to two million years in a wide range of environments (Berry, 1983), indicating a high durability for the markers. Each marker would weigh in excess of 25 metric tons, making its movement unlikely. Its monolithic structure would ensure its integrity against anything short of planned demolition. The obvious importance of the markers, together with their number and the difficulty of the demolition, would make their total destruction unlikely.*

Multiple markers placed at the periphery of the repository would be highly accessible to any person approaching the site, regardless of direction. The height and spacing of the markers would ensure their visibility from the ground and would also permit detection by certain remote aerial or satellite reconnaissance techniques (Foster and Ha11, 1981; Watkins, 1981). Thus the peripheral markers are also highly detectable.

The first level messages included on the peripheral markers include the symbol and the written message in several languages and pictographs. This multiplicity of message type, coupled with its location at the site, should make the markers highly effective. * Some societal protection against such demolition would be afforded were
biohazardous/radioactive waste still a matter of public concern. 
Central Monument

The central monument markers and the base mat, as described in Section 7.1.2, would be monolithic in construction. The markers would weigh about 200 metric tons and the NGS marker about 20 metric tons. The durability of these markers would be further enhanced by anchoring each one to a piling. The central monuments would be highly detectable because of their size and prominent location at the center of the earthworks and central plaza. Also, as on the peripheral markers, the message would be written both pictographically and in several languages. Even if large parts of the higher level messages were destroyed, the residual first level message, because of the presence of the other messages and markers and the prominent onsite location, should be comprehensible. The presence of three markers would add redundancy to the overall system.

Central Monument Vaults

Although the central monument markers would be highly durable, the durability of the three smaller document vaults (see Figure 7-7) would be somewhat less. The vaults would weigh approximately 17 metric tons (without the lids), sufficient to deter casual vandalism or removal. The sides of the vaults would contain the biohazardous waste symbol and a first level message engraved in the granite both pictographically and in several languages. Thus, the vaults (without considering their contents) together with the central markers should effectively convey the first level message.

\subsubsection{Second Level Channels}

The second level message, shown in Figure 5-2 and discussed in Section 5.2, warns of biohazardous waste and briefly describes the extent of the repository as well as the location of the waste. This message would be transmitted by peripheral markers, the central monument, land use records, and offsite archives. The discussion of the effectiveness of all but the land use records is identical with that given in the preceding section for the first level message channels, and therefore is not repeated here. 
Land Use Records

The incorporation of repository-related information into land use records, as described in Section 7.2, is specified by the U.S. Environmental Protection Agency as a postclosure requirement for the disposal of both hazardous waste and low-level radioactive waste. Many historical records of land use and ownership, and some records of mining, go back many hundreds of years (Kroker, 1977); however, without deliberate action by society to maintain and update the land records, deeds, and site plans, local records will not be durable for more than several hundreds of years.

Nevertheless, while they exist, these records will be conveyed to each individual who attempts to take title to, or make legal use of, the repository site. The second level message incorporated in land use records has the advantage of being distinctly coupled with the ownership and description of the repository site, but there is some uncertainty related to site identification if the records are stored far from the repository or if the terrain of the site is substantially altered over the period of interest. There is also a distinct possibility that the warnings contained in land use records may be retranslated over the centuries; there is, however, no assurance that this will be done.

The durability of the site markers increases the likelihood that the site will appear on future maps (first level message), and the maps in turn will spread the knowledge of the site. The second level caution message and brief repository description would probably be successfully transmitted to future generations for 10,000 years. The inclusion of references to additional sources of information, as well as the request to translate and update the messages when appropriate, will also increase the effectiveness of all the messages.

\subsubsection{Third Level Channels}

The third level message (see Figure 5-3) would be transmitted only by engraving into the surfaces of the central site monument (markers and vaults) and at offsite archives. Since the monument was rated high in durability and detectability, primarily because of its size and monolithic construction, these same ratings are assigned to the third level messages. 
Although a limited number of media and forms would be used for the third level messages, the message would be repeated on several surfaces and would exist in many offsite archives. It would be written in several languages and presented pictographically, and would contain diagrams showing the extent and location of the waste. Thus, the third level message should be comprehensible, and its relatively high information content warrants a high rating for its ability to elicit the desired response. The references to more detailed information stored away from the site will support the effectiveness of the fourth level messages, and the request to translate and retransmit the messages will aid in perpetuating the information.

The large number of offsite archives containing fourth level information substantially enhances the likelihood that, even if third level information is partially destroyed, the residual third level messages will survive and be understood for the 10,000-year period of interest.

\subsubsection{Fourth Level Channels}

The fourth level messages of detailed technical information (see Section 5.4) would be transmitted in two ways. A briefer version of about 200 pages would be placed in the three central monument vaults, and the complete version of about 1,500 pages would be stored in many offsite archives. The length and detail of these messages, as we 11 as the multiple languages and symbols used, would ensure a very high degree of comprehensibility and ability to elicit the desired response.

The fourth level messages would be conveyed by both onsite and offsite means, each having a life expectancy of less than several thousand years. However, considerable redundancy is provided by the many offsite archive locations and the references to them in the third level messages. For this reason the offsite level channels should be of medium durability with the likelihood that they would endure and be understood for 2,000 to 10,000 years.

The onsite central monument vaults are rated somewhat lower than the offsite archives. The potential weak point of the vaults is that the information contained inside of them can be permanently removed from them and be destroyed. Methods are not available to ensure that the vault contents will remain intact for the ful1 10,000 years. Conversely, having three identical 
vaults with identical contents would increase the likelihood that at least one message would remain intact. Also the apparent importance of the monument and the vaults and their contained information suggests that the request for a relay system (third and fourth level messages) to perpetuate the messages may be heeded. Thus, there is a reasonable probability that the messages in at least one of the vaults would survive more than 2,000 years.

Because the three central monument vaults have massive covers to prevent casual inspection, the contained level 4 information is not easily accessible to individuals visiting the site. However, because the third level message would announce the existence of the message it would be moderately detectable.

\subsection{OVERALL ASSESSMENT OF COMMUNICATION METHODS}

The previous evaluations, though only qualitative, illustrate the effectiveness and the redundancy that can be built into a communication system. Additional redundancy is provided by the use of four different levels of message and the way many of the message channels reinforce and support each other. Furthermore, little credit has been taken for the reasonably likely prospect that future generations will deem the identification of biohazardous waste sites to be in society's best interest and will act accordingly to perpetuate the knowledge through a relay system. A long-term communication system would ultimately rely most heavily on permanent markers and monuments with the messages tied integrally to the structure. These passive measures should require no maintenance to transmit their messages up to 10,000 years into the future. The presence of these markers and monuments enhances the likelihood of perpetuating knowledge about repositories through other means as wel1.

For significant human interference with waste repositories to occur, the technological level of the responsible society must approximate that of our own. The institutions accompanying such technologies, for example, education, government, communication, and large-scale energy generation and transmission, should not be totally ignored in assessing the likelihood of perpetution of information. Although specific institutions readily change, many basic institutional functions transcend reorganization and continue. This reinforces the expectation that knowledge of the repositories will be maintained, and that 
the passive measures discussed in this report will periodically focus society's attention on the need for more active measures like surveillance, maintenance, message relaying, and education.

The least likely prospect for the future is a society armed with the technical and organizational capabilities for interfering with waste repositories but devoid of the knowledge and the societal institutions that are most likely to prevent harmful interference. The reasonably high probability that the permanent markers and monuments will endure makes the likelihood of significant inadvertent interference relatively remote indeed. 


\section{AREAS REQUIRING FUTURE WORK}

The use of a comprehensive communication system, including those components described in Section 7 , is expected to provide effective measures to reduce the likelihood of uninformed human interference activities. However, future activity, including testing and analysis, is needed to increase confidence in component and system effectiveness. The following are areas where further study could be particularly beneficial.

\subsection{EFFECTIVENESS OF MESSAGE}

To determine the effectiveness of the various levels of messages, controlled behavorial testing could be conducted. For example, the initial reactions of sample populations to the proposed biohazardous waste symbol could be studied, to determine its probable acceptance and recognition after common use. Tests using variations in symbol shapes, as well as colors, could be performed to assess possible changes to the proposed symbol. First level messages can include earthworks and remotely sensed warning designs of anomalous infrared reflective properties. The size of these symbolic designs should be analyzed with reference to existing and likely near-term satellite detection technologies. The interpretation of these messages should also be tested.

The iconic message design could be developed further, and several pictographic messages could also be tested among sample populations. The basic response of the sample population to the first level message should be determined to ensure that the primary response is one of caution. Care must be exercised to ensure that the messages used do not become attractions that produce responses opposite from those desired.

\subsection{MATERIAL AND MESSAGE DURABILITY}

Further investigation is necessary to determine the expected longevity of message channels including earthworks, monuments, vaults, and written records. The longevity of land use records as a method of transmitting repositoryrelated messages also requires further investigation. Information is needed 
on the availability and maximum sizes of natural materials for markers, as we 11 as on the various methods of incorporating messages on markers. It is desirable to maximize the durability of, and minimize weathering effects on, specific materials that might be used in message transmission. Further investigation and analysis of synthetic rock (Synroc) and composite structures (e.g., reinforced concrete clad with Synroc) is also necessary, including testing for improved performance, and ability to construct.

Both the natural and engineered materials should be tested to determine their resistance to weathering in current and predicted future atmospheres. The effectiveness of possible communication system components is a necessary area of study to determine the reliance that could be placed on several of the softer message channels, e.g., land use records, archives, and public information. Further work is needed to determine the survivability of various institutions and the contribution they could make to perpetuating repositoryrelated messages.

The future survivability of languages is another important area of study, in particular, identifying those language elements that seem to survive over long periods of time. The rate of changes in languages is also of interest as is the effect of worldwide communication and the distribution of printed documents. The results of such research could affect the selection of languages used to transmit the four levels of message.

\subsection{MESSAGE TRANSMISSION}

The effectiveness of oral transmission of repository-related messages is another area for further study. Information on the persistence, accuracy, and comprehensibility of oral messages over time will aid in planning for more effective communication regarding waste repository locations and hazards.

Pub1ic information mechanisms, including formal and informal education programs, could be studied to determine their viability as a method to accurately transmit messages and information. A specific public information and education program could then be developed and tested prior to waste disposal. 


\subsection{SITE-SPECIFIC STUDY}

A number of site-specific studies would be necessary to optimize communications system effectiveness as it relates to potential repository locations. Potential repository sites could be examined and a communication system developed that would be most effective for the site.

There are relationships between site conditions and marker longevity and effectiveness that must be examined. These include (1) the effects of weathering, based on inherent site characteristics including potential longterm climatic changes; (2) the effects of damage or obliteration by vegetative growth; and (3) the effects of seismic activities, flooding, severe erosion, or deposition.

Locally excavated or imported construction material could be evaluated in consideration of precipitation, wind, flooding, and silt deposition at potential site locations. Similarly, specific granite types available in large monolithic blocks could be evaluated and/or tested for erosion in the site-specific weather environments. Different materials may be preferred at different sites in order to maximize durability. 


\section{REFERENCES}

Aldred, Cyril, 1965. Egypt to the End of the 0ld Kingdom, MCGraw-Hill, New York, NY.

American Public Works Association, 1980. One-Call Systems, 1980-81 Directory, APWA Utility Location and Coordination Council, Chicago, IL.

Asphalt Institute, 1977. Introduction to Asphalt and Some of Its Uses, MS-5, College Park, MD.

Atkinson, R.J.C., 1956. Stonehenge, H. Hamilton, London, England.

Berry, Warren E., 1983. Durability of Marker Materials for Nuclear Waste Isolation Sites, ONWI-474, prepared by Battelle's Columbus Laboratories for Office of Nuclear Waste Isolation, Battelle Memorial Institute, Columbus, $\mathrm{OH}$.

Bishop, W. P., D. H. Frazier, I. R. Hoos, P. E. McGrath, D. S. Metlay, W. C. Stoneman, and R. A. Watson, 1978. Proposed Goals for Radioactive Waste Management, NUREG-0300, U.S. NuClear Regulatory Commission, Washington, DC.

Bouras, C., 1979. "Testing Time for the Acropolis Monuments", Stone Industries, Vol. 14, pp. 22-26.

Bratton, Fred G., 1968. A History of Egyptian Archaeology, Thomas Y. Crowe 1 Company, New York, NY.

Broecker, W. S., J. L. KuIp, and C. S. Trucek, 1956. "Lamont Natural Radiocarbon Measurements", Science, Vol. 124, No. 3213, pp. 154-65.

Budge, Ernest A., 1929. Rosetta Stone in the British Museum, Reprint of 1929 ed., AMS Press London, England.

Burl, A., 1976. The Stone Circles of the British Isles, Yale University Press, New Haven, CT. 
Courtney, W., G. Yie, and D. Kalbrenner, 1977. Effectiveness of Programs for Prevention of Damage to Pipelines by Outside Forces, U.S. DOT/MTB/OSP0-77/12, U.S. Department of Transportation, Washington, DC.

DOE, see U.S. Department of Energy.

Dreyfuss, H., 1972. Symbol Source: An Authoritative Guide to International Graphic Symbols, McGraw-Hi11, New York, NY.

Durant, Wi11, 1954. The Story of Civilization: Vol. 1-Our Oriental Heritage, Simon and Schuster, New Ynrk, NY.

Edgerton, C., 1974. The Mine Map Repository - A Source of Mine Map Data, BUMINES IC-8657, U.S. Department of the Interior, Washington, DC.

Edwards, Melvin D., 1979. NAWDEX: A Key to Finding Water Data, U.S. Geolical Survey, Washington, DC, available from the U.S. Government Printing office, Stock No. 1979-281-363/23.

e1-Baz, F., 1981. "Desert Builders knew a Good Thing When They Saw It", Smithsonian Magazine, Vol. 12, pp. 116-124.

EPA, see U.S. Environmental Protection Agency.

Fakhry, Ahmed, 1969. The Pyramids, 2nd edn., University of Chicago Press, Chicago, IL.

Fisher Scientific, 1964. "'p' Stands for Permanent", The Laboratory, ed. Harry M. Schwalb, Vol. 32, No. 4, pp. 98-101.

Foster, J., and D. Hal1, 1981. "Multisensor Analys is of Hydrologic Features with Emphasis on the SEASAT SAR", Photogrammetric Engineering and Remote Sensing, May.

Fryer, J., 1975. The Great Wall of China, New English Library, London, England. 
Geil, W. E., 1909. The Great Wall of China, Sturgis \& Walton, New York, NY.

Ge1b, I., 1973. "Written Records and Decipherment", Current Trends in Linquistics, ed. by T. Sebeok, Vol. II, pp. 253-284, Mouton, The Hague, Netherlands.

Givens, D., 1981. From Here to Eternity: Communicating with the Distant Future, University of Washington, Seattle, WA.

Greenman, Emerson F., 1970. Serpent Mound, Ohio Historical Society, Columbus, $\mathrm{OH}$.

Griswold, William W., 1981. Solution Mining in Salt Domes of the Gulf Coast Embayment, PNL-3190, Pacific Northwest Laboratory, Battelle Memorial Institute, Richland, WA.

Hallo, William W., and William K. Simpson, 1971. The Ancient Near East: A History, Harcourt Brace Jovanovich, Inc., New York, NY.

Hassan, Se1im, 1953. The Great Sphinx and Its Secrets, Government Press, Cairo, Egypt.

Hawkins, Gerald, S., 1965. Stonehenge Decoded, De11, New York, NY.

Hawkins, Gerald S., 1969. Ancient Lines in the Peruvian Desert: Final Report of the National Geographic Society, Cambridge, MA.

Hodges, Henry, 1971. Artifacts: An Introduction to Early Materials and Technology, Humanities Press, Atlantic Highlands, NJ.

Ingram, E., 1911. Geodetic Surveying, McGraw-Hi11, New York, NY.

Isbe11, W. H., 1978. "The Prehistoric Ground Drawings of Peru", Scientific American, Vol. 239, pp. 140-153. 
Kaplan, Maureen F., 1980. "Characterization of Weathered Glass by Analyzing Ancient Artifacts", Scientific Basis for Nuclear Waste Management, Vo1. 2, pp. 85-92, ed. Clyde J. M. Northrup Jr., Plenum Press, New York, NY.

Kaplan, Maureen F., 1982a. Archaeological Data as a Basis for Repository Marker Design, ONWI-354, prepared by The Ana7ytic Sciences Corporation for Office of Nuclear Waste Isolation, Battelle Memorial Institute, Columbus, $\mathrm{OH}$.

Kaplan, Maureen F., 1982b. "Ancient Glass and the Safe Disposal of Nuclear Waste", Archaeology, July-August, pp. 22-29.

Kroker, E., 1977. Das Bergbau-Archiv und Seine Bestande, Deutsches BergbauMuseum, Bochum, Federal Republic of Germany.

Kuk1a, G., J. Ange11, J. Korshozer, H. Dronia, M. Hoshiai, J. Namias, M. Rodewold, R. Yamamota, and T. Iwashima, 1977. "New Data on Climatic Trends", Nature, Vol. 270, pp. 573-580.

Kuk1a, G., A. Berger, R. Lotte, and J. Brown, 1981. "Orbital Signature of Interglacia1s", Nature, Vo1. 90, pp. 295-300.

Lum, P., 1960. The Purple Barrier, R. Hale, London, England.

Malinowski, R., 1979. "Concretes and Mortars in Ancient Aqueducts", Concrete International Design and Construction, Vol. 1, No. 1, pp. 66-76.

Marschner, R.; and H. Wright, 1978. "Asphalts from Middle Eastern Archaeological Sites", Archaeological Chemistry, II, G. Carter, ed., Advances in Chemistry Series 171, Washington, DC.

Merritt, R. C., 1978. Extractive Metallurgy of Uranium, Colorado School of Mines Research Institute, Golden, $\mathrm{CO}$.

Monte 11, W. L., 1970. The Saga of Coe Ridge - A Study in Oral History, The University of Tennessee Press, Knoxville, TN. 
Moore, J., 1978. "One-Ca11 System", NUCA, August.

Muhly, J., 1980. "Bronze Figurines and Near Eastern Metalwork", Israel Exploration Journal, Vol. 30 , pp. 148-161.

NRC, see U.S. Nuclear Regulatory Commission.

OCLC Online Computer Library Center, 1981. Questions and Answers, Apri1 1981, Columbus, $\mathrm{OH}$.

Office of Nuclear Waste Isolation, 1981. Preliminary Evaluation of SolutionMining Intrusion Into a Salt Dome Repository, ONWI-320(1), Battelle Memorial Institute, Columbus, $\mathrm{OH}$.

01mstead, Arthur T., 1951. History of the Persian Empire, University of Chicago Press, Chicago, IL.

ONWI, see Office of Nuclear Waste Isolation.

Pishdadazar, H., and A. Moghissi, 1980. "Hazardous Waste Sites in the United States", Nuclear and Chemical Waste Management, Vol. 1, pp. 3 and 4.

Putnam, F.W., 1980. "The Serpent-Mound of Ohio," Century Illustrated Monthly Magazine, April, pp. 871-88.

Ralph, E. K., H. N. Michael, and M. C. Han, 1973. "Radiocarbon Dates and Reality", MASCA Newsletter, Vol. 9, pp. 1-20.

Renfrew, Colin, 1973. Before Civilization: The Radiocarbon Revolution and Prehistoric Europe, Knopf, New York, NY.

Richeson, A., 1966. English Land Measuring to 1800: Instruments and Practices, MIT Press, Cambridge, MA.

Rifkịn, M., 1980. "One-Call Systems Save Money and Lives", Pipeline Industry, June. 
Ringwood, A. E., S. E. Kesson, E.N.G. Ware, W. Hibgerson, and A. Major, 1979. "Immobilization of High-Level Nuclear Reactor Waste in SYNROC", Nature, Vol. 278, pp. 219-223, March.

Rosenfeld, André, 1965. The Inorganic Raw Materials of Antiquity, Weidenfeld and Nicolson, London, England.

Sebeok, Thomas A., 1984. Communication Measures Designed to Bridge Ten Millenia, BMI/ONWI-532, prepared by Research Center for Language and Semiotic Studies, Indiana University, for Office of Nuclear Waste Management, Battelle Memorial Institute, Columbus, $\mathrm{OH}$.

Silverberg, R., 1965. The Great Wall of China, Chilton Books, New York, NY.

Smith, W. Stevenson, 1965. The Art and Architecture of Ancient Egypt, Penguin Books, Baltimore, MD.

Tannenbaum, Percy H., 1984. Communication Across 300 Generations: Deterring Human Interference with Nuclear Waste Repository Sites, BMI/ONWI-535, prepared by Survey Research Center, University of California, Berkeley, for Office of Nuclear Waste Isolation, Battelle Memorial. Institute, Columbus, $\mathrm{OH}$.

Thompson, D. L., 1981. "The Lost City of Antinoos", Archaeology, Vol. 34, pp. $44-50$.

Tylecote, R., 1976. A History of Metallurgy, The Metals Society, London, England.

U.S. Department of Energy, 1980. Statement of Position of the U.S. Department of Energy in the Matter of Proposed U.S. Nuclear Regulatory Commission Rulemaking on the Storage and Disposal of Nuclear Waste (Waste Confidence Rulemaking), DOE/NE-0007, Washington, DC.

U.S. Department of Energy, 1981. NWTS Program Criteria for Geologic Disposal of Nuclear Waste: Site Performance Criteria, DOE/NWTS-33(2), Office of NWTS Integration, Battelle Memorial Institute, Columbus, $\mathrm{OH}$. 
U.S. Department of Energy, 1983. "Nuclear Waste Policy Act of 1982; Proposed General Guidelines for Recommendation of Sites for Nuclear Waste Repositories", 10 CFR 960, Federal Reigster (38 FR 5670), Washington, OC.

U.S. Environmental Protection Agency, 1982a. "Environmental Standards for the Management and Disposal of Spent Nuclear Fuel, High-Level and Transuranic Waste", 40 CFR 191, Federal Register (47 FR 53196), Washington, DC, December 29.

U.S. Environmental Protection Agency, 1982b. "Standards for Owners and Operators of Hazardous Waste Treatment, Storage, and Disposal Facilities", Code of Federal Regulations, 40 CFR 264, Office of the Federal Register, Washington, DC.

U.S. Geologic Survey, 1980. Scientific and Technical Spatial, and Bibliographic Data Bases of the U.S. Geologic Survey, 1979, Geological Survey Circular 817, U.S. Department of the Interior, Washington, DC.

USGS, see U.S. Geologic Survey.

U.S. Nuclear Regulatory Commission, 1983. "Disposal of High-Level Radioactive Wastes in Geologic Repositories, Technical Criteria", 10 CFR 60, Federal Register (48 FR 28194), Washington DC, June 21.

Watkins, A., 1981. The EROS Center, U.S. Geological Survey, NTIS 1981-341 618:43, Washington, DC.

Weitzberg, Abraham, 1982. Building on Existing Institutions to Perpetuate Knowledge of Waste Repositories, ONWI-379, prepared by NUS Corporation for Office of Nuclear Waste Isolation, Battelle Memorial Institute, Columbus, OH. 
APPENDIX A 


\section{APPENDIX A \\ PICTOGRAPHIC PRESENTATION OF BIOHAZARDOUS CAUTION MESSAGE}

The pictograph that follows was developed using the concepts and guideTines discussed by Givens (1981). The objective is to convey to the reader the sense that if the area below the markers is disturbed, toxic substances will enter the ground water and lead to severe consequences. The pictograph relies on several visual images acting in concert to relay the message.

- The ground surface exhibits peripheral markers and a central monument to denote relevance to the site where those markers and monument exist.

- The ground-water system is indicated by water-drop shapes and by the chemical symbol for water (the only departure from icons, used as a redundant measure).

- A repository far below the surface is depicted with the biohazardous symbol. The fact that the object portrayed below the surface is a repository may not be at all evident to a future reader from the first frame; however, the movement of the dark material from the repository through the aquifer and into the vegetables in the third frame, coupled with the movement of the biohazardous symbol, should imply the burial of biohazardous materials below the surface.

- The pictographic sequence exaggerates reality with regard to the rapidity of contaminant transport and uptake, and with regard to the severity of the consequences. However, exaggeration is necessary because both the clarity and the relevance of the message may suffer if the pictograph attempts to indicate contaminant transport time of thousands of years. Similarly, the consequence portrayed, a painful death, over-exaggerates the cause-effect relationship and the rate of the individual's demise (one out of three suffer death in the pictograph, whereas a $10^{-4}$ to $10^{-6}$ chance would be more representative). 
The pictographic sequence is read top-to-bottom which is appropriate on a pancultural basis, i.e., various cultures read right-to-left and left-toright, but a11 read top-to-bottom (Givens, 1981).

The pictograph is intended to be indicative of the type of message that can be delivered using this technique. Additional work would be required to reach agreement on the message(s) to be delivered and the most appropriate icons to be used.

In reviewing the sequence, readers of this report are reminded that the pictograph would appear on the markers at the site. Therefore, future readers would recognize the pictographic setting as the one in which they are located while studying the pictograph. The series could easily be expanded to indicate the steps leading to the present first frame, i.e., mining the repository, emplacing the waste, and sealing the repository. 


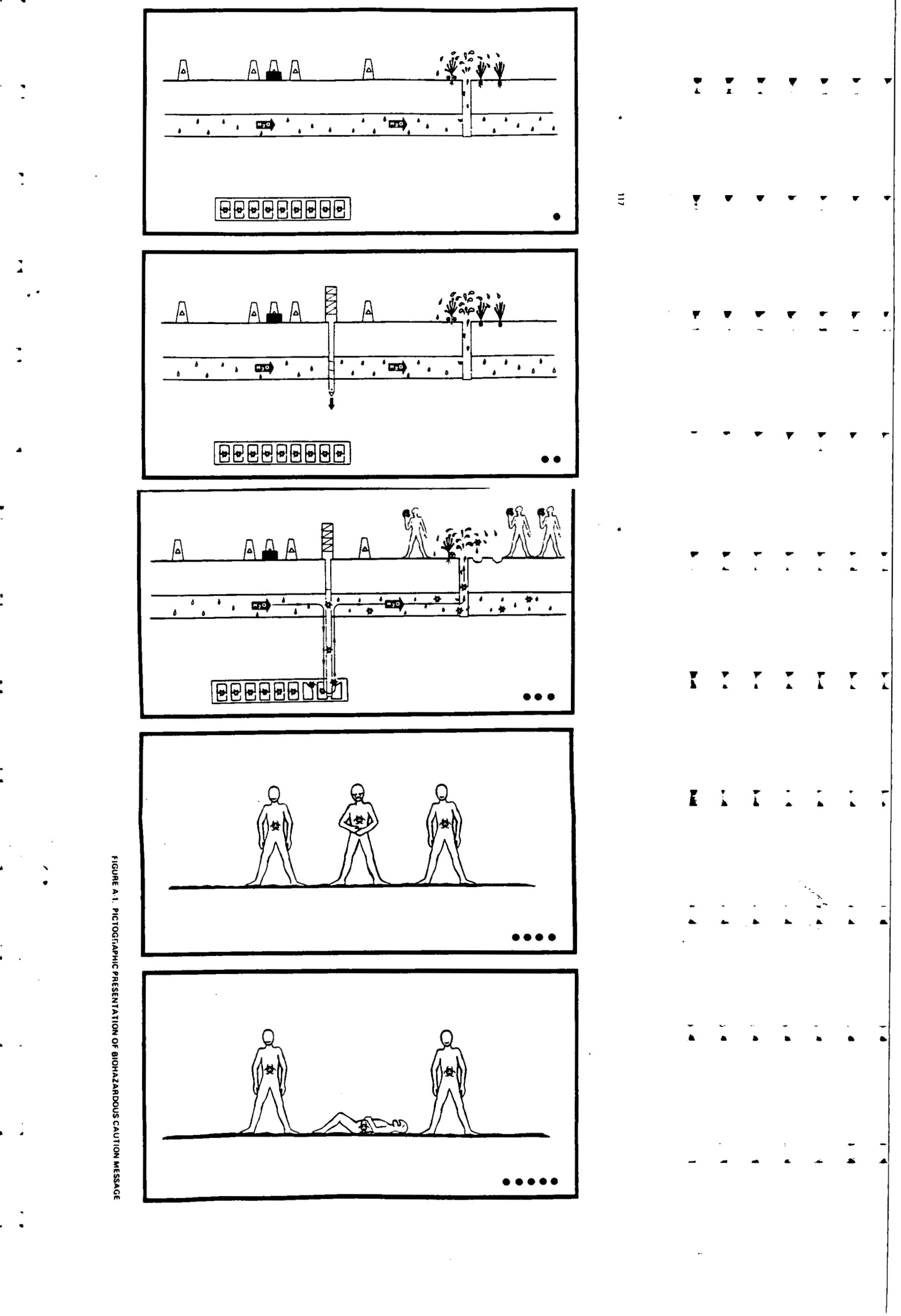


119

APPENDIX B

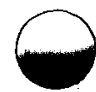


The Human Interference Task Force was composed of the following individuals:

William M. Hewitt (Chairperson)

Manager, Systems Department

Office of Nuclear Waste Isolation

Battelle Memorial Institute

Specialty: Nuclear Waste Management

D. A. Brodnick

Socioeconomic Group Leader, Nuclear Affairs

Florida Power and Light Company

Specialties: Law and Sociology

Nei1 Norman

Project Manager, Environmental Services Department

Bechtel Group, Incorporated

Specialty: Engineering

Janet Owen

Senior Scientist, Environmental Services Department

Bechtel Group, Incorporated

Specialty: Environmental Sciences

Linda U1land

Senior Scientist, Environmental Services Department

Bechtel Group, Incorporated

Specialties: Political Sciences and Public Participation

Abraham We itzberg

Senior Executive Consultant, Energy Systems Division

NUS Corporation

Specialty: Nuclear Physics

The following people are consultants to the Task Force:

Warren Berry

Manager, Corrosion Section

Battelle Columbus Laboratories

Specialty: Materials Science

\section{Paul Ekman}

Professor of Psychology

University of California, San Francisco

Specialty: Nonverbal Communication

David B. Givens

Department of Anthropology

University of Washington

Specialties: Anthropology and Nonverbal Communication 
Maureen Kaplan

The Analytic Sciences Corporation

Specialty: Archaeology

George Kukla

Senior Research Associate

Lamont-Doherty Geological Observatory

Specialty: Climatology

Thomas Sebeok

Chairman, Research Center for Language and Semiotic Studies

Indiana University

Specialties: Linguistics and Semiotics

Percy H. Tannenbaum

Director, Survey Research Center

University of California, Berkeley

Specialties: Behavioral Psychology and Public Policy 


\section{DISTRIBUTION LIST}

RES AMERICAN INC A. S. BURGESS ROBERT H. CURTIS R. STRUBLE

AEROSPACE CORP

BARRETT R. FRITZ

AGBABIAN ASSOCIATES

CHRISTOPHER M. ST JOHN

ALABAMA DEPT OF ENERGY CAMERON MCDONALD

ALABAMA STATE GEOLOGICAL SURVEY THORNTON L. NEATHERY

AMARILLO PUBLIC LIBRARY

AMERICAN EMBASSY - SWEDEN

AMERICAN NUCLEAR INSURERS DOTTIE SHERMAN

ANALYSIS AND IECHNOLOGY INC T. MAZOUR

APPLIED MECHANICS INC GRAHAM G. MUSTOE

ARGONNE NATIONAL LABORATORY

DAVID F. FENSTER

WYMAN HARRISON

I. HOWARD KITTEL

MARTIN SEITZ

MARTIN I. STEINDLER

ARINC RESEARCH CORP H. P. HIMPLER

ARIZONA PUBLIC SERVICE COMPANY HENRY W. RILEY, IR.

ARTHUR D. LITTLE INC AVIVA BRECHER CHARLES R. HADLOCK

ATKINS RESEARCH \& DEVELOPMENT - UNITED KINGDOM

T. W. BROYD

ATOMIC ENERGY CONSULTANTS

DONALD G. ANDERSON

ATOMIC ENERGY CONTROL BOARD -

CANADA

KEN SHULTZ

ATOMIC ENERGY OF CANADA LTD

T. CHAN

ANN QUINN

F. P. SARGENT

ATOMIC ENERGY RESEARCH ESTABLISHMENT

- UNITED KINGDOM

D. P. HODGKINSON

ATOMIC INDUSTRIAL FORUM INC EMANUEL GORDON

AUSTRALIAN ATOMIC ENERGY COMMISSION

BABCOCK \& WILCOX INFORMATION SERVICES

BATTELLE COLUMBUS DIVISION

SANFORD G. BLOOM

IOHN T. MCGINNIS

JEFFREY L. MEANS

NEIL. E. MILLER

STEPHEN NICOLOS

KENNETH R. YATES

BATIELLE MEMORIAL INSTITUTE IAMES DUGUID

BATTELLE NORTHWEST LABORATORIES RICHARD STRICKERT

BE INC

K. J. ANDERSON

BECHTEL GROUP INC TOM S. BAER DON B. CRANDALL

LESLIE J. JARDINE

R. C. LOVINGTON
N. A. NORMAN

GERALD L. PALAU

U. YOUNG PARK

RICHARD J. TOSETTI

BELGISCHE GEOLOGISCHE DIENST - BELGIUM NOEL VANDENBERGHE

BENDIX FIELD ENGINEERING CORP

BILL GRAHAM

DONALD LIVINCSTON

MICHAEL H. MOBLEY

IOHN C. PACER

BERKELEY CEOSCIENCES/HYDROTECHNIQUE ASSOCIATES

BRIAN KANEHIRO

BHABHA ATOMIC RESEARCH CENTER - INDIA V. SUKUMORAN

BLACK \& VEATCH

M. JOHN ROBINSON

BOEING ENGINEERING AND CONSTRUCTION COMPANY

R. B. CAIRNS

BRENK SYSTEMPLANUNG - W. GERMANY

H. D. BRENK

BRIGHAM YOUNG UNIVERSITY

HAROLD B. LEE LIBRARY

WILLIAM M. TIMMINS

BROOKHAVEN NATIONAL LABORATORY

M. S. DAVIS

P. W. LEVY

CLAUDIO PESCATORE

PETER SOO

HELEN TODOSOW (2)

BUNDESANSTALT FUR GEOWISSENSCHAFTEN UND ROHSTOFFE - W. GERMANY

MICHAEL LANGER

HELMUT VENZL AFF

BUNDESMINISTERIUM FUR FORSCHUNC UND TECHNOLOGIE - W. GERMANY

ROLF-PETER RANDL

BUREAU DE RECHERCHES GEOLOGIQUES ET MINIERES - FRANCE

PIERRE F. PEAUDECERF

BURNS AND ROE INDUSTRIAL SERVICES CORP JOHN PIRRO

C.F.H.F. BILL DUESING

CALIFORNIA ASSEMBLY COMMITTEE ON NATURAL RESOURCES GENF VARANINI

CALIFORNIA DEPT OF CONSERVATION PERRY AMIMITO

CALIFORNIA DIVISION OF:MINES \& GEOLOGY ROBERT H. SYDNOR

CAPITAL AREA GROUND WATER

CONSERVATION COMMISSION A. N. TURCAN. IR.

CARNEGIE-MELLON UNIVERSIIY INDIRA NAIR

CAYUGA LAKE CONSERVATION

ASSOCIATION INC

D. S. KIEFER

CENTER FOR ENVIRONMENTAL

INFORMATION INC

FREDERICK W. STOSS

CENTER FOR INTERDISCIPLINARY STUDIES DAVID M. ARMSTRONG

CENTRE D INFORMATIQUE GEOLOGIQUE FRANCE

GHISLAIN DEMARSILY
CHALMERS UNIVERSITY OF TECHNOLOGY SWEDEN

BERT ALLARD

CITIZENS INSTITUTE FOR A POSITIVE ENERGY

POLICY

LINDSAY AUDIN

CITY OF MONTICELLO RICHARD TERRY

CLARK UNIVERSITY IEANNE X. KASPERSON

CLEVELAND ELECTRIC ILLUMINATING COMPANY

PAUL G. KLANN

COLORADO OUTWARD BOUND SCHOOL DAVID L. BURGER PETER ANTHONY ONEIL

COLORADO SCHOOL OF MINES W. HUSTRULID

COLUMBIA UNIVERSITY M. ASHRAF MAHTAB

CONGRESSIONAL INFORMATION SERVICE LINDLEY C. MCGREW

CONNECTICUT DEPT OF ENVIRONMENTAL PROTECTION KEVIN MCCARTHY

CONNECTICUT STATE DEPARTMENT OF

HEALTH SERVICES MARGERY A. COHEN

CONROY ENGINEERING PETER CONROY

CONTINENTAL GROUP INC GEORGE F. ROLLEND

CORNELL UNIVERSITY FRED H. KULHAWY

CORTLAND COUNTY HEALTH DEPT I. V. FEUSS

D.R.E.

KARL J. ANANIA

DAMES \& MOORE

RON KEAR JEFFREY KEATON

DAPPOLONIA CONSULTING FNGINEERS INC LISA K. DONOHUE ABBY FORREST

AMINA HAMDY

CARL E. SCHUBERT

DAWCON MANAGEMENT CONSULTING

SERVICE

DAVID A. WEBSTER

DEAF SMITH COUNTY LIBRARY

DELAWARE CUSTOM MATERIEL INC HOWARD NOVITCH

DEPT OF ENERCY, MINES AND RESOURCES CANADA

A. S. IUDGE

DUGOUT RANCH ROBERT \& HEIDI REDD

DYNATECH R/D COMPANY STEPHEN E. SMITH

E.I. DU PONT DE NEMOURS \& CO D. H. TURNO

E.L.H. PUBLICATIONS - THE RADIOACTIVE EXCHANGE

HELMINSKI \& WILKEN

E.R. JOHNSON ASSOCIATES INC

E. R. JOHNSON

G. L. JOHNSON

EAL CORP LEON LEVENTHAL

EARTH SCIENCE AND ENGINEERING INC LOU BLANCK 
EAST COMPANY INC RAYMOND PEREZ

EAST TENNESSEE STATE UNIVERSITY ALBERT F. IGLAR VAY A. ROOMAN

EBASCO SERVICES INC ZUBAIR SALEEM RAYMOND H. SHUM

ECOLOGY CENTER OF LOUISIANA ROSS VINCENT

EDISON ELECTRIC INSTITUTE R. E. L. STANFORD

EDS NUCLEAR INC C. SUNDARARAJAN

EG \& G IDAHO INC LOW-LEVEL RADIOACTIVE WASTE ROGER A MAYES ROBERT M. NEILSON, JR

ELECTRIC POWER RESEARCH INSTITUTE CHAIM BRAUN

ELEKTRIZITAETS-GES. LAUFENBURG SWITZERLAND H. N. PATAK

ELSAM - DENMARK A. V. JOSH ARNE PEDERSEN

ENERGY FUELS NUCLEAR GEORGE A. JONES

ENERGY FUELS NUCLEAR INC DON M. PIILMORE

ENERGY RESEARCH GROUP INC MARC GOLDSMITH

ENGINEERS INTERNATIONAL INC FRANCIS S. KENDORSKI

ENVIRONMENT CANADA CLALDE BARRALD

ENVIRONMENTAL POLICY INSTITUTE DAVID M. BERICK FRED MILLAR

ENVIROSPHERE COMPANY ROGER G. ANDERSON K. E. LIND-HOWE

EXXON NUCLEAR COMPANY INC CERALD L. RITTER

EXXON NUCLEAR IDAHO COMPANY INC DATHAN A. CHIPMAN ROGER N. HENRY GARY WAYMIRE

FENIX \& SCISSON INC JOSE A. MACHADO CHARLENE L. SPARKMAI

FLORIDA DEPT OF ENVIRONMENTAL REGULATION HAMILTON OVES

FLORIDA INSTITUTE OF TECHNOLOGY JOSEPH A. ANGELO. JR.

FLORIDA POWER \& LICHT COMPANY JAMES R. TOMONTO

FIORIDA STATE UNIVERSITY JOSEPH F. DONOGHLE

FONTANA CORROSION CENTER DIGBY MACDONALD

FORD, BACON \& DAVIS INC ROBERT D BAIRD DARRELL H. CARD ROBERT F. OVERMYER BURTON I. THAMER

FOSTER-MILLER ASSOCIATES INC NORBERT PAAS

FOUR CORNERS COMMUNITY MENTAL HEALTH CENTER BOB GREENBERG
FOX CONSULTANTS INC MIKE E. BRAZIE

FRIENDS OF THE EARTH

LOUIS BUCKLIN RENEE PARSONS

GABIE BETTS BURTON MEMORIAL LIBRARY

GARTNER LEE ASSOCIATES LTD - CANADA ROBERT E. I. LEECH

GENERAL ATOMIC COMPANY MICHAEL STAMATELATOS

GENERAL COURT OF MASSACHUSETTS TIMOTHY I. BURKE

GEOLOGICAL SURVEY OF CANADA JEFFREY HUME IOHN SCOTT

GEOL OGICAL SURVFY OF DENMARK L. I. ANDERSEN

GEORESULTS.INC DAVID SNOW

GEORGIA INSTITUTE OF TECHNOLOGY MELVIN W. CARTER GEOFFREY G. EICHHOLZ

ALFRED SCHNEIDER CHARLES E. WEAVER

GEOTECHNICAL ENGINEERS INC RONALD C. HIRSCHFELD

GEOTHERMAL ENERGY INSTITUTE DONALDF.X.FINN

GEOTRANS IAMES MERCER

GESELLSCHAFT F. STRAHLEN U. UMWELTFORSCHUNG M.B.H. - W.

GERMANY

WOLFGANG BODE

H. MOSER

FRANZ PERZL

GILBERT/COMMONWEALTH JERRY L. ELLIS

GOLDER ASSOCIATES

DONALD M. CALDWELL.

MELISSA MATSON

I. W. VOSS

GOLDER ASSOCIATES - CANADA

CLEMENT M. K. YUEN

GRAND COUNTY PUBLIC LIBRARY

CSE NUCLEAR

MOHSEN NIROOMAND-RAD

GTC GEOLOGIC TESTING CONSULTANTS LTD -

CANADA

IOHN F. PICKENS

GULF INTERSTATE INC THOMAS I. HILL

GULF STATES UTILITIES COMPANY E. LINN DRAPER

H \& R TECHNICAL ASSOCIATES INC WILLIAM R. RHYNE

HAHN-MEITNER-INSTITUT FUR KERNFORSCHUNG BERLIN KLAUS FCKART MAASS

HANFORD ENGINEERINC DEVELOPMENT

LABORATORY

ROBERT EINZIGER

W. E. ROAKE

HARVARD UNIVERSITY

CHARLES W. BURNHAM DADE W. MOELLER

HATTIESBURG PUBLIC IIBRARY

HIGH COUNTRY CITIZENS ALLIANCE DON BACHMAN

HIGH PIAINS UNDERGROUND WATER DISTRICT

TROY SUBLETT
HIGH PLAINS WATER DISTRICT DON MCREYNOLDS DON D. SMITH .

HITACHI WORKS, HITACHI LTD MAKOTO KIKUCHI

HOUGH-NORWOOD HEALTH CARE CENTER GEORGE H. BROWN, M.D.

ILLINOIS DEPT OF NUCIEAR SAFEIY

TERRY R. LASH

MILTON ZUKOR

ILLINOIS STATE GEOLOGICAL SURVEY

ROBERT E. BERGSTROM KEROS CARTWRIGHT

IMPERIAL COLLEGE OF SCIENCE AND IECHNOLOGY - ENGLAND B. K. ATKINSON

INDIANA STATE BOARD OF HEALTH HAL S. STÖCKS

INSTITUT FUR TIEFLAGERUNG - W. GERMANY WERNT BREWITZ

H. GIES

KLAUS KUHN

E. R. SOLTER

INSTITUTE FOR CHEMICAL IECHNOLOGY - $\boldsymbol{W}$. GERMANY REINHARD ODO

INTER/FACE ASSOCIATES INC RON GINGERICH

INTERA ENVIRONMENTAL CONSULTANTS INC F. J. PEARSON, JR. LARRY RICKERTSEN ROBERT WILEMS

INTERNATIONAL ATOMIC ENERGY AGENCY AUSTRIA FRANK A. OHARA

INTERNATIONAL ENERGY ASSOCIATES LTD BLYTHE K. LYONS

INTERNATIONAL ENERGY SYSTEMS CORP IOHN A. BOWLES

INTERNATIONAL ENGINEERING COMPANY . INC

TERRY L. STEINBORN

MAX ZASLAWSKY

INTERNATIONAL RESEARCH AND

EVALUATION

R. DANFORD

IOWA STATE UNIVERSITY MARTIN C. FDELSON BERNARD I. SPINRAD

IRT CORP J. STOKES

ISMES - ITALY

F. GERA

IACKSON METROPOLITAN LIBRARY

IACKSON STATE UNIVERSITY ESTUS SMITH

IACKSON-GEORGE REGIONAL LIBRARY

JAY 1. SMITH COMPANY INC JAY L. SMITH

JGC CORPORATION - JAPAN MASAHIKO MAKINO

JOHNS HOPKINS UNIVERSITY IARED L. COHON

JOINT STUDY COMMITTEE ON ENERGY T. W. EDWARDS. JR.

KAISER ENGINEERS INC W. J. DODSON H. L. IULIEN

KALAMAZOO COLLEGE RALPHM. DEAL.

KANSAS DEPT OF HEALTH AND

ENVIRONMENT

GERALD W. ALLEN 
KANSAS STATE GEOLOGICAL SURVEY WILLIAM W. HAMBLETON JBRANSLESAKERHET - SWEDEN ARS B. NILSSON

KELLER WREATH ASSOCIATES FRANK WREATH

KERNFORSCHUNGSZENTRUM KARLSRUHE GMBH - W. GERMANY

K. D. CLOSS

R. KOESTER

KIHN ASSOCIATES HARRY KIHN

KLM ENGINEERING INC B. GEORGE KNIAZEWYCZ

KOREA INSTITUTE OF ENERGY AND RESOURCES (KIER) CHOO SEUNG HWAN

CHONG SU KIM

KQIL

KUTA RADIO

KYOTO UNIVERSITY - JAPAN YORITERU INOUE

LACHEL HANSEN \& ASSOCIATES INC DOUGLAS E. HANSEN

IAKE SUPERIOR REGION RADIOACTIVE WASTE PROIECT C. DIXON

LAW ENGINEERING TESTING COMPANY JAMES L. GRANT

LAWRENCE BERKELEY LABORATORY IOHN A. APPS

EUGENE BINNALL

THOMAS DOE

NORMAN M EDELSTEIN

IANE LONG

I. WANG

LAWRENCE LIVERMORE NATIONAL

LABORATORY

DAE H. CHUNG

EDNA M. DIDWELL

FRANCOISE. HEUZE

THOMASE. MCKONE

LAWRENCE D. RAMSPOTT (2)

W. G. SUTCLIFFE

TECHNICAL INFORMATION DEPARTMENT $\mathrm{L}-53$ JESSE L. YOW, JR

LEAGUE OF WOMEN VOTERS OF UTAH PALLA MADSEN

LOCKHEED ENGINEERING \& MANAGEMENT

COMPANY

STEVF NACHT

LOS ALAMOS NATIONAL LABORATORY

P. L. BUSSOLINI

WAYNE R. HANSEN

CLAUDE HERRICK

W. C. MYERS

DONALD T. OAKLEY

K. K. S. PILLAY

LOS ALAMOS TECHNICAL ASSOCIATES INC R. I. KINCSBURY

LOUISIANA DEPT OF TRANSPORTATION \& DEVELOPMENT GEORGE H. CRAMER, ॥

LOUISIANA GEOLOGICAL SURVEY

PEGGY ROONEY AUTIN

RENWICK DEVILLE

CHARIES G GROAT

SYED HAQUE

LOUISIANA NUCLEAR ENERGY DIVISION 1. HALL BOHLINGER (3) IANA STATE UNIVERSITY UMIE H. HOOVER
LOUISIANA TECH UNIVERSITY LIBRARY

LOUISIANA TECHNICAL UNIVERSITY R. H. THOMPSON

LUBBOCK COUNTY SOLL AND WATER CONSERVATION DISTRICT DON LANGSTON

MAINE BUREAU OF HEALTH DONALD C. HOXIE

MARTIN MARIETTA AEROSPACE - DENVER DIVISION

RICHARD BISSEGGER

MARYLAND DEPT OF HEALTH \& MENTAL

HYGIENE

MAX EISENBERC

MASSACHUSETTS DEPT OF ENVIRONMENTAL

QUALITY ENGINEERING JOSEPH A. SINNOTT

MASSACHUSETTS HOUSE OF

REPRESENTATIVES

WILLIAM ROBINSON

MASSACHUSFTIS INSTIIUTE OF

TECHNOLOCY

IOHN DEUTCH

TED GREENWOOD

RICHARD K. LESTER

MARSHA LEVINE

MATERIALS RESEARCH LABORATORY LTD CANADA

S. SINGH

MCDERMOIT INTERNATIONAL

KAREN L. FURLOW

MCMASTER UNIVERSITY - CANADA

L. W. SHEMILT

MEMBERS OF IHE GENERAL PUBLIC

L. ROBERT ANDERSON

KURT BALLING

BRET BLOSSER

THOMAS G. BRADFORD

ROGER H. BROOKS

BRUCE A. BYERS

HAZEL CHAPMAN. PH.D.

LAWRENCE CHASE PHD

TOM \& SUSAN CLAWSON

STEVE CONEWAY

M. VAL DALTON

KENNETH \& ALICE M DROCIN

ROBERT DUDEK

JEAN EARDLEY

THAUMAS P. EHR

ART FORAN

BOB GAMMELIN

CARL A. GIESE

SHIRLEY M. GIFFORD

MICHAEL I. GILBERT

STEVE \& SUF GILSDORF

OSWAID H GREAGER

DOUGLAS H. GREENIEE

KENNETH GUSCOTT

WILIIAMR. HAASE

ROBERT HIGGINS

DAVID W. JOHNSON

KENNETH S. IOHNSON

CRAIC W. JONES

JOSEPH KEYSER

THOMASH. LANGEVIN

MAX MCDOWELL

IEFF MEADOW

A. ALAN MOGHISSI

BARBARA MORRA

THEA NORDLINC

CAROLINE PETTI
MARTIN RATHKE

REP. C. HARDY REDD

TOM \& MARY REES

IOANNE SAVOIE

OWEN SEVERANCE

NORMAN C. SMITH

PATRICIA SNYDER

P. E. STRALEY-GREGA

MARGUERITE SWEENEY

JOEL SWISHER

M. I. SZULINSKI

MARK UDALL

GARY WAGNER

MARTIN \& ELAINE WALTER

JIMMY L. WHITE

LINDA WITTKOPF

SUSAN WOOLLEY

STEPHEN G. ZEMBA

MICHAEL BAKER, IR. INC

C. I. TOUHILL

MICHIGAN DEPI OF NATURAL RESOURCES

R. THOMAS SEGALL

MICHIGAN DEPT OF PUBLIC HEALTH GEORGE W. BRUCHMANN

LEE E. JAGER

MICHIGAN ENVIRONMENTAL COUNCII ROOM 305

MICHIGAN ENVIRONMENTAL PROTECTION COMMITIEE

DAVE CHAPMAN

MICHIGAN GEOLOGICAL SURVEY ROBERT C. REED

MICHIGAN PUBLIC SERVICE COMMISSION RON CALLEN

MICHIGAN STATE UNIVERSITY

WILLIAM C. TAYLOR

MINNESOTA ENVIRONMENTAL QUALITY BOARD

RICHARD PATON

MINNESOTA GFOLOGICAL SURYEY

LINDA L. LEHMAN

MAIT S. WALTON

MINNESOTA STATE ENERGY AGENCY

MINNESOTA STATE SENATE

CONRAD VEGA

MISSISSIPPI AITORNEY GENERALS OFFICE MACK CAMERON

MISSISSIPPI BUREAU OF GEOLOGY MICHAEL B.E. BOCRAD

MISSISSIPPI CITIZENS AGAINST NUCIEAR DISPOSAI

STANLEY DEAN FLINT

MISSISSIPPI DEPT OF ENERGY AND TRANSPORTATION RONALD I. FORSYTHE

MISSISSIPPI DEPT OF NATURAL RESOURCES

ALVIN R BICKER IR.

CHARLES L. BLALOCK CURTIS W. STOVER

MISSISSIPPI EMERGENCY MANAGEMENT AGENCY

JAMES E. MAHER

MISSISSIPPI LIBRARY COMMISSION SARA TUBB

MISSISSIPPI MINERAL RESOURCES INSTITUTE

MISSISSIPPI STATE BOARD OF HEALTH EDDIE S. FUENTE GUYR WILSON

MISSISSIPPI STATE HOUSE OF

REPRESENTATIVES HILLMAN TEROME FRAZIER 
MISSISSIPPI STATE UNIVERSITY

TROY I. LASWELI VICTOR L. ZITTA

MITRE CORP

IESTER A. ETTLINGER

MITSUBISHI METAL CORP

TATSUO ARIMA

MOAB NUCLEAR WASIE INFORMATION OFFICE

MICHAELENE PENDLETON (2)

MONTANA BUREAU OF MINES AND GEOLOGY

EDWARD C. BINGLER

MONTICELLO HIGH SCHOOL LIBRARY MEDIA CENTER

MONTICELIO NUCLEAR WASTE INFORMATION OFFICE CARL EISEMANN (2)

NAGRA - SWITZERLAND HANS ISSLER

NATIONAL ACADEMY OF SCIENCES JOHN T. HOLLOWAY HAROLD L. JAMES

NATIONAL AERONAUTICS AND SPACE ADMINISTRATION MICHAEL R. HELFERT MICHAEL ZOLENSKY

NATIONAL HYDROLOGY RESEARCH INSTITUTE - CANADA

DENNIS I. BOTTOMLEY

NATIONAL PARK SERVICE DONALD F. CILLESPIE CECIL D. LEWIS. IR

NATIONAL PARKS \& CONSERVATION ASSOCIATION T. DESTRY JARVIS TERRI MARTIN

NATIONAL SCIENCE FOUNDATION ROYALE ROSTENBACH

NAVAL WEAPONS STATION EARLE GENNARO MELLIS

NEW ENGLAND NUCIEAR CORP KERRY BENNERT CHARLES B. KILLIAN

NEW JERSEY INSTITUTE OF TECHNOLOGY BED STEVENSON

NEW MEXICO BUREAU OF MINES ANO MINERAL RESOURCES FRA NKE. KOTTLOWSKI

NEW MEXICO ENVIRONMENTAL EVALUATION GROUP

ROBERT H. \EILL

NEW YORK DEPT OF HEALTH DAVID AXELROD. M.D.

NEW YORK ENERGY RESEARCH \& DEVELOPMENT AUTHORITY IOHN P. SPATH 18

NEW YORK GEOLOGICAL SURVEY ROBERT H. FAKLNDINY

NEW YORK IEGISLATIVE COMMISSION ON SCIENCE \& TECHNOLOGY IAMEST MCFARLAND

NEW YORK STATE ASSEMBLY ANGELO ORAZIO

NEW YORK STATE ATTORNEY GENERAIS OFFICE

EZRA I. BIALIK

NEW YORK STATE ENERGY RESEARCH AND DEVELOPMENT AUTHORITY IOHN C. DEMPSEY

NEW YORK STATE GEOLOGICAL SURVEY IAMES R. ALBANESE
NEW YORK STATE HEALTH DEPT JOHN MATUSZEK

NEW YORK STATE PUBLIC SERVICE COMMISSION FRED HAAC

NEW YORK STATE SENATE RESEARCH SERVICE DAVID WHITEHEAD

NORTH CAROLINA STATE SENATE I. R. ALSBROOK

NORTH DAKOTA GEOLOGICAL SURVEY DON L. HALVORSON

NORTH DAKOTA STATE UNIVERSITY JOHN M. HALSTEAD

NORTHEAST OHIO FOUR COUNTY REGIONAL PLANNING \& DEVELOPMENT ORGANIZATION JOHN C. PIERSON

NORTHEAST UTILITIES SERVICE COMPANY PATRICIA ANN OCOONNELL

NORTHWESTERN UNIVERSITY BERNARD !. WOOD

NTR GOVERNMENT SERVICES THOMAS V. REYNOLDS

NUCLEAR ASSURANCE CORP IOHN V. HOUSTON IEAN RION

NUCLEAR ENERGY AGENCY/OECD - FRANCE ANTHONY MULLER

NUCLEAR SAFETY RESEARCH ASSOCIATION IZUMIKURIHARA

NUCLEAR WASTE WATCHERS HELEN LETARTE

NUS CORP

W. G. BELTER

RODNEY I DAVIS

N. BARRIE MCLEOD

DOLGLAS D. ORVIS

YONG M. PARK

DOLGLAS W' TONKAY

NUS CORPORATION DR BARRY N.NAFT

NUTECH ENGINEERS INC GARRISON KOST PALLC. SLIN

NWT CORP W. L. PEARL

OAK RIDGE NATIONAL LABORATORY

1. O. BLOMEKE

H. C. CLAIBORNE

ALLEN C. CROFF

LESLIE R. DOLE

CATHY S. FORE

DAVID C. KOCHER

E. M. OBLON

.E. B. PEELLE

ELLEN D. SMITH

STEPHEN S STOW

OHIO DFPT OF HEALTH

ROBERT M. QLILLIN

OKLAHOMA STATE DEPT OF HEALTH R. L. CRAIG

ONTARIO HYDRO - CANADA

R. W. BARNES

J. A. CHADHA

K. A. CORNEL

C. F. LEE

ONTARIO MINISTRY OF THE ENVIRONMENT -

CANADA

IAAK VIIRLAND

ORANGE COUNTY COMMUNITY COLLEGE LAWRENCE E. OBRIEN

OREGON STATE UNIVERSITY

IOHN C. RINGLI
ORGANISATION FOR ECONOMIC COOPERATION AND DEVELOPMENT -

FRANCE

PETER D. JOHNSTON

OTHA INC

JOSEPH A. LIEBERMAN

P.O.W.E.R

TIM REVELI

P.O.W.E.R.

RALPH DILLER

PACIFIC NORTHWEST LABORATORY

DON J. BRADLEY

IOHN B. BROWN

H. C. BURKHOLDER

JOHN B. BURNHAM

T.D. CHIKALLA

HARVEY DOVE

FLOYD N. HODGES

J. H. IARRETT

MAX R. KREITER

ROBERT MCCALLUM

J. E. MENDEL

I. M.RUSIN

R. JEFF SERNE

CARL. UNRUH

R. F. WESTERMAN

PARSONS BRINCKERHOFF QUADE \&

DOUGLAS INC

T. R. KUESEL

ROBERT PRIETO

MARK E. STEINER

PARSONS-REDPATH

GLEN A. STAFFORD

PENNSYLVANIA HOUSE OF REPRESENTATIVES IAMES MANDERINO

PENNSYLVANIA STATE UNIVERSITY

MICHAEL GRUTZECK WILLIAM B. WHITE

PERRY COUNTY CITIZENS AGAINST NUCIEAR WASTE DISPOSAL

MRS. DURLEY HANSON

WARREN STRICKLAND

PETTIS WALLEY

PERRY COUNTY SCHOOLS MANIEL A. COCHRAN

PHYSIKALISCH-TECHNISCHE BUNDESANSTALT

W. GERMANY

PETER BRENNECKE

HORST SCHNEIDER

PIRGIM

RICHARD LEVICK

POINT BEACH NUCLEAR PLANT [AMFS I. ZACH

PORTL AND GENERAL ELECTRJC I. W. LENTSCH

PRESQUE ISLE COURTHOUSE

PSE \& $\mathrm{C}$

IOHN I. MOLNER

PUBLIC LAW UTILITIES GROUP DORIS FAIKENHEINER

PUBLIC SERVICE INDIANA ROBERT S WEGENG

PURDUE UNIVERSITY PAUL S. I YKOUDIS

R.J. SHLEMON AND ASSOCIATES INC R. J. SHLEMON

RALPH M. PARSONS COMPANY IERROLD A. HAGEL

RE/SPEC INC

GARY D. CALLAHAN WILLIAM C. MCCLAIN

RED ROCK 4-WHEELERS

GEORGE SCHUITZ

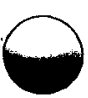


RENSSELAER POLYIECHNIC INSTITUTE JAMES WU

OURCE SYSTEMS INSTITUTE

KIRK R. SMITH

RHODE ISLAND GOVERNORS ENERGY OFFICE BRUCE VILD

RHODE ISLAND GOVERNORS OFFICE JOHN A. IVEY

RIO ALGOM CORP

DUANE MATLOCK

ROCKWELL HANFORD OPERATIONS

RONALD C. ARNETT

IAMES L. ASH

HARRY BABAD

L. R. FITCH

KARL M. LA RUE

MICHAEL J. SMITH

DAVID L. SOUTH

RICHARD T WILDE

ROCKWELL INTERNATIONAL ENERGY SYSTEMS GROUP

LAWRENCE J. SMITH

ROGERS \& ASSOCIATES ENGINEERING CORP ARTHUR SUTHERLAND

ROGERS, GOLDEN \& HALPERN IACK A. HALPERN

ROY F. WESTON INC MARTIN HANSON

DAVID HART

RONALD MACDONALD

MICHAEL $\checkmark$ MFILINGER

SAM PANNO

ROBERT SCHULER

HARRY W. SMEDES

LAWRENCE A. WHITE

ROYAL INSTITUTE OF TECHNOLOGY

SWEDEN

ROGER THUNVIK

RPC INC

JAMES VANCE

S.E. LOGAN \& ASSOCIATES INC STANLEYE LOGAN

S.M. STOLLER CORP ROBERT W. KUPP

SALT LAKE CITY TRIBUNE JIM WOOLF

SAN DIEGO GAS \& ELECTRIC COMPANY LOUIS BERNATH

SAN IOSE STATE UNIVERSITY SCHOOL OF

ENGINEERINC

R. N. ANDERSON

SAN IUAN COUNTY SHERIFF

5. RIGBY WRIGHT

SAN IUAN RECORD

DEBORAHA. MARCUS

JOYCE MARTIN

SANDIA NATIONAL LABORATORIES

LIBRARY

KEN BEALL

SHARLA BERTRAM

MARGARET S. CHU

NANCY C. FINLEY

I. KEITH IOHNSTONE

A. R. LAPPIN

R. W. IYNCH

MARTIN A. MOLECKE

IAMES T. NEAL

NESTOR R. ORIIZ

SCOTT SINNOCK

YNN D TYLER

WOLFGANG WAWERSIK

VENDELI D WEART

IIPP CENTRAL FILES
SARGENT \& LUNDY ENGINEERS LAWRENCE L. HOLISH

SAVANNAH RIVER LABORATORY

E. I. HENNELLY

CAROL IANTZEN

WILLIAM R. MCDONELL

DONALD ORTH

SCANDPOWER INC

DAN POMEROY

SCIAKY BROTHERS

JOHN C. JASPER

SCIENCE APPLICATIONS INC

JEFFREY ARBITAL.

IERRY I. COHEN

NADIA DAYEM

BARRY DIAL

IAMES E. HAMMELMAN

DEAN C. KAUL

ROBERT LARIVIERE

DAVID H. LESIER

PETER E. MCGRATH

IOHN E. MOSIER

HOWARD PRATI

MICHAEL E. SPAETH

M. D. VOEGELE

KRISHAN K. WAHI

ROBERT A. YODER

SENATE RESEARCH SERVICE

DAVID WHITEHEAD

SENECA COUNTY DEPT OF PLANNING \& DEVELOPMENT

SERIOUS IEXANS AGAINST NUCLEAR

DISPOSAL (S.T.A.N.D) DELBERT DEVIN

SHAFER EXPLORATION COMPANY WILLIAM E. SHAFER

SHANNON \& WILSON INC HARVEY W. PARKER

SHIMIZU CONSTRUCTION COMPANY ITD JUNII TAKAGI

SHIMIZU CONSTRUCIION COMPANY LTD IAPAN

TAKASHI ISHII

SIERRA CLUB

MARVIN RESNIKOFF

BROOKS YEAGER

SIERRA CLUB - COLORADO OPEN SPACE

COUNCIL

ROY YOUNC

SLICKROCK COUNIRY COUNCIL

BRUCE HUCKO

LUCY K. WALLINGFORD

SNAKE RIVER ALLIANCE

TIM MCNEIL

SOCIETY OF PROFESSIONAL ARCHEOLOGISTS L. M. PIERSON

SOCO TECHNOLOGY INC TIO C. CHEN

SOUTH DAKOTA GEOLOGICAL SURVEY RICHARD BRETZ

SOUTH DAKOTA OFFICE OF ENERGY POLICY STEVEN M. WEGMAN

SOUTH DAKOTA SCHOOL OF MINES AND

TECHNOLOGY

CANER ZANBAK

SOUTHERN STATES ENERGY BOARD I. F. CLARK

NANCY KAISER

SOUTHWEST RESEARCH AND INFORMATION

CENTER

DON HANCOCK

ALISON P MONROE
SPRINGVILLE CITY LIBRARY

ST \& E TECHNICAL SERVICES INC STANLEYM. KLAINER

ST. JOSEPH COLLEGE

CLAIRE MARKHAM

STANFORD UNIVERSITY

KONRAD B. KRAUSKOPF

GEORGE A. PARKS

IRWIN REMSON

STATE WORKING GROUP IOHN GERVERS

SIEARNS-ROGER SERVICES INC VERYL ESCHEN

STONE \& WEBSTER ENGINEERING CORP SUE NEWHAMS JOHN H. PECK

ARLENE C. PORT EVERETT M. WASHER

STUDIO GEOLOGICO FOMAR - ITALY A. MARTORANA

STUDSVIK ENERGITEKNIK AB - SWEDEN ROLF SJOBLOM

SWANSON ENVIRONMENTAL INC PETER G. COLLINS

SWISS FEDERAL OFFICE OF ENERGY U. NIEDERER

SYRACUSE UNIVERSITY WALTER MEYER

SYSTEM DEVELOPMENT CORP RHONNIE L. SMITH

SYSTEMS SCIENCE AND SOFTWARE PETER LAGUS

T.M. GATES INC TODD M. GATES

TECHNICAL INFORMATION PROJECT DONALD PAY

TECHNICAL RESEARCH CENTRE OF FINLAND SEPPO VUORI

TEKNEKRON RESEARCH INC DOUGLAS K. VOGT

TEXAS A \& M UNIVERSITY STEVE MURDOCK IAMES E. RUISSELL

IEXAS ATIORNEY GENERALS OFFICE MICHAEL PLASTER

TEXAS BUREAU OF ECONOMIC GEOIOCY WILLIAM L. FISHER

TEXAS DEPT OF HEALTH DAVID K LACKFR

TEXAS DEPT OF WATER RESOURCES C. R. BASKIN

TEXAS ENERCY COORDINATORS OFFICE ARNULFO ORTIZ

TEXAS GOVERNORS OFFICE OF GENERAL COUNSEL

R. DANIEL SMITH

IEXAS HOUSE OF REPRESENTATIVES ELLEN SALYYRS

TEXAS STATE HOUSE OF REPRESENTATIVES PETE LANEY

THE ANALYTIC SCIENCES CORP IOHN W. BARTLETT CHARLES M. KOPLIK

THE BENHAM GROUP KEN SENOUR

THE EARTH TECHNOLOGY CORP IOSEPH G. GIBSON

FIA VITAR

MATT WERNER KENNETH L. WILSON

IHE IACKSON CLARION-LEDGER MARK SCHLEIFSTFIN 
TIOGA COUNTY PLANNING BOARD THOMAS A. COOKINGHAM

IRU WASTE SYSTEMS OFFICE K. V. GILBERT

TUN ISMAIL ATOMIC RESEARCH CENTRE (PUSPATI)

SAMSURDIN BIN AHAMAD

TUSKEGEE INSTITUTE

IRA G. DILLON

U.H.D.E. - W. GERMANY FRANK STEINBRUNN

U.S. BUREAU OF LAND MANACEMENT

MARY PLUMB EDWARD R. SCHERICK CRECORYF. THAYN

U.S. BUREAU OF MINES ANIHONY IANNACCHIONE

U.S. BUREAU OF RECLAMATION JOHN BROWN REGE LEACH

U.S. DEPT OF COMMERCE PETER A. RONA

U.S. DEPT OF ENERGY CHED BRADLEY

R. COOPERSIEIN LAWRENCE H. HARMON CARL NEWTON |AMES TURI

U.S. DEPT OF ENERGY - ALBUQUERQUE OPERATIONS OFFICE PHILIP LARRAGOITE JOSEPH M. MCCOLGH

U.S. DEPT OF ENERGY - CHICAGO OPERATIONS OFFICE IICKI ALSPALCGH NL'RI BLLLLT GARY C. MARSHALL PLBLIC READING ROOM R. SELBY

U.S. DEPT OF ENERGY - CRYSTALLINE ROCK PROJECT OFFICE SALLY A. MANN

U.S. DEPT OF ENERGY - DALIAS SUPPORT OFFICE

CLRTISE. CARLSON. JR.

U.S. DEPT OF ENERGY - DIVISION OF WASTE REPOSITORY DEPLOYMENT JEFF SMILEY

U.S. DEPT OF ENERGY - GEOLOGIC REPOSITORY DIVISION

I. W. BENNETT

C.R. COOLEY 121 WARREN EISTER IIM FIORE

MARK W. FREI

CRITZ H. GEORCE RALPH STEIN

U.S. DEPT OF ENERGY - GRAND IUNCTION OFFICE

WAYNE ROBERTS

U.S. DEPT OF ENERGY - HEADQUARTERS PLBLIC READINC ROOM HENRY F. WALTER

U.S. DEPT OF ENERGY - IDAHO OPERATIONS OFFICE

M. BARAINCA

CARI P GERTZ

IAMES F LEONARD

PLBLIC READING ROOM

I. H. SAKO

U.S. DEPI OF ENERGY - NEVADA OPERATIONS OFFICE

PUBLIC READING ROOM
U.S. DEPT OF ENERGY - NUCLEAR WASTE POLICY ACT OFFICE IANIE SHAHEEN

U.S. DEPT OF ENERGY - NWTS PROGRAM OFFICE

I. O. NEFF

U.S. DEPT OF ENERGY - OAK RIDGE

OPERATIONS OFFICE PUBIIC READING ROOM

U.S. DEPT OF ENERGY - OFFICE OF B ASIC ENERGY SCIENCES MARK W. WITTELS

U.S. DEPT OF ENERGY - OFFICE OF DEFENSE WASTE AND BYPRODUCTS G. K. OERTEL

U.S. DEPI OF ENERGY - OFFICE OF PROJECT AND FACILITIES MANAGEMENT D. L. HARTMAN

U.S. DEPT OF ENERGY - REGION VIII SIGRID HIGDON

U.S. DEPT OF ENERGY - RICHLAND OPERATIONS OFFICE I. SCHREIBER

U.S. DEPI OF ENERGY - SAN FRANCISCO OPERATIONS OFFICE ENERGY RESOURCES CENTER PUBLIC READING ROOM

U.S. DEPT OF ENERGY - SAVANNAH RIVER OPERATIONS OFFICE T. B. HINDMAN

U.S. DEPT OF ENERGY - TECHNICAL INFORMATION CENTER (317)

U.S. DEPT OF LABOR KELVIN K. WL

U.S. DEPT OF THE INTERIOR PAUL A. HSIEH

U.S. ENVIRONMENIAL PROTECTION AGENCY DIVISION OF CRITERIA \& STANDARDS IAMES NEIHEISEL

U.S. ENVIRONMENTAL PROTECTION AGENCY - REGION II JOYCE FELDMAN

U.S. GENERAL ACCOUNTING OFFICE WILLIAM DAVID BROOKS

U.S. GEOLOGICAL SURVEY - ALEXANDRIA G. N. RYALS

U.S. GEOLOGICAL SURVEY - BATON ROUGE DARWIN KNOCHENMLS

U.S. GEOLOGICAL SURVEY - COLUMBUS A. M. LA SALA. IR.

U.S. GEOLOGICAL SURVEY - DENVER M. S. BEDINGER IESS M. CI.I VELAND ROBERT J. HITE

U.S. GEOIOGICAL SURVEY - JACKSON GARALD G. PARKER, JR

U.S. GEOLOGICAL SURVEY - RESTOON

I-MING CHOL JOHN ROBERTSON ELCENE H. ROSEBOOM. JR. DAVID B. STEWART NEWELL J. TRASK. JR

U.S. HOUSE SUBCOMMITIEE ON ENERGY AND THE ENVIRONMENT MORRIS K. LDALL

U.S. NATIONAL PARK SERVICE THOMAS C. WYLIE

U.S. NUCLEAR REGULATORY COMMISSION 1. CALVIN BELOTE R. BOYLE.

KIINC. CHANG

FIIIEN CHEN

PATRICIA A COMHLA
ENRICOF. CONTI

F. R. COOK

DOCKET CONIROL CENTER

PAUL F. GOLDBERC

PHILIPS. JUSTUS

MICHAFL S. KEARNEY

MALCOLMR. KNAPP

IOHN C. MCKINLEY

THOMAS J. NICHOLSON

EDWARD REGNIER

JOHN STARMER

MICHAEL WEBER

EVERETT A. WICK

ROBERT J. WRIGHT

UINTAH COUNTY LIBRARY

UNION OF CONCERNED SCIENTISTS MICHAEL FADEN

UNIIED KINGDOM DEPT OF THE

ENVIRONMENT

F. S. FEATES

UNIVERSITY OF AKRON LORETTA I. COLE

UNIVERSITY OF ARIZONA

IAAK DAEMEN

AMES G MCCRAY

SHLOMOP. NEUMAN ROY G. POST

UNIVERSITY OF CALIFORNIA AT BERKELEY TODD LAPORTE THOMAS H. PIGFORD

UNIVERSITY OF CALIFORNIA AT LOS ANGELES D OKRENT KRIS PRESTON

UNIVERSITY OF DELAWARE FRANK A. KULACKI

UNIVERSITY OF FLORIDA

DAVIDE. CLARK DOLORES C. JENKINS M. I. OHANIAN

UNIVERSITY OF HAWAII AT MANOA DAVID EPP MURLI H. MANGHNANI

UNIVERSITY OF ILLINOIS AT URBANA

CHA UPAIGN

DANIEL F. HANC MAGDI RAGHE

UNIVERSITY OF MARYLAND FRANK I. MUNNO MARVIN ROUSH

UNIVERSITY OF MICHIGAN WILLIAM KERR

UNIVERSITY OF MINNESOTA

CHARLES FAIRHURST

DONALD GILLIS RAYMOND STERIING

UNIVERSITY OF MISSISSIPPI GEORGE D. BRUNTON

UNIVERSITY OF MISSOURI AT KANSAS CITY EDWIN D. GOEBEL

SYED E. HASAN

UNIVERSITY OF MISSOURI AT ROLLA

ALLEN W. HATHEWAY

ARVIND KUMAR

NICK TSOULFANIDIS

UNIVERSITY OF NEW MEXICO HAROID M. ANDERSON DOUCLAS G. BROOKINS RODNEY C. EWING

UNIVERSITY OF OKLAHOMA DANIEL T. BOATRIGHT

UNIVERSITY OF OTIAWA - CANADA TUNCER OREN

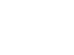


UNIVERSITY OF PITTSBURGH B. L. COHEN

VERSITY OF SOUTHERN MISSISSIPPI

CHARLES R. BRENT JAMES W. PINSON

UNIVERSITY OF TEXAS AT AUSTIN

PAUL ANAEIIONU

BUREAU OF ECONOMIC GEOLOGY

EARNEST F. GLOYNA

THOMAS C GUSTAVSON

MARTIN P. A. JACKSON

JOE O. LEDBETTER

E. G. WERMUND

UNIVERSITY OF TEXAS AT SAN ANTONIO DONALD R. LEWIS

UNIVERSITY OF TOKYO - JAPAN RYYOHEI KIYOSE

UNIVERSITY OF TORONTO - CANADA N.S. BRAR

UNIVERSITY OF UTAH

JAMES W. BUNGER

MARRIOTI LIBRARY

GARYM. SANDQUIST

UNIVERSITY OF WASHINGTON

M. A. ROBKIN

UNIVERSITY OF WISCONSIN

B. C. HAIMSON

UNIVERSITY OF WISCONSIN AT MILWAUKEE HOWARD PINCUS

UPPER PEASE SOIL AND WATER

CONSERVATION DISTRICT

W.H. MARSHALL

URS-BERGER

TONY MORGAN

URS/IOHN A. BLUME \& ASSOCIATES,

ENGINEERS

ANDREW B. CUNNINGHAM

UTAH DEPT OF NATURAL RESOURCES \& ENERGY

MARK A. PAGE

UTAH DEPT OF TRANSPORTATION

DELOY K. PETERSON
UTAH DIVISION OF ENVIRONMENTAL HEALTH

MARV H. MAXELL

UTAH DIVISION OF OIL, GAS \& MINING SALLYI. KEFER

UTAH DIVISION OF PARKS \& RECREATION IOHN KNUDSON GORDON W. TOPHAM

UTAH ENERGY OFFICE ROD MILLAR

UTAH ENVIRONMFNT CENTER JUNE WICKHAM

UTAH GEOLOGICAL AND MINERAL SURVEY GENEVIFVE ATWOOD BILL LUND MAGE YONETANI

UTAH OFFICE OF PLANNING \& BUDGET RANDY MOON (25)

UTAH SOUTHEASTERN DISTRICT HEALTH DEPARTMENT ROBERTL. FURLOW

UTAH STATE GEOLOGIC TASK FORCE DAVID D TILLSON

UTAH STATE UNIVERSITY JACK T. SPENCE

UTAHNS AGAINSI THE DUMP COALITION UTILITY DATA INSTITUTE FRED YOST

VANDERBILT UNIVERSITY FRANK L. PARKER

VEPCO

B. H. WAKEMAN

VERMONT DEPT OF WATER RESOURCES AND ENVIRONMENTAL ENGINEERING CHARLES A. RAITE

VERMONT STATE NUCLEAR ADVISORY PANEL VIRGINIA CALLAN

VIRGINIA DEPI OF HEALTH

WILLIAM F. GILLEY ROBERT G. WICKLINE

VIRGINIA DIVISION OF MINERAL RESOURCES ROBERT C. MILICI
VIRGINIA HOUSE OF DELEGATES

A. VICTOR THOMAS

VIRGINIA POLYTECHNICAL INSTITUTE ANO STATE UNIVERSITY GARY L. DOWNEY

WA STATE DEPARTMENT OF ECOIOGY DAVID W. STEVENS

WASHINGTON DEPT OF SOCIAL AND HEALTH SERVICES T. STRONG

WASHINGTON HOUSE OF REPRESENTATIVES RAY ISAACSON

WATILAB

BOB E WATI

WEBSTER PARISH LIBRARY

WEST VALLEY NUCLEAR SERVICES CO INC CHRIS CHAPMAN ERICH I. MAYER

WESTERN STATE COLLEGE FRED R. PECK

WESTINGHOUSE ELECTRIC CORP

GFORGE V. B. HALL

IAMES H. SALINC

JAMES R. SCHORNHOUIST

WIPP PROJECI

WESTINCHOUSE HLECTRIC CORPORATION

WISCONSIN DIVISION OF STAIE ENERGY ROBERT HALSTEAD

WOODS ROBERTSON ASSOCIATES - CANADA WOODWARD-CLYDE CONSULTANTS

F. R. CONWELL (2)

TERRY A GRANT

ASHOK PATWARDHAN

WESTERN REGION LIBRARY

WP-SYSTEM AB - SWEDEN IVAR SAGEFORS

WRIGHT STATE UNIVERSITY

MICHAEL FARREIL

YALE UNIVERSITY

G. R. HOLEMAN 